\title{
An Annotated Bibliography on Spatio-temporal Modelling Trends
}

\section{Willington Siabato ${ }^{1^{*}}$, Miguel Ángel Manso-Callejo ${ }^{2}$ and Elena Camossi ${ }^{3}$}

${ }^{1}$ Faculty of Human Sciences, Department of Geography, National University of Colombia, Cra 45, Bogotá, Colombia

${ }^{2}$ Universidad Politécnica de Madrid, Department of Topographic Engineering and Cartography, Madrid, Spain

${ }^{3}$ Centre for Maritime Research and Experimentation (CMRE), La Spezia, Italy

\begin{abstract}
This article presents a brief overview and an annotated bibliography on the spatio-temporal modelling approaches and spatio-temporal data models that have been proposed since the late 1980s. While some models are theoretical, others are grounded upon specific case studies that have dealt with the evolution of spatial objects over time applied to scenarios such as land use, wildfire growth, road networks reconfiguration, or the analysis of objects in movement (moving objects). A taxonomy of 14 spatio-temporal modelling trends is described, the annotated bibliography is classified accordingly. Furthermore, three sections closely related to spatio-temporal modelling issues are also included: (i) ontological modelling foundations, (ii) temporal modelling, and (iii) time geography. These sections show the origins and part of the fundamentals of spatio-temporal modelling in GIS. The purpose of this bibliography, which consists of 319 references, is to compile a comprehensive set of references that can be of help to students and researchers, as well as to practitioners, interested in spatio-temporal modelling issues. This article is supported by an extended, dynamic, online bibliography which contains over 1450 references available at http://spaceandtime.wsiabato.info.
\end{abstract}

\section{Introduction}

During the last three decades, several spatio-temporal models have been proposed [1-3]. They can be classified by considering the theoretical approach on which each model is based or the focus of interaction (e.g., processes; events; actions; movement; and dynamic objects). Several classifications have so far been suggested for spatio-temporal models. Yuan and Stewart Hornsby [4] suggest a comparison of approaches based on the origin of change and propose six categories: (i) time-stamped; (ii) changed-based; (iii) event-based; (iv) movement-based; (v) activity-based, and (vi) process-based. Another possibility relies on the distinction between the object-based and the field-based modelling approaches, where proposals can be classified according to their underlying (i) vector [5] and (ii) raster $[6,7]$ data structures; considering (iii) hybrid approaches [8-11]; or (iv) models that are flexible enough to support either raster or vector data structures [12]. The SNAP/SPAN ontology introduced by Grenon and Smith [13] provides a sound conceptual background highlighting the objects vs. fields dichotomy, as well as the concepts of snapshot, change and process. Worboys [14] presented the "brief history of time" to define a general overview of the evolution of time in GIS, presenting four main stages in the development of spatio-temporal information systems: Static GIS, Temporal snapshots, Object change, and Events and actions. Although the continuous development of spatio-temporal modelling field would make necessary to add a fifth stage to Worboys classification: intelligent agent systems. Additionally, El-Geresy et al. [15] propose five categories by considering conceptual modelling aspects: (i) location-based; (ii) object or feature-based; (iii) event-based; (iv) functional or behavioural; and (v) causal approaches. Bothwell and Yuan [16] assert that six descriptors are required to adequately describe object spatio-temporal dynamics: location; attribute (theme); extent; mutation (attribute); movement (location); and evolution (topological relationships).

Showing a broader context, Yuan and Stewart Hornsby [4] define five basic concepts for research on geographic dynamics that "address the mechanism by which geographic drivers interact with objects, people, phenomena, and places as well as the outcomes of the interactions. Geographic drivers refer to spatiotemporal activities, events, and processes, and change and movement are the outcomes of such interactions". Consequently, geographic dynamics representation and modelling approaches can be classified considering the three drivers (i.e., activities, processes, and events) and the two observable outcomes (i.e., change and movement). Table 1 summarizes these conceptual elements based on the focus of analysis, the modelling approach, and the outcomes.

At large, all spatio-temporal modelling trends are intended to describe the dynamic nature of geographic phenomena by considering one or more of the following six modelling dimensions: changes, processes, events, actions, movement (activity), and dynamic objects. Based on a comprehensive classification of the performed bibliographic review (see Section 2) and by considering the six modelling dimensions and the fundamentals on which each modelling proposal remains, for this annotated bibliography we have identified 18 modelling trends for dynamic geographic phenomena. Our classification can be reduced to 14 trends considering the pioneering proposals as a single approach, i.e., location-based ${ }^{1}$ (Table 2). Thus, this bibliography is classified according to the 14 modelling trends as shown in Figure 1. Siabato et al. [17] presents a complete analysis of the proposed classification.

This annotated bibliography focuses on the identification of spatiotemporal modelling trends and the modelling proposals published during about the last three decades. The contribution of this work falls into the given modelling trends classification and the chronological categorization of the modelling proposals while highlighting the most relevant approaches. The foundations on which spatio-temporal modelling has been grounded are also highlighted. Since some proposals are related to different modelling dimensions, we have

Other authors call this approach version-based [19] or changed-based [4].

"Corresponding Author: Prof. Willington Siabato, Faculty of Human Sciences, Department of Geography, National University of Colombia, Cra 45, Bogotá Colombia; E-mail: wlsiabatov@unal.edu.co

Citation: Siabato W (2017) An Annotated Bibliography on Spatiotemporal Modelling Trends. Int J Earth Environ Sci 2: 135. doi: https://doi. org/10.15344/2456-351X/2017/135

Copyright: () 2017 Siabato. This is an open-access article distributed under the terms of the Creative Commons Attribution License, which permits unrestricted use, distribution, and reproduction in any medium, provided the original author and source are credited. 
Citation: Siabato W (2017) An Annotated Bibliography on Spatio-temporal Modelling Trends. Int J Earth Environ Sci 2: 135. doi: https://doi.org/10.15344/2456$351 \mathrm{X} / 2017 / 135$

\begin{tabular}{|c|l|}
\hline Element & \multicolumn{1}{|c|}{ Definition } \\
\hline Activity & $\begin{array}{l}\text { Action performed by individuals (e.g., objects or humans) in space and time. "The consequence of activities by an individual } \\
\text { may generate movement of the individual or cause changes to the individual's characteristics". Activities occur at a specific } \\
\text { time. }\end{array}$ \\
\hline Event* & $\begin{array}{l}\text { An event represents an incident, "an occurrence of something with significance that drives noteworthy changes at locations } \\
\text { over time. The decision on 'significance' and 'noteworthy' is situational and problem-dependent". Events denote happening. } \\
\text { Events are occurrents, i.e., they happen and are then gone (e.g., rainfalls, landslides). }\end{array}$ \\
\hline Process* & $\begin{array}{l}\text { "A gradual transformation that transcends geographic properties, forms, and patterns over time. The determination of } \\
\text { 'gradualness' is scale-dependent", either temporal or spatial. } \\
\text { Processes mark transformation of stages or phases in space and time. While events refer to happenings, processes emphasize a } \\
\text { 'becoming' (e.g., initiation, transition, development, and evolution). A rainfall in a city, for example, is an event, but how } \\
\text { a rainstorm develops and produces rain over space and time is a process.Activities, events, and processes are all scale- } \\
\text { dependent, and their differentiation may be situationally determined. "What is an event in one situation can be a process or } \\
\text { an action in another." }\end{array}$ \\
\hline Change & $\begin{array}{l}\text { "Substitution of properties in an object, at a location, or conditions in an environment. Changes can occur to population } \\
\text { counts, identities, thematic attributes, and spatial or temporal characteristics." }\end{array}$ \\
\hline Movement & "Shift in location of a geographic object over time. The object must maintain the same identity during a movement.". \\
\hline
\end{tabular}

Table 1: Drivers and observables of geographic dynamics representation [4]

* Disagreements exist amongst researchers regarding the distinction between processes and events, see section 4.4 below for further discussion.

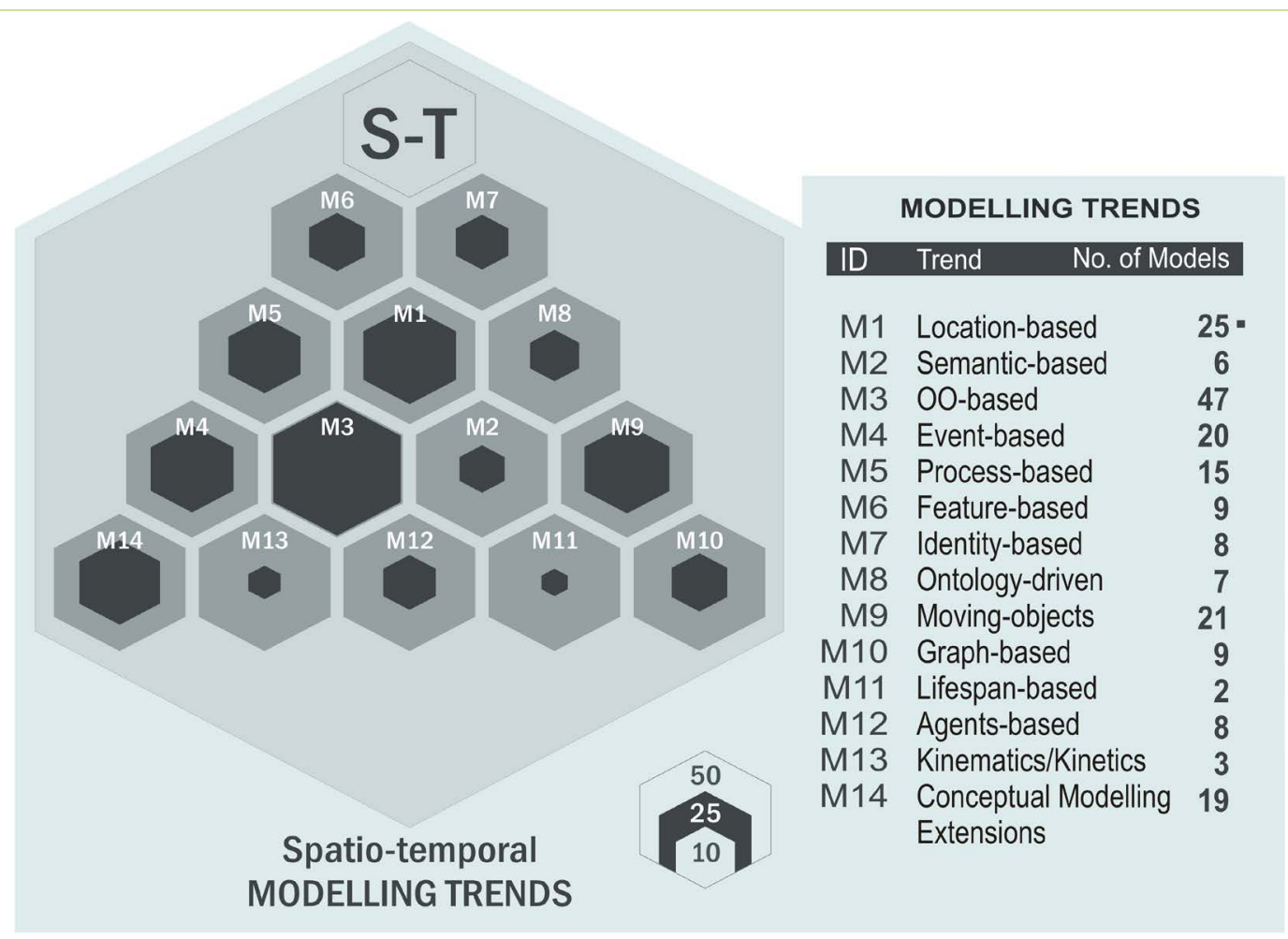

Figure 1: Classification of spatio-temporal modelling trends and number of models per approach [17].

\begin{tabular}{|l|}
\hline Location-based modelling approaches \\
\hline Snapshot method \\
\hline Base state amendment vectors \\
\hline Space-time composite model \\
\hline Time stamping \\
\hline Domain-based model \\
\hline
\end{tabular}

Table 2: Sub-classification of the location-based spatiotemporal modelling trend classified them in the dominant approach as well as in the various approaches to which each model is related (multi-approach modelling).

This article complements several bibliographies and reviews that have been published as for the temporal, spatial, and spatio-temporal research fields (Table 3). This work relies on TimeBliography $[18,20]$, a comprehensive, dynamic online bibliography on temporal geographic information systems (T-GIS) and related topics. However, while the TimeBliography is a general-purpose resource for T-GIS, this annotated bibliography is exclusively focused on the classification and description of spatio-temporal modelling trends. 
Citation: Siabato W (2017) An Annotated Bibliography on Spatio-temporal Modelling Trends. Int J Earth Environ Sci 2: 135. doi: https://doi.org/10.15344/2456-

Page 3 of 26

\begin{tabular}{|c|c|c|c|c|c|c|c|c|c|c|c|c|c|}
\hline Surveys & 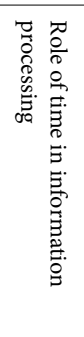 & 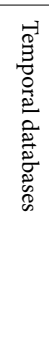 & 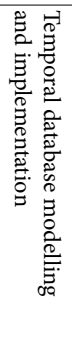 & 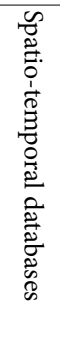 & 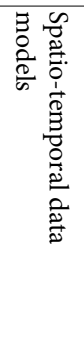 & 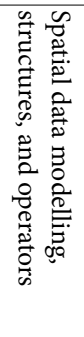 & 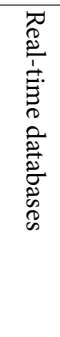 & 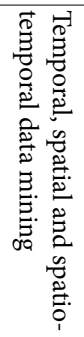 & 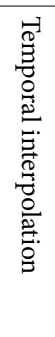 & 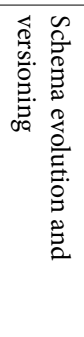 & 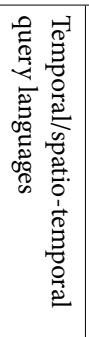 & 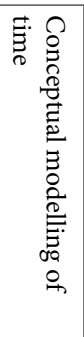 & 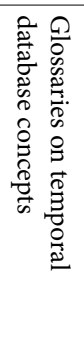 \\
\hline Bolour et al. 1982a,b & $\checkmark$ & $\checkmark$ & & & & & & & & & & & \\
\hline Roddick and Patrick 1992 & $\checkmark$ & & & & & & & & & & & & \\
\hline Theodoulidis and Loucopoulos 1991 & $\checkmark$ & & & & & & & & & & & $\checkmark$ & \\
\hline McKenzie 1986 & & $\checkmark$ & & & & & & & & & & & \\
\hline Stam and Snodgrass 1988 & & $\checkmark$ & & & & & & & & & & & \\
\hline Snodgrass 1990 & & $\checkmark$ & & & & & & & & & & & \\
\hline Soo 1991 & & $\checkmark$ & & & & & & & & & & & \\
\hline Kline 1993 & & $\checkmark$ & & & & & & & & & & & \\
\hline Tsotras and Kumar 1996 & & $\checkmark$ & & & & & & & & & & & \\
\hline Snodgrass 1996 & & $\checkmark$ & & & & & & & & & & & \\
\hline Wu et al. 1998 & & $\checkmark$ & & & & & & & & & & & \\
\hline Barrera and Al-Taha 1990 & & $\checkmark$ & $\checkmark$ & & & & & & & & $\checkmark$ & & \\
\hline Snodgrass 1992 & & & $\checkmark$ & & & & & & & & $\checkmark$ & $\checkmark$ & \\
\hline Tansel et al. 1993 & & $\checkmark$ & $\checkmark$ & & & & & & & & & & \\
\hline Snodgrass 1995 & & $\checkmark$ & $\checkmark$ & & & & & & & & $\checkmark$ & $\checkmark$ & \\
\hline Böhlen 1995 & & & $\checkmark$ & & & & & & & & & & \\
\hline Langran 1989 & & $\checkmark$ & & & $\checkmark$ & & & & & & & & \\
\hline Al-Taha et al. 1993, 1994 & & $\checkmark$ & & $\checkmark$ & & & & & & & & & \\
\hline Abraham and Roddick 1999 & & & & $\checkmark$ & $\checkmark$ & & & & & & & & \\
\hline Sellis 1999 & & & & $\checkmark$ & & & & & & & & & \\
\hline Yuan 1996 & & & & & $\checkmark$ & & & & & & & & \\
\hline Renolen 1997 & & & & & $\checkmark$ & & & & & & & & \\
\hline Pavlopoulos 1998 & & & & & $\checkmark$ & & & & & & & & \\
\hline Ratcliffe and McCullagh 1998 & & $\checkmark$ & & $\checkmark$ & $\checkmark$ & & & & & & & & \\
\hline Peuquet 2001 & & & & & $\checkmark$ & & & & & & & & \\
\hline Pelekis et al. 2004 & & & & & $\checkmark$ & & & & & & & & \\
\hline Yuan and Stewart Hornsby 2008 & & & & & $\checkmark$ & $\checkmark$ & & & & & & & \\
\hline Yuan 2008 & & & & & $\checkmark$ & & & & & & $\checkmark$ & & \\
\hline Siabato et al. 2014 & & & & & $\checkmark$ & $\checkmark$ & & & & & & $\checkmark$ & \\
\hline An et al. 2015 & & & & & $\checkmark$ & & & & & & & & \\
\hline Demšar et al. 2015 & & & & & $\checkmark$ & & & & & & & & \\
\hline Siabato et al. 2017 & & & & & $\checkmark$ & & & $\checkmark$ & & & & & \\
\hline Siabato et al.In print & & & & $\checkmark$ & $\checkmark$ & & & & & & & $\checkmark$ & \\
\hline Peuquet 1984 & & & & & & $\checkmark$ & & & & & & & \\
\hline Güting 1994 & & & & & & $\checkmark$ & & & & & & & \\
\hline Ríos Viqueira et al. 2005 & & & & & & $\checkmark$ & & & & & & & \\
\hline Clarke and Irmischer 2017 & & & & & & $\checkmark$ & & $\checkmark$ & & & & & \\
\hline Ozsoyoglu and Snodgrass 1995 & & $\checkmark$ & & & & & $\checkmark$ & & & & & & \\
\hline Ulusoy 1995 & & & & & & & $\checkmark$ & & & & & & \\
\hline Roddick and Spiliopoulou 1999 & & & & & & & & $\checkmark$ & & & & & \\
\hline Roddick et al. 2001 & & & & & & & & $\checkmark$ & & & & & \\
\hline Roddick 1992 & & & & & & & & & & $\checkmark$ & & & \\
\hline Roddick 1995 & & & & & & & & & & $\checkmark$ & & & \\
\hline Rahm and Bernstein 2006 & & & & & & & & & & $\checkmark$ & & & \\
\hline Zhang and Hunter 2000 & & & & & & & & & $\checkmark$ & & & & \\
\hline Chomicki 1994 & & & & & & & & & & & $\checkmark$ & & \\
\hline Jensen et al. 1992 & & & & & & & & & & & & & $\checkmark$ \\
\hline Dyreson et al. 1994 & & & & & & & & & & & & & $\checkmark$ \\
\hline Jensen et al. 1998 & & & & & & & & & & & & & $\checkmark$ \\
\hline Bettini et al. 1998 & & & & & & & & & & & & & $\checkmark$ \\
\hline
\end{tabular}

Table 3: Bibliographies, annotated bibliographies, and surveys related to temporal and spatio-temporal aspects. 
In the remainder of the article, Section 2 describes the harvested bibliographic sources. Section 3 presents a brief introduction to the spatio-temporal modelling research area while Section 4 lists the core annotated bibliography. The lists presented in this section compose the central part of this article. Then, Section 5 lists some additional fundamental references related to spatio-temporal modelling in GIS. Finally, in Section 6, we present a discussion, and some remarks and recommendations.

\section{Description of Bibliographic Sources}

So as to define the bibliography presented in this article, we have harvested the bibliographic sources described in Table 5. Over 1,450 references have been compiled and published in a dynamic, online bibliography called TimeBliography (/tıIm'blingrəfi/) [18,20] "TimeBliography is an online resource created to provide students and researchers with a dynamic bibliography whose focus is oriented towards temporal aspects of GIS and other [analytical]cross-related topics.". Apart from support the annotated bibliography presented herein, this online resource intends to cover the absence of an up-todate bibliography related to T-GIS as a whole as well as to complement previous surveys and bibliographic compilations (Table 3). TimeBliography is categorized in 36 topics according to the different research subjects that have made multiple contributions to T-GIS These categories, described in Table 4, were defined by considering several research agendas [21] and academic programmes [22] that have influenced the GIScience development and consequently spatiotemporal modelling. For this annotated bibliography, we have mainly considered the second category: Spatio-temporal Modelling. Table 4 shows in bold the additional sections related to this bibliography.

In a preliminary analysis, several conclusions can be extracted from the TimeBliography (Figure 2). For instance, by doing a simple graphical, trend analysis the application reveals that the most prolific period as for the spatio-temporal modelling area has been from 1998 to 2005 . Nonetheless, it must be highlighted that interest in this topic is growing nowadays, mainly motivated by the huge spread of technologies and devices able to track moving objects, e.g., smartphones, GPS receivers, smartwatches, amongst others. Mobile sensors are currently a universal, pervasive technology on which several research efforts have been focused. Reflecting such interest, in 2011, we started to collect references concerning the handling of time for modelling spatial phenomena. Part of the results of this surveyed work is this annotated bibliography; a continuous updated version is available online at http://spaceandtime.wsiabato.info. Figure 2 to Figure 7 provide an infographic of the main bibliographic characteristics and resources compiled in the TimeBliography. Siabato et al. [18] offers a complete description of this academic resource.

\section{Spatio-temporal Modelling in Brief ${ }^{2}$}

The importance of time for analysing geographic phenomena has been considered since Hägerstrand's studies [23-25]. A review of the earliest bibliography related to space and time, [26], shows that, while researchers in fields such as databases and information systems had not ignored spatio-temporal issues, the work they performed simply showed bare sketches of temporal geographic information systems (T-GIS)not even considering a basic spatio-temporal model [27]. Most research was focused on spatial and temporal databases independently. Later, these independent branches of research converged and became the basis for spatio-temporal database models that supported the earlier steps of T-GIS [12]. Figure 2 shows some relevant milestones in the evolution of T-GIS.

\begin{tabular}{|l|l|}
\hline Source & URL \\
\hline ISI Web of Knowledge & http://isiknowledge.com \\
\hline $\begin{array}{l}\text { IEEE Xplore Digital } \\
\text { Library }\end{array}$ & http://ieeexplore.iee.org \\
\hline ACM Digital Library & http://dl.acm.org \\
\hline SpringerLink & http://www.springerlink.com \\
\hline Scopus & http://www.scopus.com \\
\hline Scirus & http://www.scirus.com \\
\hline ScienceDirect & http://www.sciencedirect.com \\
\hline CiteSeerX & http://citeseer.ist.psu.edu \\
\hline Pion Publications Ltd. & http://www.pion.co.uk \\
\hline $\begin{array}{l}\text { The DBLP Computer } \\
\text { Science }\end{array}$ & http://www.informatik.uni-trier.de/ ley/db \\
\hline WorldCat & http://firstsearch.oclc.org \\
\hline Ingenta & http://www.ingentaconnect.com \\
\hline Engineering Village & http://www.engineeringvillage2.org \\
\hline The AutoCarto Archives & http://mapcontext.com/autocarto/proceedings \\
\hline $\begin{array}{l}\text { International Archives of } \\
\text { the ISPRS }\end{array}$ & http://www.isprs.org/publications/archives.aspx \\
\hline EBSCO Host & http://search.ebscohost.com \\
\hline Google Scholar & http://scholar.google.es/ \\
\hline Table 5: Main scientific databases searched for the setup of the TimeBliography \\
\hline
\end{tabular}

During the 1980s, several proposals were defined to incorporate temporal data in relational databases by applying time stamps to tables $[28,29]$, tuples $[30,31]$, and cells [32]. These database models fully inspired the development of early T-GIS proposals: tables were replicated as time-stamped layers, e.g., the snapshot model [12]; tuples (rows) as time-stamped attributes (columns), e.g., the spacetime composite model [33]; and cells as spatio-temporal objects, e.g., the spatio-temporal object model [34].

Most of initial spatio-temporal attempts either lacked a conceptual framework to track changes in dynamic phenomena or were defined in the context of non-spatial applications. Langran and Chrisman [33] filled this gap creating such a conceptual framework putting into the context of GIS the studies of time conducted so far, defined the initial requirements and structure of a temporal GIS, and proposed the first spatio-temporal conceptual model in which time and space were integrated.

Early modelling approaches, namely snapshotand time-stamped, focused on changes of the geometric and attribute components on fixed geographic areas, for instance, on cadastral plots, the so-called LIS (Land Information System). Later, time-stamped and locationbased models also considered continuous updates in attributes (space + theme) modelling evolving areas as a single set. In the meantime, the object-oriented approach arose as a convenient way to model and control objects and their properties independently, i.e., as individual features. Based on the object-oriented paradigm and the Object Modelling Technique (OMT) [35], early object-oriented models (see Section 4.3) considered changes that objects undergo and the relations that such changes imply.

These approaches reached their limits quickly when researchers realized that the events that generated such changes and the processes involved were not being considered. Thus, around the middle of the 1990 s, the event-based approach $[5,6]$ arose as a means of integrating space and time, considering richer modelling elements and a semantics that could reproduce accurately the dynamic nature of geographic phenomena and the drivers that trigger changes.

${ }^{2}$ This section is based on the analysis performed [17]. Please visit http://dx.doi.org/10.1145/3141772 
Citation: Siabato W (2017) An Annotated Bibliography on Spatio-temporal Modelling Trends. Int J Earth Environ Sci 2: 135. doi: https://doi.org/10.15344/2456351X/2017/135

Page 4 of 26

\begin{tabular}{|c|c|}
\hline Category/ Subject & Description \\
\hline \multicolumn{2}{|r|}{ Section I: Core } \\
\hline Temporal GIS & $\begin{array}{l}\text { Novel research domain at large at the intersection of temporal systems and GIS and whose objective is to explicitly extend current GIS to } \\
\text { dynamic real-world phenomena. }\end{array}$ \\
\hline Spatio-temporal Modelling & Development of conceptual and logical models oriented to the representation of spatio-temporal information. \\
\hline Temporal Modelling & Conceptual and logical approaches for the modelling and representation of time. \\
\hline Spatio-temporal Analysis & Development of integrated analytical spatio-temporal frameworks for the analysis of spatio-temporal information. \\
\hline Query Languages & $\begin{array}{l}\text { Query languages applied to the manipulation of spatial and temporal properties, and relationships in space and time, and implemented by } \\
\text { spatio-temporal and standard query languages. }\end{array}$ \\
\hline Case Studies & Successful T-GIS stories that solve spatio-temporal problems in different domains, e.g., transport, naval, census, and environment. \\
\hline Time Geography & Principles and foundations of Time Geography as defined by Hägerstrand and followers. Developing of the space-time cube. \\
\hline Temporal Databases & $\begin{array}{l}\text { Domain of research in the database domain oriented to the development of conceptual and logical temporal, spatio-temporal, and moving } \\
\text { object databases. }\end{array}$ \\
\hline Surveys and Reviews & $\begin{array}{l}\text { Bibliographic compilations, annotated bibliographies, surveys, and reviews relating to temporal aspects in spatial, temporal, and spatio- } \\
\text { temporal modelling and other spatial/temporal subjects. }\end{array}$ \\
\hline Reports and Studies & $\begin{array}{l}\text { Several research agendas, foundational documents, and report studies related to the origins of T-GIS and GIScience are declared and/or } \\
\text { defined. }\end{array}$ \\
\hline \multicolumn{2}{|r|}{ Section II: Secondary } \\
\hline Moving Objects and LBS & Development of frameworks for the representation and manipulation of moving objects, services and applications derived from them. \\
\hline Data Mining and Analysis & Data mining and analysis methods related to mining in spatio-temporal databases and for spatio-temporal knowledge discovering. \\
\hline $\begin{array}{l}\text { Databases \& Spatial } \\
\text { Databases }\end{array}$ & References related to the origins, development, and evolution of databases and spatial databases. \\
\hline Spatial Data Modelling & Spatial data models and spatial data representation methods. \\
\hline Spatial Data Structures & Spatial data structures, storage data models for spatial data, data structures in information systems, encoding in spatial databases. \\
\hline Spatial Reasoning & $\begin{array}{l}\text { Qualitative spatial reasoning. Qualitative abstractions of spatial aspects of common-sense knowledge that can be able to model dynamic } \\
\text { geographic phenomena. }\end{array}$ \\
\hline AI and Logic & $\begin{array}{l}\text { Works coming from the Artificial Intelligence and Logic research fields which have contributed to model temporal aspects in information } \\
\text { systems and spatial information systems. }\end{array}$ \\
\hline Semantics and NLP & $\begin{array}{l}\text { Semantic and linguistic aspects of geography in space, processing of temporal expressions through Natural Language Processing } \\
\text { techniques, algorithms for processing of language, and general computational techniques to handle language in computer systems. }\end{array}$ \\
\hline IR, GIR, and TIR & $\begin{array}{l}\text { This section is quite related to the previous, but it is focused on Information Retrieval (IR), Geographic Information Retrieval (GIR), and } \\
\text { Temporal Information Retrieval (TIR). }\end{array}$ \\
\hline Annotating Time & $\begin{array}{l}\text { Works dealing with Natural Language Processing applied to the identification and tagging of temporal expressions considering the } \\
\text { semantic meaning and semantic relationships. }\end{array}$ \\
\hline Ontologies & List of ontologies and ontology-based methodologies applied to spatial/temporal domains. Ontological foundations of temporal GIS. \\
\hline Visualization & $\begin{array}{l}\text { Graphical representations of geographic information regarding their properties and relationships in space and/or time considering both } \\
\text { dynamic and static aspects. }\end{array}$ \\
\hline Topology & Spatial and temporal topological relationships and properties. \\
\hline \multicolumn{2}{|r|}{ Section III: Others } \\
\hline Interoperability & Interoperability of geoservices. Semantic and temporal interoperability. Types of interoperability. \\
\hline SDI and Geoservices & Trends on Spatial Data Infrastructures (SDI) as to design and implementation. Development and implementation of geoservices. \\
\hline GIS and GIScience & General background concepts of Geographic Information Systems and Science: theory and definitions, implementation, and development. \\
\hline GI and data & $\begin{array}{l}\text { Foundational topics regarding the perception, definition, and modelling of geographic information in digital systems. Evolution of } \\
\text { cartography from ancient to contemporary methods. Background concepts such as Naive Geography, and other topics that have shaped } \\
\text { geographic information and data. }\end{array}$ \\
\hline Software & $\begin{array}{l}\text { Software packages and libraries for databases, SDI, GIS, and T-GIS. Articles in which software prototypes and implementations are } \\
\text { described are also included. }\end{array}$ \\
\hline Calendars & Definition and formalization of calendars. Tools for comparing and convert dates from a calendar system to another. \\
\hline $3 \mathrm{D} / 4 \mathrm{D}$ & Three-dimensional modelling and spatio-temporal analysis in 3D environments. \\
\hline \multicolumn{2}{|r|}{ Section IV: Standardization } \\
\hline Institutions & $\begin{array}{l}\text { Online references and websites of the institutions that have made sort of contributions to T-GIS and cross-related topics, especially } \\
\text { databases and GIS. }\end{array}$ \\
\hline Standardization & Contributions to the development of methodologies for the implementation of (potential) standards. \\
\hline W3C, ISO, OGC & $\begin{array}{l}\text { These categories group several standards related to mark-up languages and/or the above-mentioned subjects. The listed standards are } \\
\text { classified according to the three most relevant standardization institutions. }\end{array}$ \\
\hline
\end{tabular}

Table 4: Description of categories in the TimeBliography.

Int J Earth Environ Sci

ISSN: 2456-351X
IJEES, an open access journal Volume 2. 2017. 135 
Citation: Siabato W (2017) An Annotated Bibliography on Spatio-temporal Modelling Trends. Int J Earth Environ Sci 2: 135. doi: https://doi.org/10.15344/2456351X/2017/135

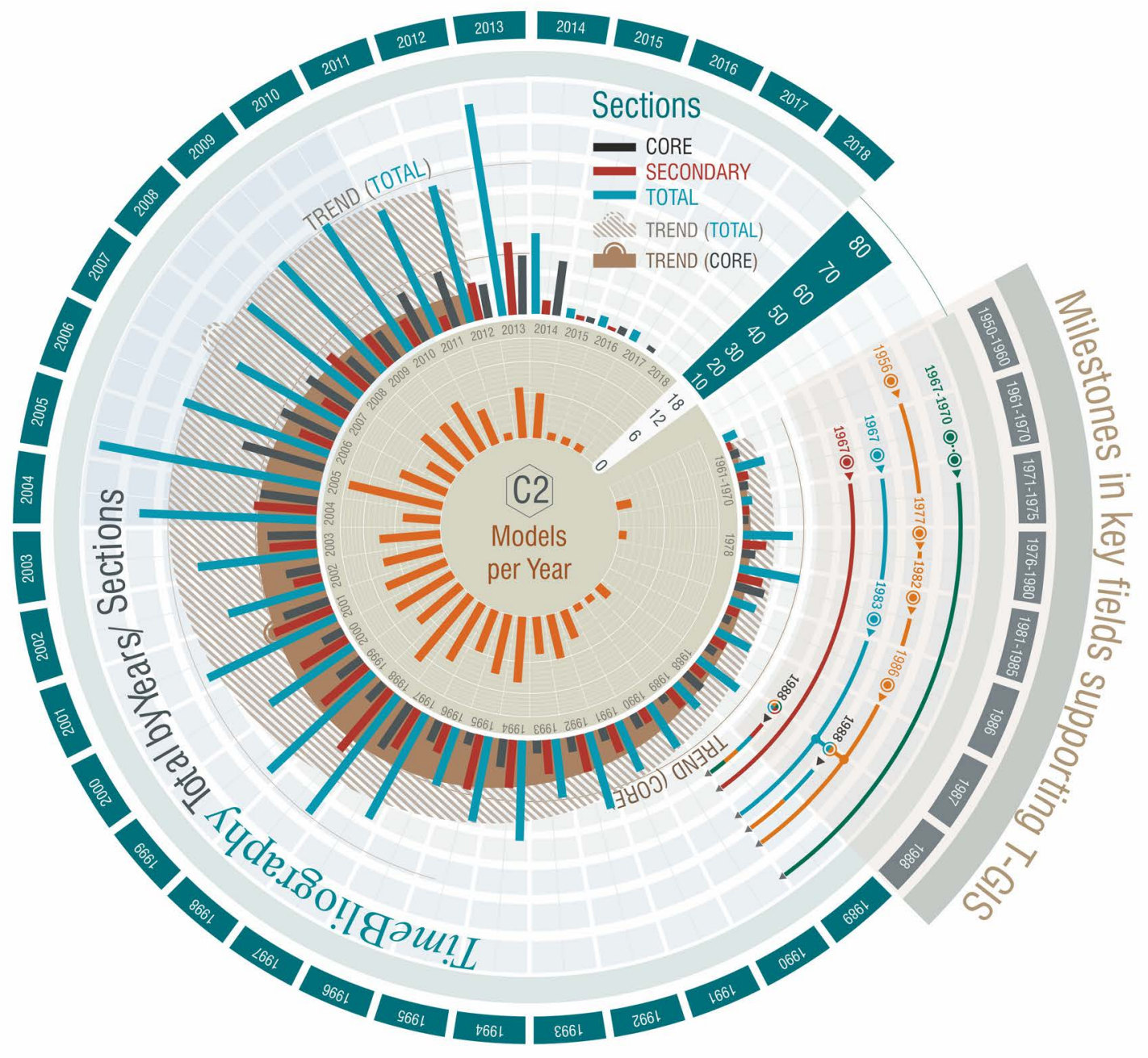

Milestones in key fields supporting T-GIS

\begin{tabular}{|c|c|c|}
\hline FIELD & YEAR & AUTHOR \\
\hline Time Geography & $-1970 \bigcirc$ & Hägerstrand \\
\hline Databases & $1956 \bigcirc$ & Phill Brooks \\
\hline Spatial Databases & $1977 \bigcirc$ & Berman \& Stonebraker \\
\hline Spatial Query Language & $1982 \bigcirc$ & Frank \\
\hline Spatial DBMS (Integrated Architecture) & $1986 \bigcirc$ & Stonebraker \& Rowe \\
\hline Spatio-Temporal Databases & $1988 \bigcirc$ & Armstrong \\
\hline Temporal Logic & $1967 \bigcirc$ & Prior \\
\hline Temporal Interval Algebra & $1983 \bigcirc$ & Allen \\
\hline Canadian GIS & $1967 \bigcirc$ & Tomlinson \\
\hline SYMAP & $1967 \bigcirc$ & Robertson \\
\hline Temporal GIS & $1988 \bigcirc$ & Langran \& Chrisman \\
\hline
\end{tabular}

Figure 2: Representation of references by Sections and modelling trends per year in the TimeBliography. 
Citation: Siabato W (2017) An Annotated Bibliography on Spatio-temporal Modelling Trends. Int J Earth Environ Sci 2: 135. doi: https://doi.org/10.15344/2456351X/2017/135

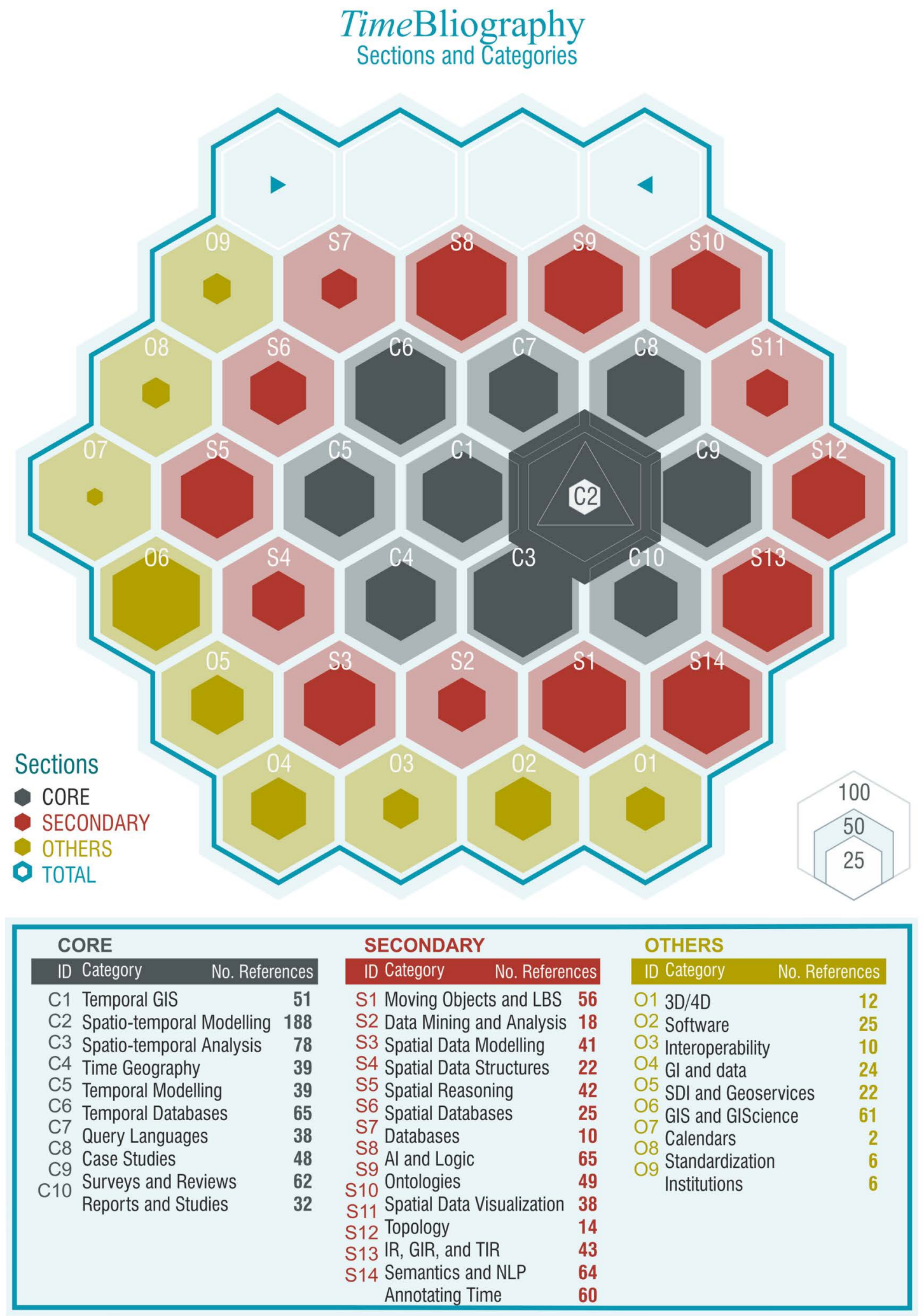

Figure 3: Infographic of categories and sections in the TimeBliography. 
Citation: Siabato W (2017) An Annotated Bibliography on Spatio-temporal Modelling Trends. Int J Earth Environ Sci 2: 135. doi: https://doi.org/10.15344/2456351X/2017/135

\section{TimeBliography}

Type of Publications journal Articles Books

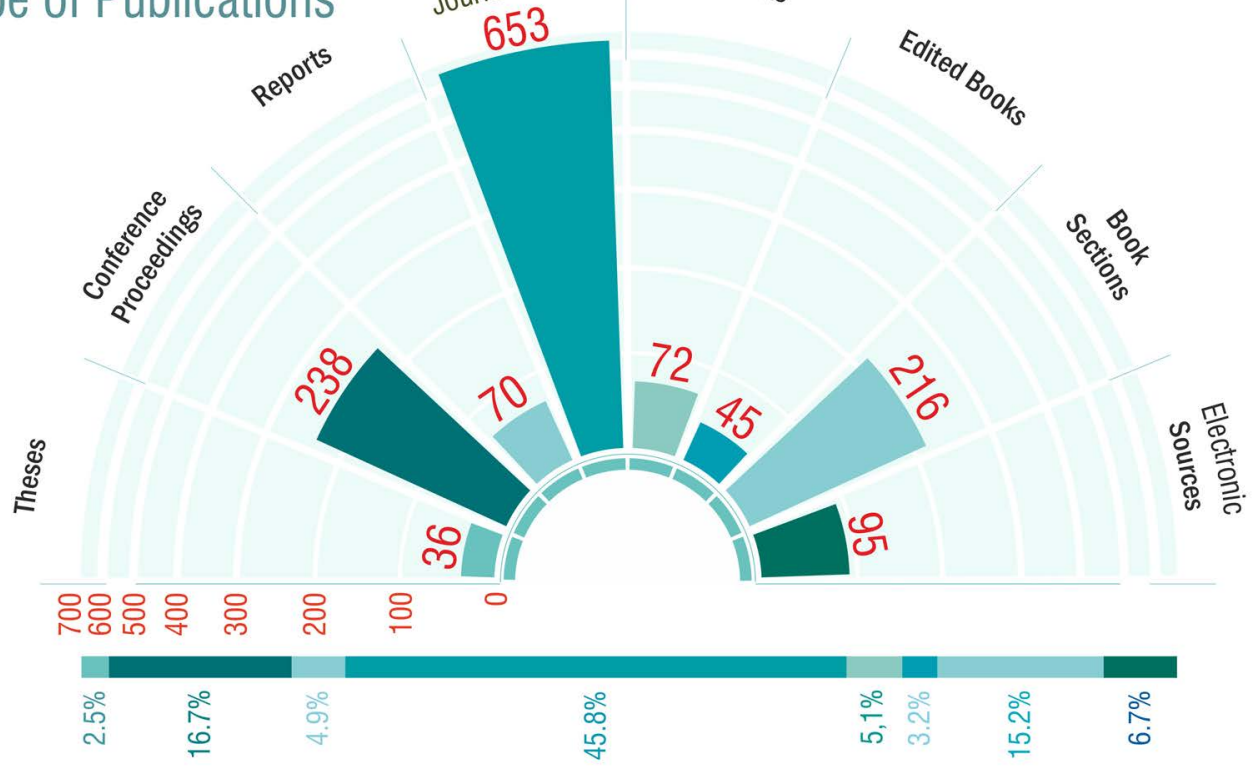

Figure 4: Infographic of type of publications registered in TimeBliography.

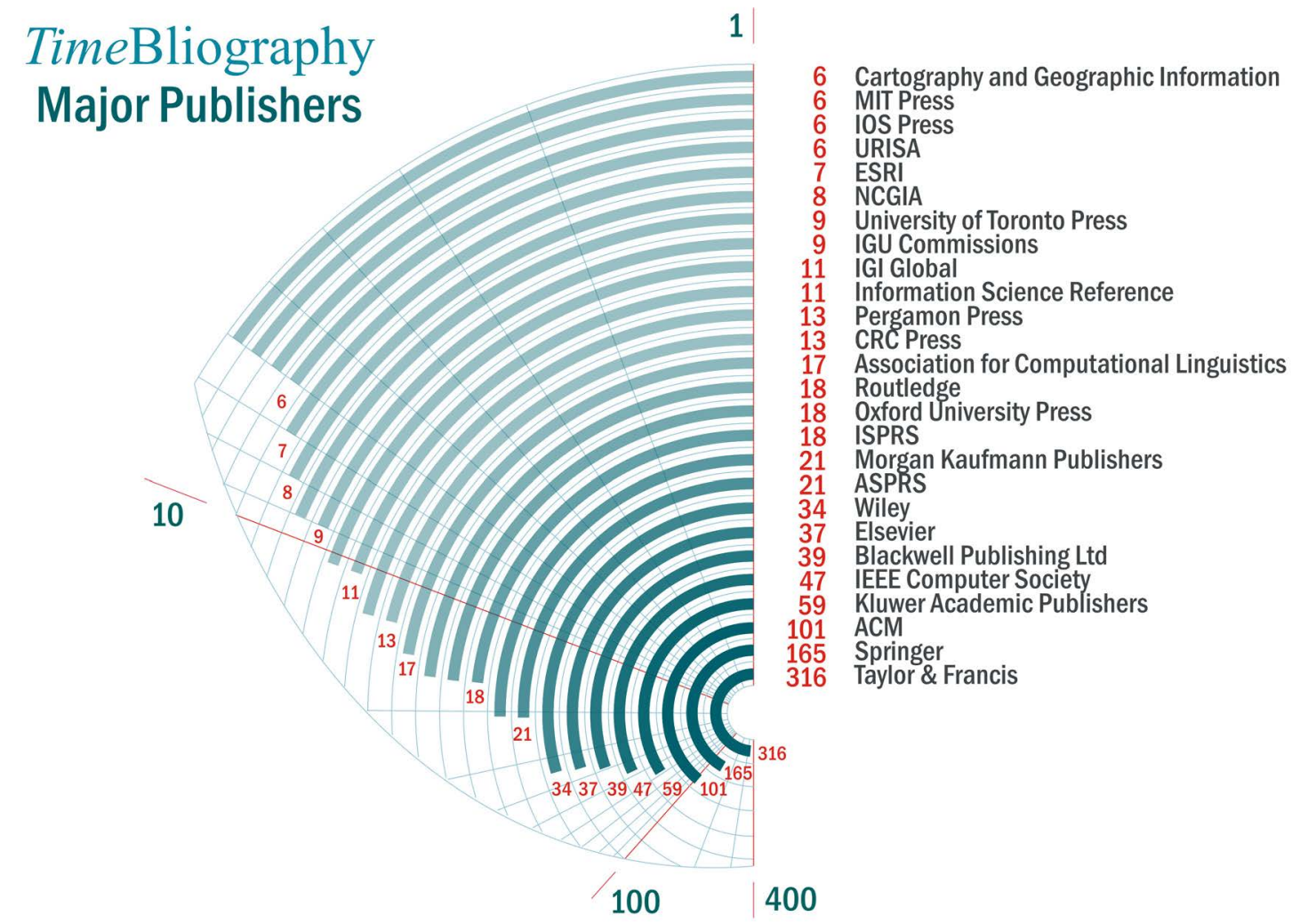

Figure 5: Infographic of major publishers inserted in the TimeBliography's database 
Citation: Siabato W (2017) An Annotated Bibliography on Spatio-temporal Modelling Trends. Int J Earth Environ Sci 2: 135. doi: https://doi.org/10.15344/2456$351 X / 2017 / 135$

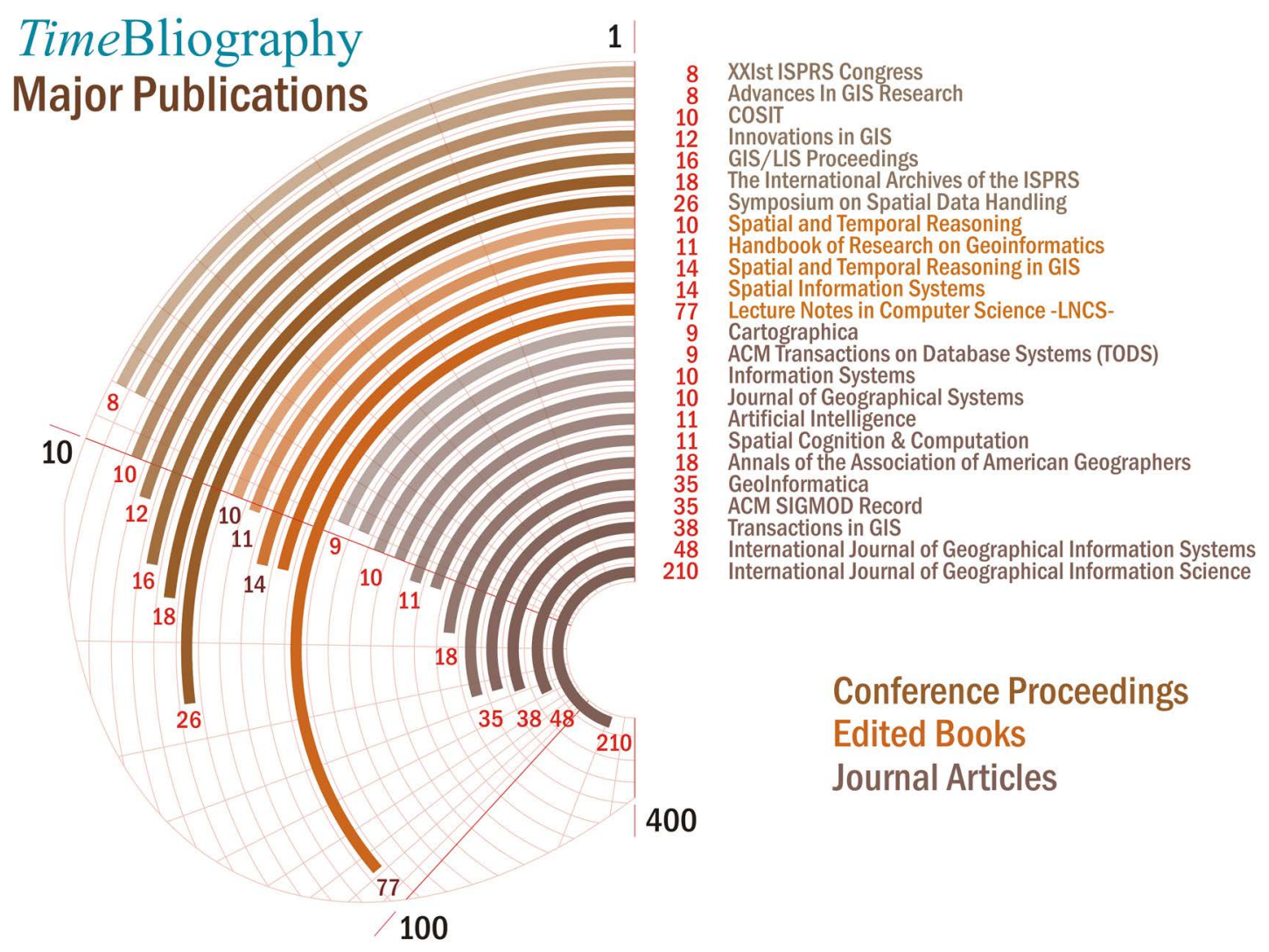

Figure 6: Infographic of major journals, conference proceedings, and edited books.

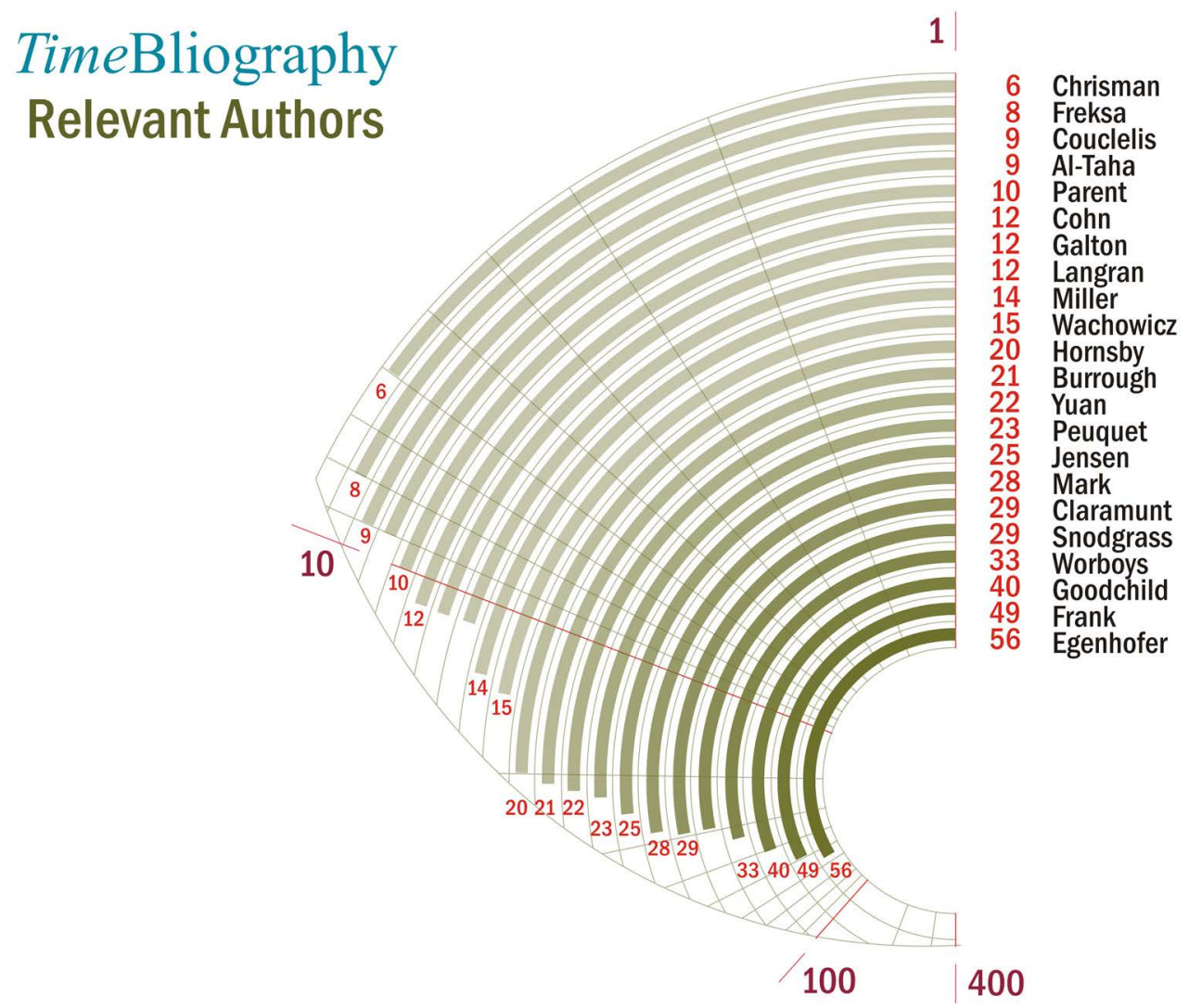

Figure 7: Infographic of the authors most referenced in the TimeBliography. 
The late 1980s and first half of the 1990s have been the most relevant period for research in T-GIS. During this period, the spatio-temporal problem arose and T-GIS was established as a formal research area in the GIS field. As the consolidation of GIScience progressed [36], T-GIS started to be defined as a relevant and independent topic in research agendas [37,38]. More recent agendas still define spatio-temporal issues as long-term research topics [39,40]. Different modelling proposals ranging from time-stamped models to the object-oriented and event-driven approaches were defined and became established (see Section 4 for further details).

While spatio-temporal models evolved, GIS research progressively moved from asking basic questions such as "what changed?" or "where does it change?" to more fundamental ones such as "why changed?" or to "how does it change?". Such questions provided the path to define new modelling approaches as shown in the models listed in this bibliography. This way, the spatio-temporal modelling trends listed in this bibliography have evolved per the dynamic dimensions modelled (e.g., object vs. action) and the focus of analysis, i.e., what/ why is changing/evolving (in) space over time. As shown, initial trends rapidly evolved from a time-stamping [41] and a locationbased [33] modelling to an object-oriented perspective [42], and subsequently to event/process-based $[6,43]$ and domain/semanticbased [44] modelling trends. More recent perspectives and modelling proposals, [45-50], are still based on the same foundations: drivers and observables (Table 1). It must be highlighted that the definition of modelling approaches based on agents [51,47] and kinematic/kinetic $[52,53]$ trends is a recent and innovative tendency. As shown in Figure 1 , these are the two last trends identified.

Although significant results have been obtained (see Section 5.1, Ontological modelling foundations), much work has still to be done before achieving (i) a general spatio-temporal model and (ii) the basic functionalities for a general-purpose T-GIS [40]. On the other hand, so far GIS software does not reflect the progress that the GIScience community has achieved in the integration of time and space within GIS software, e.g., temporal data query languages and spatio-temporal analysis capabilities are not completely available. Such integration is often the exception and lacks standardization. There is no consensus amongst researchers and developers regarding the integration of solid foundations and temporal components into GIS; there is no standard as it exists for the spatial dimension in which concepts and software packages are built upon robust theoretical and modelling principles $[54,55]$, as well as upon a set of standards such as those normalized by ISO and the Open Geospatial Consortium (OGC) regarding geoservices, and spatial data modelling and representation [56].

On the implementation side, most temporal GIS and temporal database technologies developed so far are rather limited or have remained in the research phase, e.g., the T-GIS prototype TEMPEST [57] or some of the prototypes and applications supported by the TimeCenter [58]. It is only recently, after several years of theoretical approaches and domain-specific case studies and proposals, that commercial companies and free and open source software organizations (FOSS) have started to offer general-purpose temporal components, modules, and tools. For instance, (i) the temporal capabilities offered in ArcGIS [59]; (ii) the temporal manager of QGIS [60]; (iii) the spacetime GIS design based on Hägerstrand's classical time geography [61,62]; (iv) the Oracle 11g Flashback Data Archive [63]; (v) the Allen's algebra operators supported by PostgreSQL/PostGIS [64]; (vi) the abstract data types defined in the SECONDO platform $[65,66]$; (vii) the spatio-temporal functionality that Hermes $[67,68]$ provides to Oracle $10 \mathrm{~g}$ and PostgreSQL/PostGIS; or (viii) the visualization, analytical, and reporting tools offered in GeoTime [68,69]. These software packages and libraries offer, amongst other functionalities, simple but reliable capabilities for (i) spatio-temporal analysis (e.g., hot spot analysis with space and time, a GIS-based analytical timegeographic framework); (ii) querying periods and instants using Period Data Type; (iii) database managing for historical data (e.g., storage and retrieval); (iv) constructing and querying databases with dynamic objects that change location, shape and size; and (v) dynamic visualization of features (e.g., time-slider and temporal filtering). This last capability complements and improves the typical approaches for the animation of temporal and historical data [71-73] in the sense that it provides analytic information and not merely animated scenes.

A complete analysis and thorough review of the evolution of spatiotemporal modelling trends is available in [17].

\section{Annotated bibliography}

From the full bibliographic collection (1450+ references), this annotated bibliography lists 319 references sorted in 17 lists: 12 correspond to spatio-temporal modelling trends; 1 shows proposals for conceptual modelling processes; and the remaining 4 lists highlight key cross-related topics: (i) the ontological foundations, (ii) temporal modelling;(iii) time geography; and (iii) other key references in spatio-temporal modelling and reasoning. Each list is sorted in ascending chronological order by considering publication date. First collection, composed of 180 references, contains most of the modelling proposals published in peer-reviewed journals and conferences as of December 2014. Second collection includes 19 references related to conceptual modelling extensions developed to integrate time and space in representational modelling approaches. Third collection, described in Section 5, shows 110 key references considering relevant works that have contributed to the development of spatio-temporal modelling, mainly focused on temporal modelling and time geography. This collection includes 13 references that present spatio-temporal modelling concepts non-classified in the main lists. Since a modelling proposal can relate more than one modelling trend, e.g., events/processes, several models (references) have been included/duplicated in the different sections of this bibliography, hence arbitrary misclassifications are avoided. Finally, we present an additional list of 10 articles that we consider as the must-reads for anyone that would like to be introduced to the spatio-temporal modelling of geographic phenomena.

\section{Location-based models}

As mention above, earlier T-GIS modelling proposals were fully inspired in the temporal database research field. The 22 modelling proposals listed in this section are based on three main modelling foundations: (i) time-stamped layers (tables); (ii) time-stamped attributes (rows/columns); and (iii) time-stamping cells (attributes). As shown in Table 2, location-based model is a generalization of 27 modelling trends.

\section{Snapshot}

1. Sinton, D. F. $1978,<<$ The inherent structure of information as a constraint to analysis: Mapped thematic data as a case study $>>$ in: First International Advanced Study Symposium on topological data structures for Geographic Information Systems, G. Dutton (Ed.) Cambridge-MA-USA:Harvard University Laboratory for Computer Graphics and Spatial Analysis, pp.1-17, Dedham-MA-USA, 1978. 
2. Armstrong, M. P. 1988, <<Temporality in spatial databases $>>$ in: GIS/ LIS '88: Accessing the World, Falls Church-VA-USA:American Society for Photogrammetry and Remote Sensing, (978-0944426203), pp.880-89, San Antonio-TX_USA:Marriott Rivercenter Hotel, 30 November - 2 December 1988.

3. Beller, A. 1991, << Spatial/Temporal Events in a GIS $>>$ in: GIS/LIS ' 91 , A.S. Sensing (Ed.) Bethesda-MD-USA:American Society for Photogrammetry and Remote Sensing, (0944426751), pp.766-75, Atlanta-GA-USA:The Forum, October 28-November 011991.

4. Beller, A. 1991, <<A Temporal GIS Prototype for Global Change Research $>>$ in: GIS/LIS '91, A.S. Sensing (Ed.) Bethesda-MD-USA:American Society for Photogrammetry and Remote Sensing, (0944426751), pp.752-65, Atlanta-GAUSA:The Forum, October 28-November 011991.

5. Armenakis, C. 1992, <<Electronic Mapping of Time-Dependent Data $>$ in Proceedings of ASPRS/ACSM/RT, Bethesda-MD-USA:American Society for Photogrammetry and Remote Sensing, (944426832), pp.445-54, Washington-USA August 03-08 1992.

6. Dragicevic, S. and Marceau, D. J. 2000, $<<$ A fuzzy set approach for modelling time in GIS >>International Journal of Geographical Information Science, Vol.14 No.3, pp.225-45, 2000. doi:10.1080/136588100240822.

7. McIntosh, J. and Yuan, M. 2005, $<<$ A framework to enhance semantic flexibility for analysis of distributed phenomena $>$ International Journal of Geographical Information Science, Vol.19 No.10, pp999-1018, November 2005 doi:10.1080/13658810500197652.

8. Goodchild, M. F., Yuan, M. and Cova, T. J. 2007, $<<$ Towards a general theory of geographic representation in GIS $>>$ International Journal of Geographical Information Science, Vol.21 No.3, pp.239-60, March 2007. doi:10.1080/13658810600965271

9. Gómez, L., Kuijpers, B. and Vaisman, A. A. 2011, $<<$ A data model and query language for spatio-temporal decision support $>$ GeoInformatica, Vol.15 No.3, pp.455-96, July 2011. doi:10.1007/s10707-010-0110-7.

\section{Time stamping}

10. Hunter, G. J. and Williamson, I. P. 1990, $<<$ The development of a historical digita cadastral database $>>$ International Journal of Geographical Information Systems, Vol.4 No.2, pp.169-79, 1990. doi:10.1080/02693799008941538.

11. Gómez, L., Kuijpers, B. and Vaisman, A. A. 2011, $<<$ A data model and query language for spatio-temporal decision support $>>$ GeoInformatica, Vol.15 No.3, pp.455-96, July 2011. doi:10.1007/s10707-010-0110-7.

\section{Amendment}

12. Kelmelis, J. A. 1991, Time and Space in Geographic Information: Toward a Four Dimensional Spatio-Temporal data model, Ph.D Thesis, The Pennsylvania State University:University Park-PA-USA, Department of Geography, 1991

13. Hazelton, N. W. 1991, Integrating Time, Dynamic Modeling, and Geographical Information Systems Development of Four-Dimensional GIS, Ph.D Thesis, (F. Leahy Adv.) The University of Melbourne:Melbourne-Australia, Department of Surveying and Land Information, 1991.

14. Langran, G. 1992, Time in Geographic Information Systems, Technical Issues in GIS, D. J. Peuquet and D. F. Marble (Eds.), 1st, London-UK:Taylor \& Francis, March 261992.

15. Hazelton, N. W., Leahy, F. and Williamson, I. P. 1992, <<Integrating Dynamic Modeling and Geographic Information Systems $>>$ URISA Journal, Vol.4 No.2, pp.47-58, Fall 1992.

\section{Composite model}

24. Langran, G. and Chrisman, N. R. 1988, $<<$ A framework for temporal geographic information $>>$ Cartographica: The International Journal for Geographic Information and Geovisualization, Vol.25 No.3, pp.1-14, Autum 1988. doi:10.3138/ K877-7273-2238-5Q6V.

25. Langran, G. 1992, Time in Geographic Information Systems, Technical Issues in GIS, D. J. Peuquet and D. F. Marble (Eds.), 1st, London-UK:Taylor \& Francis, March 261992.

\section{Three-domain model}

Yuan's Three-Domain Model [74-76] represents semantic, spatial, and temporal objects and provides links between them to describe geographic processes and phenomena. The three-domain representation, developed in the context of wildfire studies, is defined as a "normalization of the snapshot, space-time composite, and spatiotemporal object models"[76]. In this sense, this proposal inherits the characteristics of the location-based approach, although it goes one step further regarding the utility that spatio-temporal systems can bring to users through GIS in considering queries about attributes, location, spatial properties and relationships, as well as time and temporal properties and relationships. Yuan proposes a set of the minimum spatio-temporal queries that any spatio-temporal system should answer (simple and range queries). The three-domain model is proposed as a modelling approach to answering such queries; it focuses on the functionality of the model in actual systems through the implementation of the three-domain framework. The advantage of this vector-based model is its ability to handle changes in the three modelling components; this characteristic represents a significant improvement over existing models that handle either the time or, as in most cases, the location. The three-domain model considers time as a temporal object instead of an attribute.

26. Peuquet, D. J. 1994, <<It's About Time: A Conceptual Framework for the Representation of Temporal Dynamics in Geographic Information Systems $>>$ Annals of the Association of American Geographers, Vol.84 No.3, pp.441-61, 1994. doi:10.1111/j.1467-8306.1994.tb01869.x.

27. Yuan, M. 1994, <<Wildfire conceptual modeling for building GIS spacetime models $>>$ in: GIS/LIS '94, Bethesda-MD-USA:American Society for Photogrammetry and Remote Sensing, (978-1570830136), pp.860-89, Phoenix USA:Phoenix Civic Plaza, October 25-27 1994

28. Smith, T. R. 1994, $<<$ On the integration of database systems and computational support for high-level modelling of spatio-temporal phenomena $>$ in: M.F. Worboys (Eds.), Innovations in GIS 1: Selected Papers from the First National Conference on GIS Research UK. Innovations in GIS Vol.1. Bristol-PA-USA:Taylor \& Francis, pp.11-24, 1994.

29. Yuan, M. 1997, <<Modeling semantical, temporal and spatial information in geographic information systems $>>$ in: M. Craglia and H. Couclelis (Eds.), Geographic Information Research: Bridging the Atlantic. Vol.1. London-UK:Taylor \& Francis, pp.334-47, January 281997.

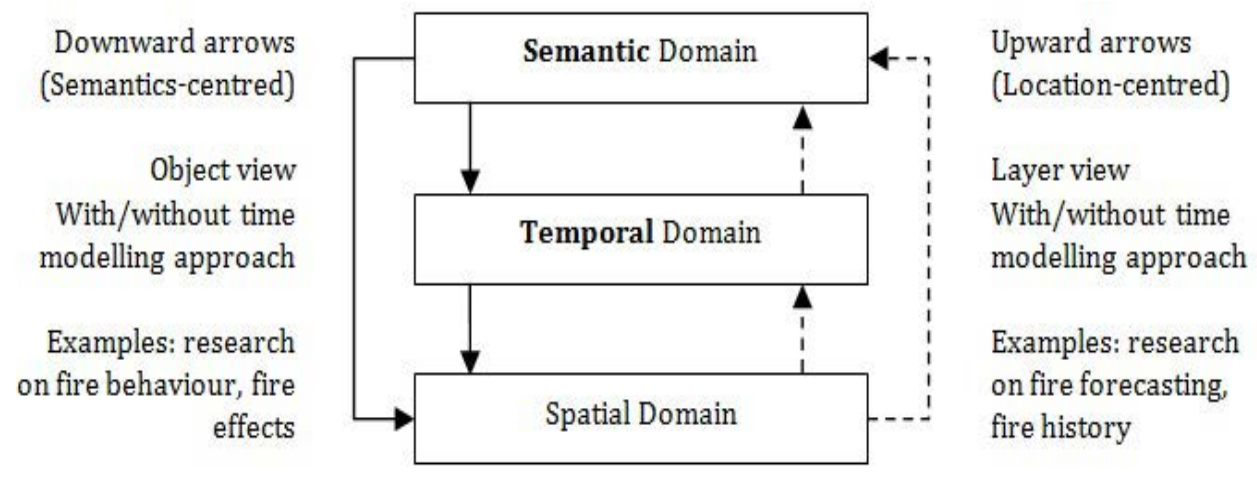

Figure 8: Conceptual framework of the three-domain model [74]. 
22. Yuan, M. 1997, <<Use of knowledge acquisition to build wildfire representation in Geographical Information Systems>>International Journal of Geographical Information Science, Vol.11 No.8, pp.723-46, 1997. doi:10.1080/136588197242059.

23. Yuan, M. 1999, <<Use of a Three-Domain Representation to Enhance GIS Support for Complex Spatiotemporal Queries $>>$ Transactions in GIS, Vol.3 No.2, pp.137-59, March 1999. doi:10.1111/1467-9671.00012.

24. Yuan, M. 2000, <<Representation of dynamic geographic phenomena based on hierarchical theory $>>$ in: 9th International Symposium on Spatial Data Handling, P. Forer, A. Yeh and J. He (Eds.). Amherst-NY-USA:IGU Comission on Geographical Information Systems, (9783642193026), pp.2a.19-29, Beijing-China August 10-12 2000.

25. Koncz, N. A. and Adams, T. M. 2002, $<<$ A data model for multi-dimensional transportation applications $>>$ International Journal of Geographical Information Science, Vol.16 No.6, pp.551-69, September 2002. doi:10.1080/13658810210138724.

\section{Semantic-based models}

Semantic changes include variations in attributes over time and a static spatial distribution of a geographic phenomenon. Spatial changes may be either static, looking at variations of a geographic phenomenon in a snapshot (same location), or transitional, comparing states of an event at different locations through entity snapshots (movement). In brief, changes are either mutations of an entity spatially fixed, or the movement of a non-changed entity from one location to another. Time is modelled as an independent domain instead of being a location's attribute, unlike the snapshot model, or an integral part of spatial entities, as in the space-time composites and spatio-temporal objects [77]. Although this trend is related to the three-domain model, it can be classified as a distinct modelling approach considering the following proposals. The focus is on the variation of attributes. However, noticed that references 26 and 27 are focused on attributes while the remaining considers the meaning/ semantic of the geographic information as a data set or derivate concepts, e.g., trajectories.

\section{Snapshot}

26. Yuan, M. 1997, << Modeling semantical, temporal and spatial information in geographic information systems $>>$ in: M. Craglia and H. Couclelis (Eds.), Geographic Information Research: Bridging the Atlantic. Vol.1. London-UK:Taylor \& Francis, pp.334-47, January 281997.

27. McIntosh, J. and Yuan, M. 2005, $<<$ A framework to enhance semantic flexibility for analysis of distributed phenomena $>>$ International Journal of Geographical Information Science, Vol.19 No.10, pp999-1018, November 2005. doi:10.1080/13658810500197652.

28. Spaccapietra, S., Parent, C., Damiani, M. L., Macedo, J. A. d., Porto, F and Vangenot, C. 2008, $<<$ A conceptual view on trajectories $>>$ Data \& Knowledge Engineering, Vol.65 No.1, pp.126-46, April 2008. doi:10.1016/j.datak.2007.10.008.

29. Zheni, D., Frihida, A., Ghezala, H. B. and Claramunt, C. 2009, $<<A$ Semantic Approach for the Modeling of Trajectories in Space and Time > in: C.A. Heuser and G. Pernul (Eds.), Advances in Conceptual Modeling - Challenging Perspectives. Lecture Notes in Computer Science -LNCS- Vol.5833. Berlin - Germany:Springer Verlag, pp.347-56, 2009. doi:10.1007/978-3-642-04947-7_41.

30. Siabato, W. and Manso-Callejo, M. Á. 2011, <<Integration of temporal and semantic components into the Geographic Information through mark-up languages. Part I: definition >> in: B. Murgante, O. Gervasi, A. Iglesiaset al. (Eds.), Computational Science and Its Applications ICCSA 2011. Lecture Notes in Computer Science -LNCS- Vol.6782. Berlin - Germany:Springer Verlag, pp.394-409, Junio 20-23 2011. doi:10.1007/978-3-642-21928-3_28.

31. Bogorny, V., Renso, C., de Aquino, A. R., de Lucca Siqueira, F. and Alvares, L. O. 2014, $<<$ CONSTAnT - A Conceptual Data Model for Semantic Trajectories of Moving Objects $>>$ Transactions in GIS, Vol.18 No.1, pp.66-88, February 2014. doi:10.1111/tgis.12011.

\section{Object oriented-based models}

Object-orientation (OO) is a popular approach used to model geographic entities in T-GIS design. In spatio-temporal data modelling, it has been widely recognized as a powerful tool that captures the meaning of concepts within a problem domain [78]. Since $\mathrm{OO}$ is a natural strategy for representing the behaviour of dynamic entities over space and time [79-81], several authors have proposed a significant number of models considering different perspectives and based on such an approach. OO has been the most prolific approach in the spatio-temporal modelling trends because of its flexibility in handling independent objects and their properties. The concept of a unique object identity is a key element of the objectmodelling approach, and, as such, it has been recognized as a reliable component in tracking changes and the evolution of independent objects and is, therefore, applied in most of the spatio-temporal models. However, it does not offer a continuous identification of the phenomenon since it changes when a new object is created. In contrast to the identity modelling approach (see Section 4.6), the identity disappears or changes when the object dies or mutates. The object orientation in the spatio-temporal modelling was pioneered by Worboys et al. [82,83]. The main strength of this approach is providing conceptual elements to allow the modelling of geographic entities as independent units. The following list includes Object-Oriented and Object-Relational models indistinctively. It must be noted that while OO models only support persistence for objects and usually do not consider neither query language nor relational referential integrity, Object-Relational data modelling supports most of objectoriented concepts (inheritance, distinction between a class and an object, custom or complex data types) as well as relevant relational concepts (relational query language and integrity). In this sense, an object-relational system is said to provide a middle ground between relational databases and object-oriented databases. In most of the cases, geographic databases implement the object-relational model. A large number of models have been proposed by considering these approaches; this section lists 47 relevant references.

\section{Snapshot}

32. Egenhofer, M. J. and Frank, A. U. 1989, << Object-oriented modelling in GIS: inheritance and propagation $>>$ in: Ninth International Symposium on Computer-Assisted Cartography -Auto-Carto 9-, Falls Church-VAUSA:American Society for Photogrammetry and Remote Sensing, (0944426-55-7), pp.588-98, Baltimore-MD-USA, April 02-07 1989.

33. Worboys, M. F. 1992, <<A model for spatio-temporal information $>>$ in: 5th International Symposium on Spatial Data Handling, P.J. Bresnahan, E. Corwin and D.J. Cowen (Eds.). South California - USA:University of South California, (978-0963353221), pp.602-11, Charleston USA:International Geographic Union, August 03-07 1992.

34. Ramachandran, B. 1992, Modelling temporal changes in the structure of real-world entities within a GIS environment using an object-oriented approach, Master's Thesis, University of Edinburgh:Edinburgh Scotland, Department of Geography, September 1992.

35. Worboys, M. F. 1992, << Object-Oriented Models of Spatiotemporal Information >> in: GIS/LIS ' 92, Bethesda-MD-USA:American Congress on Surveying and Mapping, (0944426921), pp.825-34, San Jose-CAUSA, November 10-12 1992.

36. Bjørnas, O. M. and Skogan, D. 1993, Multimodels and spatio-temporal modeling in object-oriented GIS, Master's Thesis, Norwegian Institute of Technology:Trondheim - Norway, Department of Computer and Information Science, 1993.

37. Worboys, M. F. 1994, $<<$ A unified model for spatial and temporal information $>>$ The Computer Journal, Vol.37 No.1, pp.26-34, January 1994. doi:10.1093/comjnl/37.1.26. 
38. Wachowicz, M. and Healey, R. G. 1994, <<Towards temporality in GIS $>>$ in: M.F Worboys (Eds.), Innovations in GIS 1: Selected Papers from the First National Conference on GIS Research UK. Innovations in GIS Vol.1. Bristol-PA-USA:Taylor \& Francis, pp.105-15, 1994.

39. Ramachandran, B., MacLoad, F. and Dowers, S. 1994, $<<$ Modelling Temporal Changes in a GIS using an Object-Oriented Approach $>>$ in: Sixth International Symposium on Spatial Data Handling, T.C. Waugh and R.G. Healey (Eds.). London-UK:Taylor \& Francis, (978-0748402670), pp.518-37, Edinburgh-Scotland, September 05-09 1994

40. Hamre, T. 1994, <<An Object-Oriented Conceptual Model for Measured and Derived Data Varying in 3D Space and Time $>>$ in: Sixth International Symposium on Spatial Data Handling, T.C. Waugh and R.G. Healey (Eds.). London-UK:Taylor \& Francis, (978-0748402670), pp.868-81, Edinburgh-Scotland, September 05-09 1994. doi:10.1.1.35.3465.

41. Story, P. A. and Worboys, M. F. 1995, <<A design support environment for spatiotemporal database applications $>>$ in: A.U. Frank and W. Kuhn (Eds.), Spatia Information Theory. A Theoretical Basis for GIS. Lecture Notes in Computer Science -LNCS- Vol.988. Berlin - Germany:Springer Verlag, pp.413-30, 1995. doi:10.1007/3-540-60392-1_27.

42. Rojas Vega, E. and Kemp, Z. 1995, <<An Object-Oriented Data Model for SpatioTemporal Data $>$ in: Ninth Annual Symposium on Geographic Information Systems in Natural Resources Management -GIS 95-, P. O Reilly (Ed.) Fort CollinsCO-USA:GIS World Inc., (9781882610150), pp.399-406, Vancouver-BC-Canada, March 27-30 1995.

43. Wachowicz, M. 1995, Object-Oriented Design for Temporal GIS, Ph.D Thesis, (R G.Healey and M.F. Worboys Advs.) University of Edinburgh:Edinburgh - Scotland Department of Geography, 1995

44. Raper, J. F. and Livingstone, D. 1995, <<Development of a geomorphological spatial model using object-oriented design $>>$ International Journal of Geographical Information Systems, Vol.9 No.4, pp.359-83, July 1995. doi:10.1080/02693799508902044

45. Yearsley, C. M. and Worboys, M. F. 1995, <<A deductive model of planar spatiotemporal objects $>>$ in: P. Fisher (Eds.), Innovations in GIS 2: Selected Papers from the Second National Conference on GIS Research UK. Innovations in GIS Vol.1. Bristol-PA-USA:Taylor \& Francis, pp.43-52, April 051995.

46. Becker, L., Voigtmann, A. and Hinrichs, K. H. 1996, <<Temporal support for geo-data in object-oriented databases $>>$ in: R.R. Wagner and H. Thoma (Eds.) Database and Expert Systems Applications. Lecture Notes in Computer Science -LNCS- Vol.1134. Berlin - Germany:Springer Verlag, pp.79-93, September 09-13 1996. doi:10.1007/BFb0034672.

47. Voigtmann, A., Becker, L. and Hinrichs, K. H. 1996, Temporal extensions for an Object-Oriented Geo-Data-Model, (Bericht Nr. 6/96-I) Münster-Germany:Institut für Informatik, February 151996.

48. Renolen, A. 1997, Modelling Spatiotemporal Information: The Spatiotempora Object Model, Trondheim-Norwey:Norwegian University of Sciences and Technology, May 23 1997. doi:10.1.1.56.3334.

49. Skjellaug, B. and Berre, A.-J. 1997, Multi-dimensional Time Support for Spatial Data Models, (253) Research Report. Oslo - Norwey:Universitetet i Oslo, May 1997. doi:10.1.1.48.2120

50. Worboys, M. F. 1998, <<A generic model for spatio-bitemporal geographic information >> in: M.J. Egenhofer and R.G. Golledge (Eds.), Spatial and Temporal Reasoning in Geographic Information Systems. Spatial Information Systems Vol.54. New York-NY-USA:Oxford University Press, pp.25-39, March 1998

51. Faria, G., Medeiros, C. B. and Nascimento, M. A. 1998, An Extensible Framework for Spatio-Temporal Database Applications, (TR- 27) Aalborg-Danmark:Time Center, April 23 1998. doi:10.1.1.92.104.

52. Worboys, M. F. 1998, <<Modelling changes and events in dynamic spatial systems with reference to socio-economic units $>>$ in: ESF GISDATA Conference on Modeling Change in Socio-Economic Units, London-UK:Taylor \& Francis, pp.112, Napthlion-Greece, 1998. doi:10.1.1.50.1443.

53. Wachowicz, M. 1999, Object-Oriented Design for Temporal GIS, Research Monographs in GIS Series, P. Fisher and J. F. Raper (Eds.), Num.15. LondonUK:Taylor \& Francis, 1999.

54. Renolen, A. 1999, Concepts and methods for modelling temporal and spatiotemporal information, Doctoral Dissertation, (J.T. Bjørke and M. Dæhlen Advs.) Norwegian University of Sciences and Technology:Trondheim-Norwey, June 1996.
55. Raza, A. and Kainz, W. 1999, $<<$ Cell tuple based spatio-temporal data model: an object oriented approach $\gg>$ in: 7th ACM International Symposium on Advances in Geographic Information Systems -GIS ' 99-, C.B. Medeiros (Ed.) New York-NYUSA:ACM, (1-58113-235-2), pp.20-25, Kansas City-MO-USA, November 02-06 1999. doi: $10.1145 / 320134.320140$.

56. Raza, A. and Kainz, W. 2000, $<<$ Designing Operators for Object-Oriented Spatiotemporal Data Model $>$ in: XIXth ISPRS Congress, K.J. Beek, M. Molenaar and D. Fritsch (Eds.). Rockville-MD-USA:International Society for Photogrammetry and Remote Sensing -ISPRS-, (ISSN 1682-1750), pp.863-70, Amsterdam-The Netherlands, July 16-23 2000. doi:10.1.1.132.4901.

57. Worboys, M. F. 2001, <<Modelling changes and events in dynamic spatial systems with reference to socio-economic units $>>$ in: A.U. Frank, J.F. Raper and J.-P. Cheylan (Eds.), Life and Motion of Socio-Economic Units. GISDATA Vol.8. London-UK:Taylor \& Francis, pp.129-38, 2001. doi:10.1.1.50.1443.

58. Raza, A. 2001, Object-Oriented Temporal GIS for Urban Applications, Núm.79,Doctoral Dissertation, (W. Kainz Adv.) ITC and University of Twente:Enschede-The Netherlands, Faculty of Geo-Information Science and Earth Observation, January 182001.

59. Frihida, A., Marceau, D. J. and Thériault, M. 2002, <<Spatio-Temporal ObjectOriented Data Model for Disaggregate Travel Behavior $>>$ Transactions in GIS, Vol.6 No.3, pp.277-94, June 2002. doi:10.1111/1467-9671.00111.

60. Li, B. and Kai, G. 2002, <<A General Object-Oriented Spatial Temporal Data Model $>>$ in: Symposium on Geospatial Theory, Processing and Applications. -ISPRS Commission IV-, C. Armenakis and Y.-C. Lee (Eds.). Rockville-MDUSA:International Society for Photogrammetry and Remote Sensing -ISPRS-, (1682-1750), pp.1-6, Ottawa-ON-Canada, July 09-12 2002.

61. Huang, B. and Claramunt, C. 2002, <<STOQL: An ODMG-based spatio-temporal object model and query language $>$ in: D.E. Richardson and P.v. Oosterom (Eds.), Advances in Spatial Data Handling. Vol.1. Berlin - Germany:Springer Verlag, pp.225-37, August 15 2002. doi:10.1.1.20.3381.

62. Jin, P., Yue, L. and Gong, Y. 2003, <<Semantics and Modeling of Spatiotemporal Changes $>>$ in: R. Meersman, Z. Tari and D. Schmidt (Eds.), On The Move to Meaningful Internet Systems 2003: CoopIS, DOA, and ODBASE. Vol.2888. Berlin - Germany:Springer Verlag, pp.924-33, 2003. doi:10.1007/978-3-540-39964-3_58.

63. Worboys, M. F. and Hornsby, K. 2004, <<From Objects to Events: GEM, the Geospatial Event Model >> in: M.J. Egenhofer, C. Freksa and H.J. Miller (Eds.), Geographic Information Science. Lecture Notes in Computer Science -LNCSVol.3234. Berlin - Germany:Springer Verlag, pp.327-44, October 20-23 2004. doi:10.1007/978-3-540-30231-5_22.

64. McIntosh, J. and Yuan, M. 2005, $<<$ A framework to enhance semantic flexibility for analysis of distributed phenomena $>>$ International Journal of Geographical Information Science, Vol.19 No.10, pp999-1018, November 2005. doi:10.1080/13658810500197652.

65. Ruiju, Z., Deren, L. and Daixue, S. 2005, <<An Object-Oriented Spatio-Temporal Data Model $>$ in: International Symposium on Spatio-temporal Modeling, Spatial Reasoning, Analysis, Data Mining and Data Fusion, Rockville-MDUSA:International Society for Photogrammetry and Remote Sensing -ISPRS-, pp.1-4, Beijing-China:Peking University - China, August 27- 292005.

66. Khaddaj, S., Adamu, A. and Morad, M. 2005, $<<$ Construction of an Integrated Object Oriented System for Temporal GIS $>>$ American Journal of Applied Sciences, Vol.2 No.12, pp1584-94, December 2005. doi:10.3844/ajassp.2005.1584.1594.

67. Huang, B. and Claramunt, C. 2005, <<Spatiotemporal Data Model and Query Language for Tracking Land Use Change $>>$ Transportation Research Record: Journal of the Transportation Research Board, Vol.1902 pp.107-13, December 2005. doi:10.3141/1902-13.

68. Camossi, E. 2005, Spatio-temporal multigranularity in an object data model, Ph.D Thesis, (E. Bertino and M. Bertolotto Advs.) Università degli Studi di Milano:Milano-Italy, Dipartimento di Informatica e Comunicazione, November 2004 .

69. Camossi, E., Bertolotto, M. and Bertino, E. 2006, $<<$ A multigranular object-oriented framework supporting spatio-temporal granularity conversions $>>$ International Journal of Geographical Information Science, Vol.20 No.5, pp.511-34, May 2006. doi:10.1080/13658810600607451.

70. Lohfink, A., Carnduff, T., Thomas, N. and Ware, M. 2007, <<An object-oriented approach to the representation of spatiotemporal geographic features $>>$ in: 15th Annual ACM International Symposium on Advances in Geographic Information Systems, H. Samet and C. Shahabi (Eds.). New York-NY-USA:ACM, (978-1-59593914-2), pp.35:1-:8, Seattle-WA-USA:Hyatt Regency Bellevue, November 7-9 2007. doi:10.1145/1341012.1341058. 
71. Huang, R. and Peng, Z.-R. 2008, $<<$ A spatiotemporal data model for dynamic transit networks $>>$ International Journal of Geographical Information Science, Vol.22 No.5, pp.527-45, May 2008. doi:10.1080/13658810701492399.

72. Li, Y.-D., Tong, X.-H. and Liu, M.-L. 2008, <<A Unified Version-Based Spatiotemporal Data Model $>$ in: XXIst ISPRS Congress - Silk Road for Information from Imagery, Rockville-MD-USA:International Society for Photogrammetry and Remote Sensing -ISPRS-, (1682-1750), pp.103-08, Beijing-China, July 03-11 2008. doi:10.1.1.155.4499.

73. Jiang, Y. and Bi, S. 2008, $<<$ Dynamic Object-Oriented Model and its Applications for Digital Earth $>$ in: M. Ehlers, K. Behncke, F.-W. Gerstengarbeet al. (Eds.) Digital Earth Summit on Geoinformatics 2008: Tools for Global Change Research. Heidelberg - Germany:Wichmann Herbert, pp.298-307, November 2008.

74. Huang, B. and Chandramouli, M. 2009, <<Spatio-Temporal Object Modeling $>>$ in: H.A. Karimi (Eds.), Handbook of Research on Geoinformatics. Hershey-PAUSA:Information Science Reference, pp.137-43, January 2009. doi:10.4018/978-159140-995-3.ch018.

75. Lohfink, A., McPhee, D. and Ware, M. 2010, $<<$ A UML-based Representation of Spatio-Temporal Evolution in Road Network Data >>Transactions in GIS, Vol.14 No.6, pp.853-72, December 2010. doi:10.1111/j.1467-9671.2010.01236.x.

76. Venkateswara Rao, K., Govardhan, A. and Chalapati Rao, K. V. 2011, <<An ObjectOriented Modeling and Implementation of Spatio-Temporal Knowledge Discovery System >>International Journal of Computer Science \& Information Technology, Vol.3 No.2, pp.61-76, April 2011. doi:10.5121/ijcsit.2011.3205.

77. Le, H. H., Gabriel, P., Gietzel, J. and Schaeben, H. 2013, <<An object-relationa spatio-temporal geoscience data model $>>$ Computers \& Geosciences, Vol.57 No.0, pp.104-15, August 2013. doi:10.1016/j.cageo.2013.04.014.

78. Zhu, R., Guilbert, E. \& Wong, M. S. 2017, 'Object-oriented tracking of the dynamic behavior of urban heat islands', International Journal of Geographical Information Science, vol. 31, no. 2, pp. 405-424.

\section{Event-based and Process-based models}

While time-stamping approaches focus on the idea of change to enhance spatial data with temporal components, event-oriented approaches "focus on the dynamic happening as a whole, and not just the time of the event." [4]. When there is a change, a time-stamp marks the time of the change; the event-based approach, however, allows the distinction of event attributes and relations besides object attributes and relations [4].

Siabato et al. [17] provide a general discussion about these concepts. The authors show several academic insights about the definitions of processes and events, and their differences. It is not clear where the relationship between them; depending on the phenomena modelled their nature changes. Galton, Worboys, Yuan, Stewart Hornsby, Claramunt, and Thériault have provided valuable discussion as to these conceptual elements. Some definitions seem to be contradictory. According to Galton and Worboys [84], there is a general consensus that the "key concepts required for the modelling of dynamic phenomena include object, state, process and event", but definitions are not so clear. Galton and Worboys [14] states that while objects and processes can experience change and such changes can be described as multiple states, an event does not experience change. An event is by definition a completed episode of history that does not experience changes after being; the event appears in time and can subsequently appear in another point in time as a subsequent event but different from the previous one. Yuan and Stewart Hornsby [4] offer a conceptualization quite aligned with Galton's. In contrast, Yuan [85] asserts that an event is a spatio-temporal aggregate of its associated processes, and a process is a sequential change of states in space and time. While events operate at the coarsest spatial and temporal resolution, states have the finest resolutions. Despite differences, both Yuan and Galton agree that a process involves different states. Claramunt and Thériault [43] also considers a process as the aggregation former finish and the latter begin. There is not a single or exclusive

of simultaneous or related changes; he states that changes and events are a natural way to define processes. An event can be modelled as a set of processes that transform entities. As Worboys [14] states, "one person's process is another's event, and vice versa". For instance, when a volcano erupts the eruption can be catalogued as a process if one considers the behaviour of the lava and the resulted tablelands; however, the eruption itself can be considered as an event, i.e., the volcano erupted at one specific instant. This discussion can be even deeper when considering more general concepts such as continuants and occurrents. "Ultimately, events and processes are central to the understanding of geographic worlds. They constitute information of interest to many, and perhaps, the majority of applications and scientific inquiries" [40].

Despite the blurred definitions, a large number of spatio-temporal models considering events and processes have been proposed. The usefulness and efficiency of these approaches have been demonstrated in the implementation of several case studies, mainly applied to environmental and transport studies. Nonetheless, the modelling, representation, and querying of events and processes are not a straightforward task. The application of spatial and temporal multigranularities in the representation of a phenomenon adds a significant complexity in the modelling tasks.

Several modelling proposals have combined both approaches; we have therefore included them both in the event- and in the processbased lists. A total of 28 single modelling proposal are listed in this section. 7 out of 28 proposals are multi-approach modelling, thus, subsection 4.4.1 lists 20 references for event-based and subsection 4.4.2 lists 15 for process-based

\section{Event-based models}

79. Beller, A. 1991, << Spatial/Temporal Events in a GIS $>>$ in: GIS/LIS ' 91 , A.S. Sensing (Ed.) Bethesda-MD-USA:American Society for Photogrammetry and Remote Sensing, (0944426751), pp.766-75, Atlanta-GA-USA:The Forum, October 28-November 011991.

80. Peuquet, D. J. and Wentz, E. A. 1994, <<An approach for time-based analysis of spatiotemporal data $>>$ in: Sixth International Symposium on Spatial Data Handling, T.C. Waugh and R.G. Healey (Eds.). London-UK:Taylor \& Francis, (9780748402670), pp.489-504, Edinburgh-Scotland, September 05-09 1994.

81. Peuquet, D. J. and Duan, N. 1995, <<An event-based spatiotemporal data model (ESTDM) for temporal analysis of geographical data $>>$ International Journal of Geographical Information Systems, Vol.9 No.1, pp.7-24, 1995. doi:10.1080/02693799508902022.

82. Claramunt, C. and Thériault, M. 1995, <<Managing Time in GIS: An EventOriented Approach $>>$ in: Recent Advances in Temporal Databases: Proceedings of the International Workshop on Temporal Databases, J. Clifford and A. Tuzhilin (Eds.). London-UK:Springer Verlag, (3-540-19945-4), pp.23-42, ZurichSwitzerland, September 17-18 1995.

83. Allen, E., Edwards, G. and Bédard, Y. 1995, <<Qualitative causal modeling in temporal GIS $>>$ in: A.U. Frank and W. Kuhn (Eds.), Spatial Information Theory. A Theoretical Basis for GIS. Lecture Notes in Computer Science -LNCS- Vol.988. Berlin - Germany:Springer Verlag, pp.397-412, 1995. doi:10.1007/3-540-60392$1 \_26$.

84. Claramunt, C. and Thériault, M. 1996, <<Toward semantics for modelling spatiotemporal processes within GIS $>>$ in: Seventh International Symposium on Spatial Data Handling, M.-J. Kraak and M. Molenaar (Eds.). London-UK:Taylor \& Francis, (978-0748405916), pp.47-64, Delft - The Netherlands, August 1996.

85. Worboys, M. F. 1998, <<Modelling changes and events in dynamic spatial systems with reference to socio-economic units $>>$ in: ESF GISDATA Conference on Modeling Change in Socio-Economic Units, London-UK:Taylor \& Francis, pp.112, Napthlion-Greece, 1998. doi:10.1.1.50.1443.

86. Chen, J. and Jiang, J. 2000, $<<$ An Event-Based Approach to Spatio-Temporal Data Modeling in Land Subdivision Systems $>>$ GeoInformatica, Vol.4 No.4, pp.387-402, December 2000. doi:10.1023/A:1026565929263.

Int J Earth Environ Sci

ISSN: $2456-351 \mathrm{X}$

IJEES, an open access journal

Volume 2. 2017. 135 
87. Yuan, M. 2001, <<Representing Complex Geographic Phenomena in GIS >>Cartography and Geographic Information Science, Vol.28 No.2, pp.83-96, April 2001. doi:10.1559/152304001782173718.

88. Worboys, M. F. 2001, <<Modelling changes and events in dynamic spatial systems with reference to socio-economic units $>>$ in: A.U. Frank, J.F. Raper and J.-P. Cheylan (Eds.), Life and Motion of Socio-Economic Units. GISDATA Vol.8 London-UK:Taylor \& Francis, pp.129-38, 2001. doi:10.1.1.50.1443.

89. Thériault, M., Claramunt, C., Séguin, A.-M. and Villeneuve, P. P. 2002, $<<$ Temporal GIS and statistical modelling of personal lifelines $>>$ in: D.E. Richardson and P.v. Oosterom (Eds.), Advances in Spatial Data Handling. Vol.1. Berlin Germany:Springer Verlag, pp.433-50, August 15 2002. doi:10.1.1.222.1126.

90. Worboys, M. F. and Hornsby, K. 2004, <<From Objects to Events: GEM, the Geospatial Event Model >> in: M.J. Egenhofer, C. Freksa and H.J. Miller (Eds.) Geographic Information Science. Lecture Notes in Computer Science -LNCS Vol.3234. Berlin - Germany:Springer Verlag, pp.327-44, October 20-23 2004. doi:10.1007/978-3-540-30231-5_22.

91. Sengupta, R. and Yan, C. 2004, <<A Hybrid Spatio-Temporal Data Mode and Structure (HST-DMS) for Efficient Storage and Retrieval of Land Use Information $>>$ Transactions in GIS, Vol.8 No.3, pp.351-66, June 2004.

92. McIntosh, J. and Yuan, M. 2005, $<<$ A framework to enhance semantic flexibility for analysis of distributed phenomena>>International Journal of Geographical Information Science, Vol.19 No.10, pp999-1018, November 2005 doi:10.1080/13658810500197652.

93. Worboys, M. F. 2005, <<Event-oriented approaches to geographic phenomena $>>$ International Journal of Geographical Information Science, Vol.19 No.1, pp.1-28, January 2005. doi:10.1080/13658810412331280167.

94. McIntosh, J. and Yuan, M. 2005, <<Assessing Similarity of Geographic Processes and Events $>>$ Transactions in GIS, Vol.9 No.2, pp.223-45, March 2005. doi:10.1111/ j.1467-9671.2005.00214.x

95. Worboys, M. F. and Duckham, M. 2006, $<<$ Monitoring qualitative spatiotemporal change for geosensor networks $>>$ International Journal of Geographical Information Science, Vol.20 No.10, pp1087-108, November 2006 doi:10.1080/13658810600852180

96. Stewart, K., Fan, J. and White, E. 2013, <<Thinking about Space-Time Connections Spatiotemporal Scheduling of Individual Activities $>>$ Transactions in GIS, Vol.17 No.6, pp.791-807, December 2013. doi:10.1111/tgis.12028.

97. Ferreira, K. R., Câmara, G. and Vieira Monteiro, A. M. 2014, $<<$ An Algebra for Spatiotemporal Data: From Observations to Events $\gg>$ Transactions in GIS, Vol.18 No.2, pp.253-69, May 2013. doi:10.1111/tgis.12030.

98. Llaves, A. and Kuhn, W. 2014, $<<$ An event abstraction layer for the integration of geosensor data $>$ International Journal of Geographical Information Science, Vol.28 No.5, pp.1085-106, May 2014. doi:10.1080/13658816.2014.882513.

\section{Process-based models}

99. Peuquet, D. J. 1994, <<It's About Time: A Conceptual Framework for the Representation of Temporal Dynamics in Geographic Information Systems $>>$ Annals of the Association of American Geographers, Vol.84 No.3, pp.441-61, 1994. doi:10.1111/j.1467-8306.1994.tb01869.x.

100. Claramunt, C. and Thériault, M. 1995, <<Managing Time in GIS: An EventOriented Approach $>>$ in: Recent Advances in Temporal Databases: Proceedings of the International Workshop on Temporal Databases, J. Clifford and A Tuzhilin (Eds.). London-UK:Springer Verlag, (3-540-19945-4), pp.23-42, ZurichSwitzerland, September 17-18 1995

101. Claramunt, C. and Thériault, M. 1996, <<Toward semantics for modelling spatiotemporal processes within GIS $>>$ in: Seventh International Symposium on Spatial Data Handling, M.-J. Kraak and M. Molenaar (Eds.). London-UK:Taylor \& Francis, (978-0748405916), pp.47-64, Delft - The Netherlands, August 1996.

102. Claramunt, C., Parent, C. and Thériault, M. 1997, $<<$ Design patterns for spatiotemporal processes $>>$ in: S. Spaccapietra and F.J. Maryanski (Eds.), Searching for Semantics: Data Mining and Reverse Engineering - 7th IFIP 2.6 Working Conference on Database Semantics DS-7. IFIP Conference Proceedings Vol.124. London-UK:Chapman \& Hall, pp.415-28, October 07-10 1997. doi:10.1.1.52.3769.

103. Worboys, M. F. 1998, <<Modelling changes and events in dynamic spatial systems with reference to socio-economic units $>>$ in: ESF GISDATA Conference on Modeling Change in Socio-Economic Units, London-UK:Taylor \& Francis, pp.112, Napthlion-Greece, 1998. doi:10.1.1.50.1443.

104. Claramunt, C., Thériault, M. and Parent, C. 1998, $<<$ A qualitative representation of evolving spatial entities in two-dimensional topological spaces $>>$ in: S. Carver (Eds.), Innovations in GIS 5: selected papers from the fifth National Conference on GIS Research UK. Innovations in GIS Vol.5. London-UK:Taylor \& Francis, pp.12131, April 30 1998. doi:10.1.1.97.6533.
105. Claramunt, C., Parent, C., Spaccapietra, S. and Thériault, M. 1999, <<Database Modelling for Environmental and Land Use Changes >> in: J. Stillwell, S. Geertman and S. Openshaw (Eds.), Geographical Information and Planning. Advances in Spatial Science. Berlin - Germany:Springer, pp.181-202, September 1999. doi:10.1007/978-3-662-03954-0_10.

106. Yuan, M. 2001, <<Representing Complex Geographic Phenomena in GIS >>Cartography and Geographic Information Science, Vol.28 No.2, pp.83-96, April 2001. doi:10.1559/152304001782173718.

107. Worboys, M. F. 2001, <<Modelling changes and events in dynamic spatial systems with reference to socio-economic units $>>$ in: A.U. Frank, J.F. Raper and J.-P. Cheylan (Eds.), Life and Motion of Socio-Economic Units. GISDATA Vol.8. London-UK:Taylor \& Francis, pp.129-38, 2001. doi:10.1.1.50.1443.

108. Yang, Y. and Claramunt, C. 2003, <<A Process-oriented Multi-representation of Gradual Changes $>>$ Journal of Geographic Information and Decision Analysis, Vol.7 No.1, pp.1-13, 2003. doi:10.1.1.6.771.

109. McIntosh, J. and Yuan, M. 2005, <<Assessing Similarity of Geographic Processes and Events $>>$ Transactions in GIS, Vol.9 No.2, pp.223-45, March 2005. doi:10.1111/ j.1467-9671.2005.00214.x.

110. Worboys, M. F. and Duckham, M. 2006, $<<$ Monitoring qualitative spatiotemporal change for geosensor networks $>>$ International Journal of Geographical Information Science, Vol.20 No.10, pp1087-108, November 2006. doi:10.1080/13658810600852180.

111. Goodchild, M. F., Yuan, M. and Cova, T. J. 2007, <<Towards a general theory of geographic representation in GIS $>>$ International Journal of Geographical Information Science, Vol.21 No.3, pp.239-60, March 2007. doi:10.1080/13658810600965271.

112. Liu, Y., Goodchild, M. F., Guo, Q. H., Tian, Y. and Wu, L. 2008, <<Towards a General Field model and its order in GIS >>International Journal of Geographical Information Science, Vol.22 No.6, pp.623-43, June 2008. doi:10.1080/13658810701587727.

113. Pultar, E., Cova, T. J., Yuan, M. and Goodchild, M. F. 2010, <<EDGIS: a dynamic GIS based on space time points $>>$ International Journal of Geographical Information Science, Vol.24 No.3, pp.329-46, March 2010. doi:10.1080/13658810802644567.

\section{Feature-based models}

The three main components of geographic information are space, theme, and time [86,87]. These core components can be modelled individually and collectively. A feature relies on such dimensions for its representation and modelling. The following modelling proposals consider one, two or all of them to model dynamic geographic information; yet most of them are focused on the spatial dimension. Feature-based models are also known as entity-based models. In general, models are grounded in an entity-based perception of geographic phenomena and represent geographic entities as feature objects in GIS. This section comprises 9 models.

114. Usery, E. L. 1996, <<A Feature-Based Geographic Information System Model $>>$ Photogrammetric Engineering \& Remote Sensing, Vol.62 No.7, pp.83338, July 1996.

115. Stefanakis, E. $2003,<<$ Modelling the history of semi-structured geographical entities $>>$ International Journal of Geographical Information Science, Vol.17 No.6, pp.517-46, 2003. doi:10.1080/1365881031000114080.

116. Yang, Y. and Claramunt, C. 2003, <<A Process-oriented Multi-representation of Gradual Changes $>>$ Journal of Geographic Information and Decision Analysis, Vol.7 No.1, pp.1-13, 2003. doi:10.1.1.6.771.

117. Xiao-juan, L., Lian-wang, Y., Hui-li, G., Wen-ji, Z. and Yong-hua, S. 2005, <<Featurebased Spatio-temporal Data Model and its Application in Landuse Monitoring $>>$ in: International Symposium on Spatio-temporal Modeling, Spatial Reasoning, Analysis, Data Mining and Data Fusion, Rockville-MD-USA:International Society for Photogrammetry and Remote Sensing -ISPRS-, pp.1-6, Beijing-China:Peking University - China, August 27-29 2005.

118. Le, Y. 2005, Representing time in Base Geographic Data, Ph.D Thesis, (E.L. Usery Adv.) The University of Georgia:Athens-GA-USA, Department of Geography, 2005.

119. Choi, J., Seong, J. C., Kim, B. and Usery, E. L. 2008, <<Innovations in Individual Feature History Management - The Significance of Feature-based Temporal Model >>GeoInformatica, Vol.12 No.1, pp.1-20, March 2008. doi:10.1007/s10707007-0019-y.

120. Wu, X., Cui, W., Huang, Y. and Yang, X. 2008, $<<$ Research on Change-of-Feature Based Spatio-Temporal Object Relational Model $>>$ in: XXIst ISPRS Congress - Silk Road for Information from Imagery, Rockville-MD-USA:International Society for Photogrammetry and Remote Sensing -ISPRS-, (1682-1750), pp.119-22, BeijingChina, July 03-11 2008. 
121. Lohfink, A., McPhee, D. and Ware, M. 2010, $<<$ A UML-based Representation of Spatio-Temporal Evolution in Road Network Data $>>$ Transactions in GIS, Vol.14 No.6, pp.853-72, December 2010. doi:10.1111/j.1467-9671.2010.01236.x.

122. Maldonado Ibañez, A. and Vázquez Hoehne, A. 2010, $<<$ Diseño de primitivas geométricas espacio-temporales para describir fenómenos dinámicos $>>$ GeoFocus, (Artículos) Vol.10 No.1, pp.232-51, November 2010

\section{Identity-based models}

In contrast to modelling proposals in which the modelling focus remain in one of the three main components (space, time, and theme), the identity-based change trend focuses on the identity of the evolving object. This characteristic being a significant contribution considering the ID restriction in the Object-Oriented modelling trend (see Section 4.3). Models aligned in this trend are based upon the explicit description of change with respect to states of existence and non-existence for identifiable objects. A key element in the model is the concept of object identity, "that unique characteristic that distinguishes one object from another" [88]. The identity is a means of tracking and querying the existence of specific objects and types of objects independently of specific attribute values, properties, or structure (i.e., common elements). For instance, in cadastral applications the evolution of cadastral plots can be physical or juridical. From the physical point of view, the evolution of the plots and parcels results into the creation and deletion of geometries that represents the physical evolution of the plots. A link between the former and new plots is not explicit. When considering the juridical viewpoint, a tracking of the identity of previous and current owners is a key element. In these kinds of scenarios, the identity-based model is better than the approaches focused on physical characteristics (geometry, attributes).A unique identifier of a plot allows one to easily identify its owner's history. In contrast to object-oriented approaches, identity-based modelling allows this unique identifier to remain over time and does not die (disappears) along with objects, the identifier is inherited (transition property). This modelling proposal is quite specific and only 8 models have been proposed, 3 of them mixed with other trends.

123. Hornsby, K. and Egenhofer, M. J. 1997, <<Qualitative representation of change >> in: S.C. Hirtle and A.U. Frank (Eds.), Spatial Information Theory A Theoretica Basis for GIS. Lecture Notes in Computer Science -LNCS- Vol.1329. Berlin Germany:Springer Verlag, pp.15-33, October 15-18 1997. doi:10.1007/3-54063623-4_40.

124. Hornsby, K. and Egenhofer, M. J. 1998, <<Identity-Based Change Operations for Composite Objects $>>$ in: 8th International Symposium on Spatial Data Handling, T.K. Poiker and N.R. Chrisman (Eds.). Vancouver-BC-Canada:International Geographical Union, pp.202-13, Vancouver-BC-Canada:The Harbour Centre, July 11-15 1998. doi:10.1.1.10.4314

125. Hornsby, K. and Egenhofer, M. J. 2000, <<Identity-based change: a foundation for spatio-temporal knowledge representation $>>$ International Journal of Geographical Information Science, Vol.14 No.3, pp.207-24, 2000. doi:10.1080/136588100240813.

126. Sriti, M., Thibaud, R. and Claramunt, C. $2005,<<$ A Fuzzy Identity-Based Temporal GIS for the Analysis of Geomorphometry Changes $>>$ in: S. Spaccapietra and E. Zimányi (Eds.), Journal on Data Semantics III. Lecture Notes in Computer Science -LNCS- Vol.3534. Berlin - Germany:Springer Verlag, pp.81-99, August 2005. doi:10.1007/11496168_4.

127. Nixon, V. and Stewart Hornsby, K. 2010, $<<$ Using geolifespans to model dynamic geographic domains $>>$ International Journal of Geographical Information Science, Vol.24 No.9, pp.1289-308, September 2010. doi:10.1080/13658811003601448.

128. Plumejeaud, C., Mathian, H., Gensel, J. and Grasland, C. 2011, $<<$ Spatio-temporal analysis of territorial changes from a multi-scale perspective $>>$ International Journal of Geographical Information Science, Vol.25 No.10, pp1597-612, October 2011. doi:10.1080/13658816.2010.534658.

129. Del Mondo, G., Rodríguez, M. A., Claramunt, C., Bravo, L. and Thibaud, R. 2013, << Modeling consistency of spatio-temporal graphs $>>$ Data \& Knowledge Engineering, Vol.84 pp.59-80, March 2013.doi:10.1016/j.datak.2012.12.007.

130. Yi, J., Du, Y., Liang, F., Zhou, C., Wu, D. and Mo, Y. 2014, $<<$ A representation framework for studying spatiotemporal changes and interactions of dynamic geographic phenomena>>International Journal of Geographical Information Science, Vol.28 No.5, pp.1010-27, May 2014. doi:10.1080/13658816.2014.890201.

\section{Ontology-driven models}

Ontologies have proven to be a reliable means for ordering and integrating specific-domain information. Ontology-based models are focused on the evolution of one specific characteristic; such a characteristic corresponds to the ontology' score domain. Therefore, ontology-driven models apply domain-specific ontologies. The following proposals consider the use of ontologies for modelling different behaviours derived from evolution of geographic information. 7 models have been classified in the bibliographic collection considering this core method.

131. Perry, M., Hakimpour, F. and Sheth, A. P. 2006, <<Analyzing theme, space, and time: an ontology-based approach $>>$ in: 14th annual ACM international symposium on Advances in geographic information systems (GIS `06), R.A. By and S. Nittel (Eds.). New York-NY-USA:ACM, (1-59593-529-0), pp.147-54, ArlingtonVA-USA, November 10-11 2006. doi:10.1145/1183471.1183496.

132. Kauppinen, T., Deichstetter, C., Kepler, J., Linz, U., Väätäinen, J. and Hyvönen, E. 2006, $<<$ Ontology-based modeling and visualization of cultural spatio-temporal knowledge $>$ in: New Developments in Artificial Intelligence and the Semantic Web- Proceedings of the 12th Finnish Artificial Intelligence Conference -STeP 2006-, E. Hyvönen, T. Kauppinen, J. Kortela, M. Laukkanen, T. Raiko, et al. (Eds.). Helsinki - Finland:Finnish Artificial Intelligence Society, (978-952-5677-03-4), pp.37-45, Espoo-Finland:Helsinki University of Technol, Octubre 26-27 2006. doi:10.1.1.106.4711.

133. Bittner, T., Donnelly, M. and Smith, B. 2009, $<<$ A spatio-temporal ontology for geographic information integration $>$ International Journal of Geographical Information Science, Vol.23 No.6, pp.765-98, June 2009. doi:10.1080/13658810701776767.

134. Siabato, W. and Manso-Callejo, M. Á. 2011, <<Integration of temporal and semantic components into the Geographic Information through mark-up languages. Part I: definition $>>$ in: B. Murgante, O. Gervasi, A. Iglesiaset al. (Eds.), Computational Science and Its Applications - ICCSA 2011. Lecture Notes in Computer Science -LNCS- Vol.6782. Berlin - Germany:Springer Verlag, pp.394-409, Junio 20-23 2011. doi:10.1007/978-3-642-21928-3_28.

135. Lopez-Pellicer, F. J., Lacasta, J., Florczyk, A., Nogueras-Iso, J. and Zarazaga-Soria, F. J. $2012,<<$ An ontology for the representation of spatiotemporal jurisdictional domains in information retrieval systems $>>$ International Journal of Geographical Information Science, Vol.26 No.4, pp.579-97, April 2012. doi:10.1080/13658816.2 011.599811 .

136. Gantner, F., Waldvogel, B., Meile, R. and Laube, P. 2013, $<<$ The Basic Formal Ontology as a Reference Framework for Modeling the Evolution of Administrative Units $>>$ Transactions in GIS, Vol.17 No.2, pp.206-26, April 2013. doi:10.1111/ j.1467-9671.2012.01356.x.

137. Stewart, K., Fan, J. and White, E. 2013, <<Thinking about Space-Time Connections: Spatiotemporal Scheduling of Individual Activities $>>$ Transactions in GIS, Vol.17 No.6, pp.791-807, December 2013. doi:10.1111/tgis.12028.

\section{Conceptual Modelling Extensions}

The huge spread of mobile and sensoring technologies has allowed significant and rich spatio-temporal datasets to be obtained, and, due to this, moving objects have recently arisen as a very active research area. Many research efforts have been addressed in data modelling [89], querying methods [90,91], identification and representation of mobility patterns [92-94], computing with spatial trajectories [92] and pedestrian networks [93], and space-time interpolation and locational inference [97,98,], amongst others. Specific spatio-temporal modelling approaches have been proposed for moving objects [89,99101], especially for phenomena represented by point geometries. Furthermore, methodologies for the representation of changing areas as moving regions have also been studied. A recent review of existing quantitative methods for analysing movement data was presented by Long and Nelson [53]. The Moving Objects Spatio-Temporal data model (MOST) proposed in Wolfson's research [102,103,104] can be considered a pioneering proposal for the modelling of moving objects. Furthermore, methodologies for the representation of changing areas as moving regions have also been studied [105-107]. Please notice that the following references are exclusively focused on the spatio- 
temporal modelling approaches proposed for Moving Objects, and they do not reflect the vast recent bibliography produced in this area, especially during the last years. TimeBliography list 55 additional references related to Moving Objects. We highlight 21 modelling proposals for moving object son this bibliography.

138. Sistla, A. P., Wolfson, O., Chamberlain, S. and Dao, S. 1997, $<<$ Modeling and querying moving objects $>>$ in: 13th International Conference on Data Engineering, Los Alamitos-CA-USA:IEEE Computer Society, (0-8186-7807-0), pp.422-32, Birmingham-UK:University of Birmingham, April 07-11 1997. doi:10.1109/ ICDE.1997.581973.

139. Erwig, M., Güting, R. H., Schneider, M. and Vazirgiannis, M. 1999, <<SpatioTemporal Data Types: An Approach to Modeling and Querying Moving Objects in Databases $>$ GeoInformatica, Vol.3 No.3, pp.269-96, September 1999. doi:10.1023/A:1009805532638.

140. Güting, R. H., Böhlen, M. H., Erwig, M., Jensen, C. S., Lorentzos, N. A., Schneider M. and Vazirgiannis, M. 2000, $<<$ A foundation for representing and querying moving objects $>>$ ACM Transactions on Database Systems (TODS), Vol.25 No.1, pp.1-42, March 2000. doi:10.1145/352958.352963.

141. Forlizzi, L., Güting, R. H., Nardelli, E. and Schneider, M. 2000, $<<$ A data model and data structures for moving objects databases $>>$ ACM SIGMOD Record, Vol.29 No.2, pp.319-30, June 2000. doi:10.1145/342009.335426.

142. Vazirgiannis, M. and Wolfson, O. 2001, <<A Spatiotemporal Model and Language for Moving Objects on Road Networks >> in: C.S. Jensen, M. Schneider, B. Seegere al. (Eds.), Advances in Spatial and Temporal Databases. Lecture Notes in Compute Science -LNCS- Vol.2121. Berlin - Germany:Springer Verlag, pp.20-35, July 12-15 2001. doi:10.1007/3-540-47724-1_2.

143. Hornsby, K. and Egenhofer, M. J. 2002, <<Modeling Moving Objects over Multiple Granularities $>>$ Annals of Mathematics and Artificial Intelligence, Vol.36 No.1-2, pp.177-94, September 2002. doi:10.1023/A:1015812206586.

144. Brakatsoulas, S., Pfoser, D. and Tryfona, N. 2004, $<<$ Modeling, Storing, and Mining Moving Object Databases $>>$ in: International Database Engineering an Applications Symposium (IDEAS `04), Washington D.C. - USA:IEEE Computer Society, (0-7695-2168-1), pp.68-77, Coimbra-Portugal, July 7-9 2004. doi:10.1109/ IDEAS.2004.45.

145. Güting, R. H. and Schneider, M. 2005, Moving Objects Databases, Data Management Systems, M. Kaufmann (Eds.), San Francisco-CA-USA:Morgan Kaufmann Publishers, 2005

146. Jacquez, G. M., Greiling, D. A. and Kaufmann, A. M. 2005, $<<$ Design and implementation of a Space-Time Intelligence System for disease surveillance>>Journal of Geographical Systems, Vol.7 No.1, pp.7-23, May 2005 doi:10.1007/s10109-005-0147-6.

147. Noyon, V., Devogele, T. and Claramunt, C. 2005, $<<$ A Formal Model for Representing Point Trajectories in Two-Dimensional Spaces $>>$ in: J. Akoka, S.W Liddle, I.-Y. Songet al. (Eds.), Perspectives in Conceptual Modeling. Lecture Notes in Computer Science -LNCS- Vol.3770. Berlin - Germany:Springer Verlag, pp.208 17, 2005. doi:10.1007/11568346_23.

148. du Mouza, C. and Rigaux, P. 2005, <<Mobility Patterns $>>$ GeoInformatica, Vol.9 No.4, pp.297-319, December 2005. doi:10.1007/s10707-005-4574-9.

149. Güting, R. H., Teixeira de Almeida, V. and Ding, Z. 2006, $<<$ Modeling and querying moving objects in networks $>>$ The VLDB Journal - The International Journal on Very Large Data Bases, Vol.15 No.2, pp.165-90, June 2006. doi:10.1007/s00778-0050152-x.

150. Stewart Hornsby, K. and Cole, S. 2007, $<<$ Modeling Moving Geospatial Objects from an Event-based Perspective $>>$ Transactions in GIS, Vol.11 No.4, pp.555-73, August 2007. doi:10.1111/j.1467-9671.2007.01060.x.

151. Noyon, V., Claramunt, C. and Devogele, T. 2007, $<<$ A Relative Representation of Trajectories in Geogaphical Spaces $>>$ GeoInformatica, Vol.11 No.4, pp.479-96, December 2007. doi:10.1007/s10707-007-0023-2.

152. Spaccapietra, S., Parent, C., Damiani, M. L., Macedo, J. A. d., Porto, F. and Vangenot, C. $2008,<<$ A conceptual view on trajectories $>>$ Data \& Knowledge Engineering, Vol.65 No.1, pp.126-46, April 2008. doi:10.1016/j.datak.2007.10.008.

153. Kuijpers, B. and Othman, W. 2009, <<Modeling uncertainty of moving objects on road networks via space-time prisms $>>$ International Journal of Geographical Information Science, Vol.23 No.9, pp.1095-117, September 2009. doi:10.1080/13658810802097485

154. Zheni, D., Frihida, A., Ghezala, H. B. and Claramunt, C. 2009, $<<$ A Semantic Approach for the Modeling of Trajectories in Space and Time $>>$ in: C.A. Heuser and G. Pernul (Eds.), Advances in Conceptual Modeling - Challenging Perspectives. Lecture Notes in Computer Science -LNCS- Vol.5833. Berlin - Germany:Springer Verlag, pp.347-56, 2009. doi:10.1007/978-3-642-04947-7_41.
155. Frihida, A., Zheni, D., Ghezala, H. B. and Claramunt, C. 2009, $<<$ Modeling Trajectories: A Spatio-Temporal Data Type Approach $>>$ in: 20th International Workshop on Database and Expert Systems Application (DEXA 09), A.M. Tjoa and R.R. Wagner (Eds.). Los Alamitos-CA-USA:IEEE Computer Society, (978-07695-3763-4), pp.447-51, Linz-Upper Austria-Austria, August 31-September 04 2009. doi:10.1109/DEXA.2009.70.

156. $\mathrm{Xu}, \mathrm{J}$. and Güting, R. H. 2013, $<<$ A generic data model for moving objects $>>$ GeoInformatica, Vol.17 No.1, pp.125-72, January 2013. doi:10.1007/ s10707-012-0158-7.

157. Bogorny, V., Renso, C., de Aquino, A. R., de Lucca Siqueira, F. and Alvares, L. O. 2014, $<<$ CONSTAnT - A Conceptual Data Model for Semantic Trajectories of Moving Objects $>>$ Transactions in GIS, Vol.18 No.1, pp.66-88, February 2014. doi:10.1111/tgis.12011.

158. Long, J. A., Nelson, T. A. and Nathoo, F. S. 2014, $<<$ Toward a kinetic-based probabilistic time geography >>International Journal of Geographical Information Science, Vol.28 No.5, pp.855-74, May 2014. doi:10.1080/13658816.2013.818151.

\section{Graph-based models}

While the graph-based modelling approach seems to have been put aside during the 2000s, the current decade shows an active interest in this approach. The simplicity of defining relationships amongst geographic entities and the representation of their evolution results in significant flexibility for the representation of changes, movement, and events, which in turn allows the integration of graphs with other modelling trends. 9 proposals are based on the node-relation function derived from graphs; two main authors cover all the proposals: Renolen and Del Mondo.

Although the three-domain model uses a graph to represent the transitions amongst spatial objects at different locations, the first graph-based modelling approach, called the History Graph Model, was proposed by Renolen [108]. The main purpose of the history graph model is to identify all types of temporal behaviour and to manage both objects and events. This model is intended to visualize the temporal element in order to reproduce the evolution of geographic information. On the other hand, Del Mondo et al. [109] propose a discrete, spatio-temporal graph-based model oriented to the modelling of evolving, two-dimensional regions. The authors introduce a formal approach for analysing the consistency of relationships of evolving entities. This proposal is an extension of previous research [110] in which the authors modelled the spatio-temporal interactions networks derived from the evolution of entities considering spatial relations, spatio-temporal relations, and temporal filiations, which in turn allow the representation of spatial and temporal connections.

159. Renolen, A. 1996, << History graphs: conceptual modeling of Spatio-Temporal Data $>$ in: GIS Frontiers in Business and Science Conference, M. Konecny (Ed.) Bern - Switzerland:International Cartographic Association -ICA-, Brno-Czech Republic:Masaryk University, January 011996.

160. Renolen, A. 1997, Modelling Spatiotemporal Information: The Spatiotemporal Object Model, Trondheim-Norwey:Norwegian University of Sciences and Technology, May 23 1997. doi:10.1.1.56.3334.

161. Renolen, A. 1999, Concepts and methods for modelling temporal and spatiotemporal information, Doctoral Dissertation, (J.T. Bjørke and M. Dæhlen Advs.) Norwegian University of Sciences and Technology:Trondheim-Norwey, June 1996.

162. Stefanakis, E. 2003, $<<$ Modelling the history of semi-structured geographical entities $>>$ International Journal of Geographical Information Science, Vol.17 No.6, pp.517-46, 2003. doi:10.1080/1365881031000114080.

163. Del Mondo, G., Stell, J. G., Claramunt, C. and Thibaud, R. 2010, <<A Graph Model for Spatio-temporal Evolution>>Journal of Universal Computer Science, Vol.16 No.11, pp1452-77, 2010. doi:10.3217/jucs-016-11-1452.

164. Stell, J. G., Del Mondo, G., Thibaud, R. and Claramunt, C. 2011, <<Spatio-temporal evolution as bigraph dynamics $>>$ in: M.J. Egenhofer, N. Giudice, R. Moratzet al (Eds.), Spatial Information Theory. 10th International Conference -COSIT'11-. Lecture Notes in Computer Science -LNCS- Vol.6899. Berlin - Germany:Springer Verlag, pp.148-67, 2011. doi:10.1007/978-3-642-23196-4_9. 
165. Del Mondo, G., Rodríguez, M. A., Claramunt, C., Bravo, L. and Thibaud, R. 2013, <<Modeling consistency of spatio-temporal graphs $>>$ Data \& Knowledge Engineering, Vol.84 pp.59-80, March 2013. doi:10.1016/j.datak.2012.12.007.

166. Thibaud, R., Del Mondo, G., Garlan, T., Mascret, A. and Carpentier, C. 2013 $<<$ A Spatio-Temporal Graph Model for Marine Dune Dynamics Analysis and Representation $>>$ Transactions in GIS, Vol.17 No.5, pp.742-62, October 2013 doi:10.1111/tgis.12006.

167. van de Weghe, N., de Roo, B., Qiang, Y., Versichele, M., Neutens, T. and de Maeyer, P. 2014, $<<$ The continuous spatio-temporal model (CSTM) as an exhaustive framework for multi-scale spatio-temporal analysis $>>$ International Journal of Geographical Information Science, Vol.28 No.5, pp.1047-60, May 2014. doi:10.10 80/13658816.2014.886329.

\section{Agents-based models}

Lifespan-based approaches model the spatio-temporal phenomena considering their duration. Such models are based on the definition of object lifespan used in temporal database modelling [110]. One approach to determining objects' life spans is to tag every object with a pair of time stamps: one for the time of creation and one for the time of ending. The simple time-stamping model [41] applies this approach. In general, lifespan is defined as the duration of the modelled geographic phenomenon or event. Lifespan are recurrently considered in all modelling approaches but only two models focus on the duration of the geographic phenomena.

168. Skjellaug, B. and Berre, A.-J. 1997, Multi-dimensional Time Support for Spatia Data Models, (253) Research Report. Oslo - Norwey:Universitetet i Oslo, May 1997. doi:10.1.1.48.2120.

169. Nixon, V. and Stewart Hornsby, K. 2010, << Using geolifespans to model dynamic geographic domains $>>$ International Journal of Geographical Information Science, Vol.24 No.9, pp.1289-308, September 2010. doi:10.1080/13658811003601448.

\section{Temporal modelling}

Another modelling approach that has arisen in the last decade is the evolution from objects to agents. While an object can be defined as an entity described by attributes and with a set of actions, an agent is an object with goals and the ability to control itself and interact in an environment. While agents are characterized by autonomy, reactivity, and proactivity, objects are passive and dependent on external actions. The agent is able to react autonomously to changes in an environment. This difference has been considered by researchers in the spatio-temporal modelling field. The agent-based modelling approach $[47,112,113]$ is indeed a research line that has recently opened in spatio-temporal modelling with enormous sun exploited potential. Agents have properties that objects do not, and perhaps evolution from the object-oriented and event-driven paradigms to the agent-oriented foundations [114] could be a promising pathway for the advantages that the simulation of interaction amongst geographic entities can offer. In this sense, different software that supports agents can offer different possibilities. Intelligent agents can be merged in AI systems for improving spatio-temporal reasoning, e.g., the control and prediction of traffic in transport networks. Autonomous agents can evolve in order to adapt their capabilities to achieve their objectives, e.g., how should a system react in case that a geographic area suddenly changes or disappears (floods, landslides)? The possibilities increase when considering distributed agent systems or cooperative multiagent systems. Different levels of analysis and reasoning can be achieved when agents from different systems interact. In this section, we highlight eight modelling proposals, most of them derived from case-studies.

170. Gimblett, H. R. (Ed.) 2002, Integrating Geographic Information Systems and Agent-Based Modeling Techniques for Simulating Social and Ecological Processes, Studies in the Sciences of Complexity: New York-NY-USA:Oxford University Press, January 172002
171. Batty, M., Desyllas, J. and Duxbury, E. 2003, $<<$ The discrete dynamics of smallscale spatial events: agent-based models of mobility in carnivals and street parades $>>$ International Journal of Geographical Information Science, Vol.17 No.7, pp.673-97, 2003. doi:10.1080/1365881031000135474.

172. Brown, D. G., Riolo, R., Robinson, D. T., North, M. and Rand, W. 2005 $<<$ Spatial process and data models: Toward integration of agent-based models and GIS >>Journal of Geographical Systems, Vol.7 No.1, pp.25-47, May 2005. doi:10.1007/s10109-005-0148-5.

173. Bennett, D. A. and Tang, W. 2006, <<Modelling adaptive, spatially aware, and mobile agents: Elk migration in Yellowstone>>International Journal of Geographical Information Science, Vol.20 No.9, pp.1039-66, October 2006. doi:10.1080/13658810600830806

174. Yu, C. and Peuquet, D. J. 2009, <<A GeoAgent-based framework for knowledgeoriented representation: Embracing social rules in GIS $>>$ International Journal of Geographical Information Science, Vol.23 No.7, pp.923-60, July 2009. doi:10.1080/13658810701602104

175. Raubal, M. and Winter, S. 2010, <<A Spatio-Temporal Model Towards Ad-Hoc Collaborative Decision-Making >> in: M. Painho, M.Y. Santos and H. Pundt (Eds.) Geospatial Thinking. Lecture Notes in Geoinformation and Cartography -LNG\&CVol.0. Berlin - Germany:Springer Verlag, pp.279-97, 2010. doi:10.1007/978-3-64212326-9_15.

176. Heppenstall, A. J., Harland, K., Ross, A. N. and Olner, D. 2013, <<Simulating Spatial Dynamics and Processes in a Retail Gasoline Market: An Agent-Based Modeling Approach >> Transactions in GIS, Vol.17 No.5, pp.661-82, October 2013. doi:10.1111/tgis.12027.

177. Torrens, P. M. 2014, <<High-resolution space-time processes for agents at the builthuman interface of urban earthquakes $>>$ International Journal of Geographical Information Science, Vol.28 No.5, pp.964-86, May 2014. doi:10.1080/13658816.2 013.835816 .

\section{Kinematics/kinetics}

Some proposals create an innovative method for representing continuous space-time fields in temporal GIS based on the principles of fluid kinematics, i.e., measures of direction and movement, and kinectis, i.e., considering the cause of change (direction, movement, acceleration). Authors propose a temporal GIS framework that uses velocity as the basic unit of spatio-temporal representation to identify kinematic flows and features indicative of geographic processes, such as divergence and convergence. Kinematics is usually applied to real fluid flow, but some proposals have applied such a concept to a virtual flow that reflects the changes in scalar attribute values over the Earth's surface. Thus, any dynamic phenomena able to be represented by scalar values can be modelled by this approach,e.g., meteorological phenomena. The kinematic representation combines Lagrangian and Eulerian concepts to capture the direction and amount of change of a field in space and time effectively. Three proposals have been published in this very recent modelling approach.

178. Bothwell, J. and Yuan, M. 2010, <<Apply concepts of fluid kinematics to represent continuous space-time fields in temporal GIS >>Annals of GIS, Vol.16 No.1, pp.2741, March 2010. doi:10.1080/19475681003700872.

179. Bothwell, J. and Yuan, M. 2011, <<A kinematics-based GIS methodology to represent and analyze spatiotemporal patterns of precipitation change in IPCC A2 scenario $>>$ in: 19th ACM SIGSPATIAL International Conference on Advances in Geographic Information Systems, New York-NY-USA:ACM, (978-1-4503-1031-4), pp.152-61, Chicago-IL-USA, November 1-4 2011. doi:10.1145/2093973.2093995.

180. Long, J. A., Nelson, T. A. and Nathoo, F. S. 2014, $<<$ Toward a kinetic-based probabilistic time geography >>International Journal of Geographical Information Science, Vol.28 No.5, pp.855-74, May 2014. doi:10.1080/13658816.2013.818151.

\section{Modelling proposals for moving-objects}

At another level of abstraction, the database community has developed several novel conceptual models to integrate time and space in representational modelling approaches. Early proposals were based on extensions of the standard logical models: (i) the entityrelationship (ER) model [115], (ii) the Object Modelling Technique 
(OMT) [116], and (iii) the Unified Modelling Language (UML) [117]. We have found evidence of 19 works dealing with modelling extensions.

1. Caron, C., Bédard, Y. and Gagnon, P. 1993, <<MODUL-R: un formalisme individuel adapté pour les SIRS $>>$ Revue de Géomatique, Vol.3 No.3, pp.283-306, June 1993.

2. Bédard, Y., Caron, C., Maamar, Z., Moulin, B. and Valliere, D. 1996, << Adapting data models for the design of spatio-temporal databases $>>$ Computers, Environment and Urban Systems, Vol.20 No.1, pp.19-41, January 1996. doi:10.1016/S0198 9715(96)00008-7.

3. Hadzilacos, T. and Tryfona, N. 1997, <<An extended entity-relationship model for geographic applications $>>$ ACM SIGMOD Record, Vol.26 No.3, pp.24-29, September 1997. doi:10.1145/262762.262766.

4. Parent, C., Spaccapietra, S. and Zimányi, E. 1997, <<Conceptual Modeling for Federated GIS over the Web $>>$ in: International Symposium on Information Systems and Technologies for Network Society, Y. Kambayashi, Y. Masunaga, M. Takizawa and Y. Anzai (Eds.). Singapore:World Scientific, (978-9810232948), pp.173-82, Japan, September 1997.

5. Tryfona, N. and Hadzilacos, T. 1998, $<<$ Logical data modeling of spatiotemporal applications: definitions and a model $>>$ in: International Database Engineering and Applications Symposium -IDEAS' 98 -, B. Eaglestone, B.C. Desai and J. Shao (Eds.). Los Alamitos-CA-USA:IEEE Computer Society, (0-8186-8307-4), pp.14-23, Cardiff-Wales, July 8-10 1998. doi:10.1109/IDEAS.1998.694347.

6. Tryfona, N. 1998, <<Modeling Phenomena in Spatiotemporal Databases: Desiderata and Solutions >> in: G. Quirchmayr, E. Schweighofer and T.J. Bench-Capon (Eds.), Database and Expert Systems Applications. Lecture Notes in Computer Science -LNCS- Vol.1460. Berlin - Germany:Springer Verlag, pp.155-65, August 241998 doi:10.1007/BFb0054477.

7. Tryfona, N. and Jensen, C. S. 1999, <<Conceptual Data Modeling for Spatiotemporal Applications $>>$ GeoInformatica, Vol.3 No.3, pp.245-68, September 1999. doi:10.1023/A:1009801415799.

8. Claramunt, C., Parent, C., Spaccapietra, S. and Thériault, M. 1999, $<<$ Database Modelling for Environmental and Land Use Changes >> in: J. Stillwell, S. Geertman and S. Openshaw (Eds.), Geographical Information and Planning. Advances in Spatial Science. Berlin - Germany:Springer, pp.181-202, September 1999. doi:10.1007/978-3-662-03954-0_10.

9. Parent, C., Spaccapietra, S. and Zimányi, E. 1999, $<<$ Spatio-temporal conceptual models: data structures + space + time $>>$ in: 7 th ACM International Symposium on Advances in Geographic Information Systems -ACMGIS '99-, New York-NYUSA:ACM, (1-58113-235-2), pp.26-33, Kansas City-MO-USA, November 02-06 1999. doi:10.1145/320134.320142.

10. Tryfona, N. and Jensen, C. S. 2000, $<<$ Using abstractions for spatio-temporal conceptual modeling $>>$ in: ACM Symposium on Applied Computing, New YorkNY-USA:ACM, (1-58113-240-9), pp.313-22, Como-Italy, March 19-21 2000 doi:10.1145/335603.335775

11. Price, R., Tryfona, N. and Jensen, C. S. 2000, $<<$ Extended Spatiotemporal UML Motivations, Requirements and Constructs $>>$ Journal of Database Management, Vol.11 No.4, pp.14-27, Oct.-Dec. 2000. doi:10.4018/jdm.2000100102.

12. Price, R. 2001, Conceptual Modeling Techniques for Spatiotemporal Applications, Ph.D Thesis, (R. Kotagiri and B. Srinivasan Advs.) Monash University:Caulfield East Victoria-Australia, School of Computer Science and Software Engineering, November 2001

13. Zipf, A. and Kruger, S. 2001, $<<$ TGML - extending GML by Temporal Constructs - A Proposal for a Spatiotemporal Framework in XML $>$ in: Ninth ACM International Symposium on Advances in Geographic Information Systems -ACMGIS 2001-, W.G. Aref (Ed.) New York-NY-USA:ACM, (1-58113-443-6), pp.94-99, Atlanta-GA-USA, November 09-10 2001. doi:10.1.1.61.3182.

14. Price, R., Tryfona, N. and Jensen, C. S. 2002, <<Extending UML for space- and time-dependent applications $>>$ in: K. Siau (Eds.), Advanced Topics in Database Research. Vol.1. Hershey-PA-USA:IGI Global, pp.342-66, 2002.

15. Camossi, E., Bertolotto, M., Bertino, E. and Guerrini, G. 2003, $<<$ A multigranular spatiotemporal data model $>$ in: 11th ACM International Symposium on Advances in Geographic Information Systems -GIS ` 03-, New York-NY-USA:ACM, (1-58113-730-3), pp.94-101, New Orleans-Louisiana-USA, November 07-08 2003. doi: $10.1145 / 956676.956689$.

16. Stefanakis, E. $2003,<<$ Modelling the history of semi-structured geographical entities>>International Journal of Geographical Information Science, Vol.17 No.6, pp.517-46, 2003. doi:10.1080/1365881031000114080.

17. Ríos Viqueira, J. R. 2003, Formal Extension of the Relational Model for the Management of Spatial and Spatio-temporal Data, Ph.D Thesis, (N.A. Lorentzos and N.R. Brisaboa Advs.) Universidade da Coruña:A Coruña - Spain, Departamento de Computación, July 2003.
18. Camossi, E. 2005, Spatio-temporal multigranularity in an object data model, Ph.D Thesis, (E. Bertino and M. Bertolotto Advs.) Università degli Studi di Milano:Milano-Italy, Dipartimento di Informatica e Comunicazione, November 2004

19. Camossi, E., Bertolotto, M. and Bertino, E. 2006, $<<$ A multigranular object-oriented framework supporting spatio-temporal granularity conversions $>>$ Internationa Journal of Geographical Information Science, Vol.20 No.5, pp.511-34, May 2006. doi:10.1080/13658810600607451

\section{Key References Related to Spatio-temporal Modelling}

This section presents three additional lists as for three topics closely related to spatio-temporal modelling: (i) ontological modelling foundations, (ii) temporal modelling, and (iii) time geography. These references complement the bibliography by providing the foundations for most the models above-referenced.

\section{Ontological modelling foundations}

The ontological foundations are the background and general accepted concepts on which spatio-temporal models have been supported. This section presents a set of comprehensive studies on which strong theoretical background for T-GIS has been developed. For instance, the studies of Galton $[9,117,118]$ in which he defines key elements namely histories and life-histories, continuants and chronicles, and dynamic collectives, or the well-known SNAP/ SPAN ontology presented by Grenon and Smith [13]. Some relevant elements include(i) the dichotomy object/field [9,119]; (ii) the multiple viewpoints from which such representation models are considered, including the hybrid model; (iii) the integration of multiple temporal models in the spatial component providing the roots for modelling spatio-temporal phenomena (linear/cyclic/branching; transactional/ event/observational; discrete/continuous) [30,120,121]. These concepts have been broadly accepted as foundations on which most of the models and key concepts listed in this bibliography rely. This section lists 19 works that describe such foundations.

1. Peuquet, D. J. 1994, <<It's About Time: A Conceptual Framework for the Representation of Temporal Dynamics in Geographic Information Systems $>>$ Annals of the Association of American Geographers, Vol.84 No.3, pp.441-61, 1994. doi:10.1111/j.1467-8306.1994.tb01869.x.

2. Galton, A. P. 1995, <<Towards a qualitative theory of movement $>>$ in: A.U. Frank and W. Kuhn (Eds.), Spatial Information Theory. A Theoretical Basis for GIS. Lecture Notes in Computer Science -LNCS- Vol.988. Berlin - Germany:Springer Verlag, pp.377-96, 1995. doi:10.1007/3-540-60392-1_25.

3. Galton, A. P. 1997, <<Space, Time, and Movement $>>$ in: O. Stock (Eds.), Spatial and Temporal Reasoning. Dordrecht - The Netherlands:Kluwer Academic Publishers, pp.321-52, 1997. doi:10.1007/978-0-585-28322-7_10.

4. Frank, A. U. 1998, <<Different Types of "Times" in GIS $>>$ in: M.J. Egenhofer and R.G. Golledge (Eds.), Spatial and Temporal Reasoning in Geographic Information Systems. Spatial Information Systems Vol.54. New York-NY-USA:Oxford University Press, pp.40-62, 1998.

5. Smyth, C. S. 1998, <<A representational framework for geographic modeling >> in: M.J. Egenhofer and R.G. Golledge (Eds.), Spatial and Temporal Reasoning in Geographic Information Systems. Spatial Information Systems Vol.54. New YorkNY-USA:Oxford University Press, pp.191-213, March 1998.

6. Cohn, A. G., Gotts, N. M., Cui, Z., Randell, D. A., Bennett, B. and Gooday, J. 1998, <<Exploiting temporal continuity in qualitative spatial calculi $>>$ in: M.J. Egenhofer and R.G. Golledge (Eds.), Spatial and Temporal Reasoning in Geographic Information Systems. Spatial Information Systems Vol.54. New YorkNY-USA:Oxford University Press, pp.5-24, March 1998. doi:10.1.1.34.6681.

7. Chrisman, N. R. 1998, <<Beyond the snapshot: changing the approach to change, error and process $>>$ in: M.J. Egenhofer and R.G. Golledge (Eds.), Spatial and Temporal Reasoning in Geographic Information Systems. Spatial Information Systems Vol.54. New York-NY-USA:Oxford University Press, pp.85-93, March 1998. 
8. Muller, P. 1998, <<Space-time as a primitive for space and motion $>>$ in: N. Guarino (Eds.), Formal Ontology in Information Systems. Frontiers in Artificial Intelligence and Applications Vol.46. Amsterdam - The Netherlands:IOS Press, pp.63-76, 1998.

9. Mark, D. M. and Egenhofer, M. J. 1998, <<Geospatial Lifelines $>>$ in: Integrating Spatial and Temporal Databases. Dagstuhl Seminar, O. Günther, T. Sellis and B. Theodoulidis (Eds.). Dagstuhl-Wadern-Germany:Schloss Dagstuhl, (SeminarReport 228), p.12, Dagstuhl-Wadern-Germany:Schloss Dagstuhl - Leibniz Center for Informatics, November 23-27 1998.

10. Kelmelis, J. A. 1998, << Process Dynamics, Temporal Extent, and Causal Propagation as the Basis for Linking Space and Time >> in: M.J. Egenhofer and R.G. Golledge (Eds.), Spatial and Temporal Reasoning in Geographic Information Systems. Spatial Information Systems Vol.54. New York-NY-USA:Oxford University Press, pp.94-103, 1998

11. Galton, A. P. 2000, Qualitative Spatial Change, Spatial Information Systems, P. A. Burrough, M. F. Goodchild, R. A. McDonnell, et al. (Eds.), New York-NYUSA:Oxford University Press, 2001.

12. Galton, A. P. 2001, <<Space, time, and the representation of geographical reality $>>$ Topoi, Vol.20 No.2, pp.173-87, December 2001 doi:10.1023/A:1017913008827.

13. Erwig, M. and Schneider, M. 2002, <<Spatio-temporal predicates $>>$ IEEE Transactions on Knowledge and Data Engineering, Vol.14 No.4, pp.881-901, JulyAugust 2002. doi:10.1109/TKDE.2002.1019220.

14. Galton, A. P. 2003, <<Desiderata for a Spatio-temporal Geo-ontology >> in: W Kuhn, M.F. Worboys and S. Timpf (Eds.), Spatial Information Theory. Foundations of Geographic Information Science, International Conference -COSIT 2003Lecture Notes in Computer Science -LNCS- Vol.2825. Berlin - Germany:Springer Verlag, pp.1-12, September 24-28 2003. doi:10.1007/b13481.

15. Frank, A. U. 2003, <<Ontology for Spatio-temporal Databases $\gg$ in: M. Koubarakis, T. Sellis, A.U. Franket al. (Eds.), Spatio-Temporal Databases The CHOROCHRONOS Approach. Vol.2520. Berlin - Germany:Springer Verlag, pp.977, March 2003. doi:10.1007/978-3-540-45081-8_2.

16. Galton, A. P. $2004,<<$ Fields and objects in space, time, and space-time $>>$ Spatial Cognition \& Computation, Vol.4 No.1, pp.39-68, March 2004. doi:10.1207/ s15427633scc0401_4.

17. Grenon, P. and Smith, B. 2004, $<<$ SNAP and SPAN: Towards Dynamic Spatial Ontology $>>$ Spatial Cognition \& Computation, Vol.4 No.1, pp.69-104, January 2004. doi:10.1207/s15427633scc0401_5.

18. Galton, A. P. $2005,<<$ Dynamic collectives and their collective dynamics $>>$ in: A.G Cohn and D.M. Mark (Eds.), Spatial Information Theory. International Conference -COSIT 2005-. Lecture Notes in Computer Science -LNCS- Vol.3693. Berlin Germany:Springer Verlag, pp.300-15, 2005. doi:10.1007/11556114_19.

19. Galton, A. P. and Worboys, M. F. 2005, $<<$ Processes and events in dynamic geonetworks $>>$ in: A. Rodríguez, I.F. Cruz, M.J. Egenhoferet al. (Eds.), GeoSpatia Semantics. Lecture Notes in Computer Science -LNCS- Vol.3799. Berlin Germany:Springer Verlag, pp.45-59, 2005. doi:10.1007/11586180.

\section{Lifespan-based models}

How to represent time is an obvious and fundamental characteristic in temporal GIS; however, how to do it is a complex issue. Frank [121] proposes several ways to represent time in a GIS. However, time as a specific subject has been studied long before in other fields different than the spatial and spatio-temporal ones. First known reference in studies of time can be traced to Hamilton. Several works regarding modelling of time has been published in the last 50 years, for instance, natural language [122], information systems [123], logic [124,125], and artificial intelligence $[126,127]$. In spatial systems, time can be perceived moving forwards in a linear fashion for some geographic phenomena, while for other phenomena it moves in a cyclical way. While linear-time phenomena do not repeat at any interval, cyclical phenomena repeat at a defined frequency (e.g., daily and seasonally). Most of the models listed in this bibliography follow a linear, discrete temporal model and consider a discrete view of the world Without being exhaustive, since this bibliography is not focused in time modelling, the following references correspond to studies that somehow have contributed to the development of spatio-temporal systems. We have selected 39 key works for temporal modelling issues.
1. Hamilton, W. R. 1837, <<Theory of Conjugate Functions, or Algebraic Couples; with a Preliminary and Elementary Essay on Algebra as the Science of Pure Time >>Transactions of the Royal Irish Academy, Vol.17 pp.293-422, January 1837.

2. Apostle, H. G. 1969, Aristotle's Physics. Translated with Commentaries and Glossary by, Physics Today, Num.24. Bloomington - USA:Indiana University Press, 1969

3. Isard, W. 1970, $<<$ On notions and models of time $>>$ Papers in Regional Science, Vol.25 No.1, pp.7-32, April 1970. doi:10.1007/BF01935814.

4. Lamport, L. 1978, <<Time, clocks, and the ordering of events in a distributed system $>>$ Communications of the ACM, Vol.21 No.7, pp.558-65, July 1978. doi:10.1145/359545.359563.

5. Bennett, R. J. 1979, Spatial Time Series: analysis-forecasting-control, LondonUK:Pion Ltd, 1979

6. Humberstone, L. I. 1979, <<Interval semantics for tense logic: Some remarks $>>$ Journal of Philosophical Logic, Vol.8 No.1, pp.171-96, 1979. doi:10.1007/ BF00258426.

7. Bolour, A. and Dekeyser, L. J. 1983, <<Abstractions in temporal information $>>$ Information Systems, Vol.8 No.1, pp.41-49, January 1983. doi:10.1016/0306-4379(83)90029-7.

8. van Benthem, J. 1983, The logic of time: a model-theoretic investigation into the varieties of Temporal Ontology and Temporal Discourse, Synthese Library, J. Hintikka, D. Davidson, G. Nuchelmans, et al. (Eds.), 2nd, 216 Vol. Num.156. Dordrecht - The Netherlands:Kluwer Academic Publishers, 1983.

9. Allen, J. F. 1983, < $<$ Maintaining knowledge about temporal intervals $>>$ Communications of the ACM, Vol.26 No.11, pp832-43, November 1983. doi:10.1145/182.358434.

10. Allen, J. F. and Hayes, P. J. 1985, $<<$ A common-sense theory of time $>>$ in: 9th international joint conference on Artificial intelligence -IJCAI' $85-$-, A.K. Joshi (Ed.) San Francisco-CA-USA:Morgan Kaufmann Publishers, (978-0-934-61302-6), pp.528-31, Los Angeles-CA-USA, August 19-23 1985.

11. Ariav, G. 1986, $<<$ A temporally oriented data model $>>A C M$ Transactions on Database Systems (TODS), Vol.11 No.4, pp.499-527, December 1986. doi:10.1145/7239.7350.

12. Studer, R. 1986, <<Modeling Time Aspects of Information Systems $>>$ in: Second International Conference on Data Engineering -ICDE 86-, Washington DCUSA:IEEE Computer Society, (0-8186-0655-X), pp.364-73, Los Angeles-CA-USA, February 5-7 1986.

13. Ladkin, P. B. 1986, << Primitives and Units for Time Specification $>>$ in: 5 th National Conference on Artificial Intelligence -AAAI86-, San Francisco-CA-USA:Morgan Kaufmann Publishers, (978-0-262-51054-7), pp.354-59, Philadelphia-PA-USA, August 11-15 1986

14. Ladkin, P. B. 1986, <<Time Representation: A Taxonomy of Internal Relations $>>$ in: 5th National Conference on Artificial Intelligence -AAAI86-, San FranciscoCA-USA:Morgan Kaufmann Publishers, (978-0-262-51054-7), pp.360-66, Philadelphia-PA-USA, August 11-15 1986.

15. Clifford, J. and Croker, A. 1987, $<<$ The Historical Relational Data Model (HRDM) and Algebra Based on Lifespans $>>$ in: Third International Conference on Data Engineering, Washington DC-USA:IEEE Computer Society, (0-8186-0762-9), pp.528-37, Los Angeles-CA-USA, February 03-05 1987. doi:10.1.1.93.4720.

16. Lorentzos, N. A. and Johnson, R. G. 1987, <<TRA: A Model for a Temporal Relational Algebra $>>$ in: C. Rolland, F. Bodart and M. Léonard (Eds.), Temporal Aspects in Information Systems. North Holland - The Netherlands:Elsevier, pp.95108, May 13-15 1987.

17. Lorentzos, N. A. 1988, A Formal Extension of the Relational Model for the Representation and Manipulation of Generic Intervals, Ph.D Thesis, (R.G. Johnson Adv.) University of London:London-UK, Department of Computer ScienceBirkbeck College, August 1988

18. Kuhn, S. T. and Portner, P. 1989, <<Tense and time $>>$ in: D.M. Gabbay and J.F. Guenthner (Eds.), Handbook of Philosophical Logic. Synthese Library Vol.7. Dordrecht - The Netherlands:Kluwer Academic Publishers, pp.277-345, February 1989

19. Allen, J. F. and Hayes, P. J. 1989, <<Moments and points in an interval-based temporal logic $>>$ Computational Intelligence, Vol.5 No.3, pp.225-38, September 1989. doi:10.1111/j.1467-8640.1989.tb00329.x.

20. Worboys, M. F. 1990, <<Reasoning about GIS using Temporal and Dynamic Logics $>>$ in: Temporal Relations in Geographic Information Systems: a workshop at the University of Maine, R. Barrera, A.U. Frank and K.K. Al-Taha (Eds.). Santa Barbara-CA-USA:National Center for Geographic Information and Analysis, pp.30-42, Orono-ME-USA:The University of Maine, October 12-13 1990.

21. Chen, Z. and Terrier, F. 1991, <<About temporal uncertainty $>$ in: IEEE/ ACM International Conference on Developing and Managing Expert System Programs, Los Alamitos-CA-USA:IEEE Computer Society, (0-8186-2250-4 ), pp.223-30, Washington D.C.-USA, 30 September - 02 October 1991. doi:10.1109/ DMESP.1991.171772 
22. Allen, J. F. 1991, <<Planning as temporal reasoning $>>$ in: Proceedings of the Second International Conference on Principles of Knowledge Representation and Reasoning, J.F. Allen, R.J. Brachman, E. Sandewall, H.J. Levesque, R. Reiter, et al. (Eds.). San Francisco-CA-USA:Morgan Kaufmann Publishers, (1-55860-165-1) pp.3-14, Cambridge - MA - USA, April 22-25 1991.

23. Allen, J. F. 1991, <<Temporal reasoning and planning $>>$ in: J.F. Allen, H.A. Kautz, R.N. Pelavinet al. (Eds.), Reasoning about plans. Representation And Reasoning. San Francisco-CA-USA:Morgan Kaufmann Publishers, pp.1-67, 1991.

24. Freksa, C. 1992, <<Temporal reasoning based on semi-intervals $\gg>$ Artificial Intelligence, Vol.54 No.1-2, pp.199-227, March 1992. doi:10.1016/00043702(92) $90090-\mathrm{K}$

25. Freksa, C. 1996, <<Artif. Intell.: Erratum to "temporal reasoning based on semiintervals" [54 (1992) 199-227] >>Artificial Intelligence, Vol.87 No.1-2, p. 387, Nov. 1996. doi:10.1016/S0004-3702(96)00036-7.

26. Snodgrass, R. T., Böhlen, M. H., Jensen, C. S. and Steiner, A. 1998, $<<$ Transitioning temporal support in TSQL2 to SQL3 >> in: O. Etzion, S. Jajodia and S. Sripad (Eds.), Temporal Databases: Research and Practice. Lecture Notes in Compute Science -LNCS-. Berlin - Germany:Springer, pp.150-94, doi:10.1007/BFb0053702.

27. Bettini, C., Wang, S. X. and Jajodia, S. G. 1998, <<Temporal semantic assumptions and their use in databases>>IEEE Transactions on Knowledge and Data Engineering, Vol.10 No.2, pp.277-96, March/April 1998. doi:10.1109/69.683757.

28. Goralwalla, I. A. Özsu, M. T. and Szafron, D. 1998, <<An object-oriented framework for temporal data models $>>$ in: O. Etzion, S. Jajodia and S. Sripada (Eds.), Temporal Databases: Research and Practice. Lecture Notes in Computer Science -LNCS- Vol.1399. Berlin - Germany:Springer, pp.1-35, July 011998. doi:10.1007/BFb0053696.

29. Frank, A. U. 1998, <<Different Types of "Times" in GIS >> in: M.J. Egenhofer and R.G. Golledge (Eds.), Spatial and Temporal Reasoning in Geographic Information Systems. Spatial Information Systems Vol.54. New York-NY-USA:Oxford University Press, pp.40-62, 1998.

30. Couclelis, H. 1998, <<Aristotelian Spatial Dynamics in the Age of Geographic Information Systems $>>$ in: M.J. Egenhofer and R.G. Golledge (Eds.), Spatial and Temporal Reasoning in Geographic Information Systems. Spatial Information Systems Vol.54. New York-NY-USA:Oxford University Press, pp.109-18, 1998

31. Bettini, C., Jajodia, S. G. and Wang, S. X. 2000, Time Granularities in Databases, Data Mining and Temporal Reasoning, 1st, New York-NY-USA:Springer Verlag, July 2000. doi:10.1007/978-3-662-04228-1

32. Zhang, W. and Hunter, G. J. 2000, <<Temporal Interpolation of Spatially Dynamic Object $>>$ Geolnformatica, Vol.4 No.4, pp.403-18, December 2000 doi:10.1023/A:1026518013333

33. Hornsby, K. 2001, <<Temporal Zooming $>>$ Transactions in GIS, Vol.5 No.3, pp.255-72, June 2001. doi:10.1111/1467-9671.00081.

34. Bertino, E., Ferrari, E., Guerrini, G. and Merlo, I. 2003, <<T-ODMG: an ODMG compliant temporal object model supporting multiple granularity management>>Information Systems, Vol.28 No.8, pp.885-927, December 2003. doi:10.1016/S0306-4379(02)00077-7.

35. Gentner, D. 2003, <<Spatial Metaphors in Temporal Reasoning $>>$ in: M. Gatti (Eds.), Spatial Schemas and Abstract Thought. Cambridge-MA-USA:MIT Press, pp.203-46, 2003. doi:10.1.1.85.5006.

36. Michaelis, L. A. 2006, <<Time and tense $>>$ in: B. Aarts and A. McMahon (Eds.) The Handbook of English Linguistics. Oxford-UK:Blackwell Publishing Ltd pp.220-34, 2006

37. Fisher, M. 2008, <<Temporal Representation and Reasoning $>>$ in: F. van Harmelen, V. Lifschitz and B. Porter (Eds.), Handbook of Knowledge Representation. Foundations of Artificial Intelligence Vol.1. Amsterdam-The Netherlands:Elsevier, pp.513-50, December 17 2007. doi:10.1016/S1574-6526(07)03012-X.

38. Dyreson, C. E. 2009, <<Temporal Indeterminacy >> in: L. Liu and M.T. Özsu (Eds.) Encyclopedia of Database Systems. New York-NY-USA:Springer, pp.2973-76, September 29 2009. doi:10.1007/978-0-387-39940-9.

39. Montanari, A. and Chomicki, J. 2009, <<Time Domain >> in: L. Liu and M.T. Özsu (Eds.), Encyclopedia of Database Systems. New York-NY-USA:Springer, pp.310307, September 29 2009. doi:10.1007/978-0-387-39940-9.

\section{Time geography}

Since time geography analyses geographic phenomena in a spacetime framework, it is feasible to state that it provided the initial foundations for including temporal and spatio-temporal relations in geographic phenomena analysis and, later on, extending such relations to GIS. Although time geography provided the initial elements for relating space and time systematically, it did not provide the detailed specifications required for developing standard time geographic computational tools [128]. Nonetheless, the continuous evolution of the original Hägerstrand's spatio-temporal framework and the development of GIScience have contributed to the definition of new concepts and models for the creation of such tools. Significant contributions, such as those proposed by Miller [128-129] and Delafontaine et al. [131], have transformed time geography into a strong, spatio-temporal analytical framework that is fully computationally exploitable. Currently, this framework is still continuously evolving and being applied, mainly, to the modelling and analysis of moving objects. This section presents 39 relevant references that have had a sort of impact in the evolution of T-GIS and spatio-temporal modelling. The references also show the evolution of the time geography analytical framework from a conceptual definition to a computational, analytical tool.

1. Hägerstrand, T. 1952, <<The propagation of innovation waves $>>$ Lund Studies in Geography B, Human Geography, Vol.4 pp.3-19, 1952.

2. Gilbert, E. W. 1958, <<Pioneer Maps of Health and Disease in England $>>$ The Geographical Journal, Vol.124 No2, pp.172-83, June 1958.

3. Hägerstrand, T. 1967, Innovation Diffusion As a Spatial Process, (G. Haag), A. Pred (Eds.), Chicago-IL-USA:University of Chicago Press, June 1967.

4. Tobler, W. R. 1970, <<A Computer Movie Simulating Urban Growth in the Detroit Region $>>$ Economic Geography, Vol.46 No.Supplement, pp.234-40, June 1970. doi:10.2307/143141.

5. Hägerstrand, T. $1970,<<$ What about People in Regional Science? $>>$ Papers in Regional Science, Vol.24 No.1, pp.7-24, January 1970. doi:10.1111/j.1435-5597.1970. tb01464.x.

6. Parkes, D. and Thrift, N. J. 1975, << Timing space and spacing time $>>$ Environment and Planning A, Vol.7 No.6, pp.651-70, October 1975. doi:10.1068/a070651.

7. Lenntorp, B. 1976, Paths in space-time environments: a time-geographic study of movement possibilities of individuals, Lund Studies in Geography. Series B, Num.44. Lund-Sweden:Royal University of Lund, 1976.

8. Pred, A. 1977, <<The Choreography of Existence: Comments on Hägerstrand`s Time-Geography and Its Usefulness $>>$ Economic Geography, Vol.53 No.2, pp.20721, April 1977. doi:10.1111/j.1944-8287.1997.tb00082.x.

9. Thrift, N. J. 1977, An Introduction to Time Geography, Concepts and Techniques in Modern Geography -CAT MOG-, P. J. Taylor (Eds.), XIII Vol. Num.13. NorwichUK:Geo Abstracts Ltd.-University of East Anglia, 1977.

10. Haggett, P., Cliff, A. D. and Frey, A. 1977, Location models, Locational analysis: 1 Locational models, 2 Locational methods., II Vol. Num.1. New York-NY-USA :Halstead Press, 1977.

11. Carlstein, T. D., Parkes, D. and Thrift, N. J. (Eds.) 1978, Timing Space and Spacing Time: Human Activity and Time Geography, (1st), III Vol. Num.2, New York-NYUSA:John Wiley \& Sons, 1978.

12. Tobler, W. R. 1979, <<Cellular Geography $>>$ in: S. Gale and G. Olsson (Eds.), Philosophy in Geography. Theory and Decision Library Vol.20. Dordrecht-The Netherlands:D. Reidel Publishing, pp.379-86, June 1975

13. Szegö, J. 1987, Human Cartography: Mapping the World of Man, Stockholm Sweden:Swedish Council for Building Research, December 1987.

14. Borchert, J. R. 1987, <<Maps, Geography and Geographers $>>$ The Professional Geographer, Vol.39 No.4, pp.387-89, November 1987. doi:10.1111/j.00330124.1987.00387.x.

15. Miller, H. J. 1991, <<Modelling accessibility using space-time prism concepts within geographical information systems $>>$ International Journal of Geographical Information Systems, Vol.5 No.3, pp.287-301, 1991. doi:10.1080/02693799108927856.

16. Adams, P. C. 1995, <<A Reconsideration of Personal Boundaries in SpaceTime $>>$ Annals of the Association of American Geographers, Vol.85 No.2, pp.26785, 1995. doi:10.1111/j.1467-8306.1995.tb01794.x.

17. Huisman, O. and Forer, P. 1998, <<Computational agents and urban life spaces: a preliminary realisation of the time-geography of student lifestyles $>>$ in: 3rd International Conference on GeoComputation, R.J. Abrahart (Ed.) (0-9533477-02), Bristol-UK:University of Bristol, September 17-19 1998.

18. Forer, P. 1998, <<Geometric Approaches to the Nexus of Time, Space, and Microprocess: Implementing a practical model for mundane socio-spatial systems $>$ in: M.J. Egenhofer and R.G. Golledge (Eds.), Spatial and Temporal Reasoning in Geographic Information Systems. Spatial Information Systems Vol.54. New York-NY-USA:Oxford University Press, pp.171-90, 1998. 
19. Miller, H. J. 1999, <<Measuring Space-Time Accessibility Benefits within Transportation Networks: Basic Theory and Computational Procedures $>>$ Geographical Analysis, Vol.31 No.2, pp.187-212, April 1999. doi:10.1111/j.1538-4632.1999.tb00976.x.

20. Forer, P. and Huisman, O. $2000,<<$ Space, Time and Sequencing: Substitution at the Physical/Virtual Interface $>$ in: D.G. Janelle and D.C. Hodge (Eds.), Information, Place, and Cyberspace. Issues in Accessibility. Advances in Spatial Science. Berlin Germany:Springer Verlag, pp.73-90, September 62000.

21. Gutiérrez Puebla, J. 2001, <<Escalas espaciales, escalas temporales $>>$ Estudios Geográficos, Vol.62 No.242, pp.89-104, Marzo 2001. doi:10.3989/egeogr.2001.i242.

22. Miller, H. J. 2003, <<What about people in geographic information science? $>>$ Computers, Environment and Urban Systems, (Editorial) Vol.27 No.5, pp.447-53, September 2003. doi:10.1016/S0198-9715(03)00059-0.

23. Kwan, M.-P. 2004, << GIS Methods in Time-Geographic Research: Geocomputation and Geovisualization of Human Activity Patterns $>>$ Geografiska Annaler: Series B Human Geography, Vol.86 No.4, pp.267-80, December 2004. doi:10.1111/j.04353684.2004.00167.x.

24. Miller, H. J. 2005, <<Necessary space - time conditions for human interaction $>>$ Environment and Planning B: Planning and Design, Vol.32 No.3, pp.381-401, July 2005. doi:10.1068/b31154.

25. Miller, H. J. 2005, <<What about people in geographic information science? >> in: P. Fisher and D.J. Unwin (Eds.), Re-Presenting GIS. Chichester-UK:Wiley, pp.215-42, August 2005. doi:10.1.1.7.7637.

26. Miller, H. J. 2005, <<A Measurement Theory for Time Geography $>>$ Geographical Analysis, Vol.37 No.1, pp.17-45, January 2005. doi:10.1111/j.15384632.2005.00575.x.

27. Yu, H. and Shaw, S.-L. 2008, $<<$ Exploring potential human activities in physical and virtual spaces: a spatio-temporal GIS approach >>International Journal of Geographical Information Science, Vol.22 No.4, pp.409-30, April 2008. doi:10.1080/13658810701427569.

28. Miller, H. J. and Bridwell, S. A. 2009, $<<$ A Field-Based Theory for Time Geography >>Annals of the Association of American Geographers, Vol.99 No.1, pp.49-75, 2009. doi:10.1080/00045600802471049.

29. Winter, S. and Yin, Z.-C. 2010, <<Directed movements in probabilistic time geography $>>$ International Journal of Geographical Information Science, Vol.24 No.9, pp.1349-65, September 2010. doi:10.1080/13658811003619150.

30. Delafontaine, M., Neutens, T. and van de Weghe, N. 2011, <<Modelling potential movement in constrained travel environments using rough space-time prisms $>>$ International Journal of Geographical Information Science, Vol.25 No.9, pp.1389-411, September 2011. doi:10.1080/13658816.2010.518571.

31. Shaw, S.-L. 2012, <<Guest editorial introduction: time geography - its past, present and future $>>$ Journal of Transport Geography, Vol.23 No.0, pp.1-4, July 2012 doi:10.1016/j.jtrangeo.2012.04.007.

32. Sui, D. Z. 2012, <<Looking through Hägerstrand's dual vistas: towards a unifying framework for time geography $>>$ Journal of Transport Geography, Vol.23 No.0, pp.5-16, July 2012. doi:10.1016/j.jtrangeo.2012.03.020.

33. Delafontaine, M., Neutens, T. and van de Weghe, N. 2012, $<<$ A GIS toolki for measuring and mapping space-time accessibility from a place-based perspective $>>$ International Journal of Geographical Information Science, Vol.26 No.6, pp.1131-54, June 2012. doi:10.1080/13658816.2011.635593.

34. Chen, X. and Kwan, M.-P. 2012, <<Choice set formation with multiple flexible activities under space-time constraints $>>$ International Journal of Geographical Information Science, Vol.26 No.5, pp.941-61, May 2012. doi:10.1080/13658816.2 011.624520

35. Nakaya, T. 2013, <<Analytical Data Transformations in Space-Time Region: Three Stories of Space-Time Cube $>>$ Annals of the Association of American Geographers, Vol.103 No5, pp.1100-06, September 2013. doi:10.1080/00045608.2013.792184.

36. Chai, Y. 2013, <<Space-Time Behavior Research in China: Recent Development and Future Prospect>>Annals of the Association of American Geographers, Vol.103 No5, pp.1093-99, September 2013. doi:10.1080/00045608.2013.792179.

37. Travis, C. $2014,<<$ Transcending the cube: translating GIScience time and space perspectives in a humanities GIS $>>$ International Journal of Geographical Information Science, Vol.28 No.5, pp.1149-64, May 2014. doi:10.1080/13658816. 2013.829232.

38. Miller, H. J., Raubal, M. and Jaegal, Y. 2016, $<<$ Measuring Space-Time Prism Similarity Through Temporal Profile Curves $>>$ in: T. Sarjakoski, M.Y. Santos and T.L. Sarjakoski (Eds.), Geospatial Data in a Changing World. Lecture Notes in Geoinformation and Cartography -LNG\&C-. Cham - Switzerland:Springer International Publishing, pp.51-66, 15 May 2016. doi:10.1007/978-3-319-337838 8.

39. Chen, B. Y., Yuan, H., Qingquan, L. i., Shaw, S.-L., Lam, W. H. and Chen, X. 2016 $<<$ Spatiotemporal data model for network time geographic analysis in the era of big data $>>$ International Journal of Geographical Information Science, Vol.30 No.6, pp.1041-71, June 2016. doi:10.1080/13658816.2015.1104317.

\section{Other key references in spatio-temporal modelling and reasoning}

$180+$ additional references related to spatio-temporal modelling are compiled in the categories spatio-temporal analysis, case studies, and Temporal GIS of the TimeBliography [18]. These sections respectively present modelling proposals based on (i) successful T-GIS stories that solve spatio-temporal problems in different domains, e.g., transport, naval, census, and environment; (ii) the development of integrated analytical spatio-temporal frameworks for the analysis of spatio-temporal information; as well as (iii) novel research at the intersection of temporal systems and GIS and whose objective is to explicitly extend current GIS to dynamic real-world phenomena. In addition to these categories, 13 additional references which present spatio-temporal modelling concepts non-classified in the above-listed categories are:

1. Bonfatti, F. and Monari, P. D. 1993, <<Spatio-temporal Modeling of Complex Geographical Structures $>>$ in: IFIP TC5/WG5.11 Working Conference on Computer Support for Environmental Impact Assessment -CSEIA 93-, G. Guariso and B. Page (Eds.). Amsterdam-The Netherlands:North-Holland Publishing Co., (0-444-81838-3), pp.49-60, Como-Italy, October 06-08 1993.

2. Kadmon, N. 1993, <<Topography, topology and time - the A $+3 \mathrm{~T}$ concept of geographical space in a GIS $>>$ in: 16th International Cartographic Conference, P. Mesenburg (Ed.) Bielefeld - Germany:International Cartographic Association -ICA-, (3-905084-12-0), pp.901-09, Cologne - Germany, May 3-9 1993.

3. Misund, G. 1993, Multimodels and Metamap - Towards an Augmented Map Concept, Master's Thesis, University of Oslo:Oslo - Norway, Foundation for Scientific and Industrial Research at the Norwegian Institute of Technology, November 1993.

4. Lowell, K. E. 1994, <<Probabilistic temporal GIS modelling involving more than two map classes $>>$ International Journal of Geographical Information Systems, Vol.8 No.1, pp.73-93, 1994. doi:10.1080/02693799408901987.

5. Halls, J. N., Cowen, D. J. and Jensen, J. R. 1994, <<Predictive Spatio-Temporal Modeling in GIS $>>$ in: Sixth International Symposium on Spatial Data Handling, T.C. Waugh and R.G. Healey (Eds.). London-UK:Taylor \& Francis, (9780748402670), pp.431-47, Edinburgh-Scotland, September 05-09 1994.

6. Spaccapietra, S. 2001, $<<$ Spatio-Temporal Data Models and Languages $>>$ GeoInformatica, (Editorial) Vol.5 No.1, pp.5-9, March 2001 doi:10.1023/A:1011403703806.

7. Pfoser, D. and Tryfona, N. 2001, Capturing Fuzziness and Uncertainty of Spatiotemporal Objects, (TR-59) Aalborg-Danmark:Time Center, August 082001. doi:10.1.1.73.2704.

8. Frank, A. U. 2001, << Socio-Economics Units: Their Life and Motion $>>$ in: A.U. Frank, J.F. Raper and J.-P. Cheylan (Eds.), Life and Motion of Socio-Economic Units. GISDATA Vol.8. London-UK:Taylor \& Francis, pp.21-34, 2001.

9. Stell, J. G. 2003, <<Qualitative Extents for Spatio-Temporal Granularity $>>$ Spatial Cognition \& Computation, Vol.3 No.2-3, pp.119-36, 2003. doi:10.1080/13875868 .2003.9683758.

10. Mohd. Rahim, M. S. 2006, The Development of Spatio-Temporal Data Model for Dynamic Visualization of Virtual Geographical Information System, Master`s Thesis, (D. Daman Adv.) Universiti Teknologi Malaysia:Skudai - Malaysia, Faculty of Computer Science and Information System, May 2006

11. Raza, A. 2008, <<Deriving Spatio-Temporal Relations from Simple Data Structure $>$ in: XXIst ISPRS Congress - Silk Road for Information from Imagery, Rockville-MD-USA:International Society for Photogrammetry and Remote Sensing -ISPRS-, (1682-1750), pp.13-18, Beijing-China, July 03-11 2008.

12. Wikle, C. K. and Hooten, M. B. 2010, $<<$ A general science-based framework for dynamical spatio-temporal models $>>$ TEST, Vol.19 No.3, pp.417-51, November 2010. doi:10.1007/s11749-010-0209-z.

13. Klippel, A. 2012, <<Spatial Information Theory Meets Spatial Thinking: Is Topology the Rosetta Stone of Spatio-temporal Cognition?>>Annals of the Association of American Geographers, Vol.102 No6, pp.1310-28, December 2012. doi:10.1080/0 0045608.2012.702481.

\section{Final Remarks}

This article presents a compiled, annotated bibliography focused on spatio-temporal modelling trends. By analysing the compiled references, we have identified 14 modelling trends by which we have classified the corresponding references. To make this compilation self-contained, other key references of cross-related topics such as 
time geography and temporal modelling have been also included. Additions, corrections and comments concerning the bibliography are always very welcome through TimeBliography's recommendation functionalities or emailing the contact author. We apologize with the readers and especially with the authors for any errors, misclassifications and omissions that may result from the collected bibliography. A comprehensive collection of 63 surveys and reviews, ranging from 1982 to 2017, that complements this article is available in TimeBliography, section Surveys and Reviews.

\section{Availability in BibTEX Format}

The references compiled in this bibliography are available in TimeBliography [18]. The list is regularly updated and it is always available at:

\section{http://spaceandtime.wsiabato.info}

\section{The must reads}

Finally, we would like to highlight the top-ten of the published works that, in our opinion, anyone who wants to be introduced to and informed on spatio-temporal modelling must consider reading.

1. Yuan, M. 2008, <<Adding Time into Geographic Information Systems $>>$ in: J Wilson and A.S. Fotheringham (Eds.), The Handbook of Geographic Information Science. Blackwell Companios to Geography Vol.7. Oxford-UK:Blackwell Publishing Ltd, pp.169-84, 2008.

2. Yuan, M. and Stewart Hornsby, K. 2007, Computation and visualization for understanding dynamics in geographic domains: a research agenda, U. C. Science (Eds.), 1st, Boca Raton-FL-USA:CRC Press, December 2007.

3. Miller, H. J. 2005, $<<$ What about people in geographic information science? $>>$ in P. Fisher and D.J. Unwin (Eds.), Re-Presenting GIS. Chichester-UK:Wiley, pp.21542, August 2005

4. Galton, A. P. 2004, <<Fields and objects in space, time, and space-time $>>$ Spatial Cognition \& Computation, Vol.4 No.1, pp.39-68, March 2004. doi:10.1207/ s15427633scc0401_4.

5. Peuquet, D. J. 2002, Representations of Space and Time, London-UK:The Guilford Press, 2002.

6. Frank, A. U. 2001, <<Socio-Economics Units: Their Life and Motion $>>$ in: A.U. Frank, J.F. Raper and J.-P. Cheylan (Eds.), Life and Motion of Socio-Economic Units. GISDATA Vol.8. London-UK:Taylor \& Francis, pp.21-34, 2001.

7. Peuquet, D. J. 1994, <<It's About Time: A Conceptual Framework for the Representation of Temporal Dynamics in Geographic Information Systems $>>$ Annals of the Association of American Geographers, Vol.84 No.3, pp.441-61, 1994. doi:10.1111/j.1467-8306.1994.tb01869.x.

8. Langran, G. 1992, Time in Geographic Information Systems, Technical Issues in GIS, D. J. Peuquet and D. F. Marble (Eds.), 1st, London-UK:Taylor \& Francis, March 261992.

9. Allen, J. F. 1983, <<Maintaining knowledge about temporal intervals $>>$ Communications of the ACM, Vol.26 No.11, pp832-43, November 1983. doi:10.1145/182.358434.

10. Hägerstrand, T. 1970, $<<$ What about People in Regional Science? $>>$ Papers in Regional Science, Vol.24 No.1, pp.7-24, January 1970. doi:10.1111/j.1435-5597.1970. tb01464.x.

\section{Competing Interests}

The authors declare that they have no competing interests.

\section{Acknowledgement}

The work described in this paper was supported by the Doctoral Program of the Technical University of Madrid (UPM), Grant ref. $\mathrm{CH} / 056 / 2008$, and partially supported by the UPM Training and Mobility of Researchers Programme (Resolutions 23-02-2011/28-062012).

\section{References}

1. Peuquet DJ (2001) Making space for time: Issues in space-time data representation. Geolnformatica 5: 11-32.

2. Pelekis N, Theodoulidis B, Kopanakis I, Theodoridis $Y(2004)$ Literature review of spatio-temporal database models. The Knowledge Engineering Review 19: 235-274.

3. An L, Tsou MH, Crook SE, Chun Y, Spitzberg B, et al. (2015) Space-Time Analysis: Concepts, Quantitative Methods, and Future Directions. Annals of the Association of American Geographers 105: 891-914.

4. Yuan M, Stewart Hornsby K (2008) Computation and visualization for understanding dynamics in geographic domains: a research agenda, CRC Press, Boca Raton-FL-USA.

5. Claramunt C, Thériault M (1996) Toward semantics for modelling spatiotemporal processes within GIS', in Seventh International Symposium on Spatial Data Handling, eds. Kraak MJ, Molenaar M, Taylor \& Francis, London-UK, pp. 47-64.

6. Peuquet DJ, Duan N (1995) An event-based spatiotemporal data model (ESTDM) for temporal analysis of geographical data', International Journal of Geographical Information Systems 9: 7-24.

7. Sengupta R, Yan C (2004) A Hybrid Spatio-Temporal Data Model and Structure (HST-DMS) for Efficient Storage and Retrieval of Land Use Information', Transactions in GIS 8: 351-366.

8. Tryfona N, Jensen CS (1999) Conceptual Data Modeling for Spatiotemporal Applications. Geolnformatica 3: 245-268.

9. Galton AP (2004) Fields and objects in space, time, and space-time. Spatial Cognition \& Computation 4: 39-68.

10. Mclntosh J, Yuan M (2005) Assessing Similarity of Geographic Processes and Events', Transactions in GIS 9: 223-245.

11. Liu Y, Goodchild MF, Guo QH, Tian Y, Wu L (2008) Towards a General Field model and its order in GIS. International Journal of Geographical Information Science 22: 623-643.

12. Armstrong MP (1988) Temporality in spatial databases', in GIS/LIS ' 88 : Accessing the World, American Society for Photogrammetry and Remote Sensing, Falls Church-VA-USA, pp. 880-889.

13. Grenon P, Smith B (2004) SNAP and SPAN: Towards Dynamic Spatial Ontology', Spatial Cognition \& Computation 4: 69-104.

14. Worboys MF (2005) Event-oriented approaches to geographic phenomena. International Journal of Geographical Information Science 19: 1-28.

15. El-Geresy BA, Abdelmoty AI, Jones CB (2002) Spatio-Temporal Geographic Information Systems: A Causal Perspective', in Advances in Databases and Information Systems, eds. Manolopoulos Y \& P. Návrat, Springer Verlag, Berlin - Germany, pp. 191-203.

16. Bothwell J, Yuan M (2011) A kinematics-based GIS methodology to represent and analyze spatiotemporal patterns of precipitation change in IPCC A2 scenario', in 19th ACM SIGSPATIAL International Conference on Advances in Geographic Information Systems, ACM, New York-NY-USA, pp. 152-161.

17. Siabato W, Claramunt C, Ilarri S (In print) A Survey of Modelling Trends in Temporal GIS. ACM Computing Surveys 51: 1-37.

18. Siabato W, Claramunt C, Manso-Callejo MÁ, Bernabé-Poveda MÁ (2014) TimeBliography: A Dynamic and Online Bibliography on Temporal GIS. Transactions in GIS 18: 799-816.

19. Halls PJ, Polack FA, O'Kee SE (1999) A new approach to the spatial analysis of temporal change using todes and neural nets. Cybergeo: European Journal of Geography, 139.

20. Siabato W, Claramunt C, Bernabé-Poveda MÁ (2013) An Interactive Bibliography on Temporal GIS. Journal of Spatial Information Science 7: 99-101.

21. McMaster, R. B. \& Usery, E. L. (eds.) 2004, A research agenda for Geographic Information Science, CRC Press, Boca Raton-FL-USA.

22. DiBiase D, DeMers M, Johnson A, Kemp KK, Luck AT, et al. (2006) Geographic Information Science and Technology Body of Knowledge, Association of American Geographers, Washington D.C. - USA.

23. Hägerstrand T (1952) The propagation of innovation waves', Lund Studies in Geography B, Human Geography 4: 3-19. 
24. Hägerstrand T (1967) Innovation Diffusion As a Spatial Process, University of Chicago Press, Chicago-IL-USA.

25. Hägerstrand $T$ (1970) What about People in Regional Science? Papers in Regional Science 24: 7-24.

26. Langran G (1992) Time in Geographic Information Systems, Taylor \& Francis, London-UK.

27. Peuquet DJ (1984) A conceptual framework and comparison of spatial data models. Cartographica: The International Journal for Geographic Information and Geovisualization 21: 66-113.

28. Gadia SK, Vaishnav JH (1985) A query language for a homogeneous temporal database', in Fourth ACM SIGACT-SIGMOD Symposium on Principles of Database Systems, ACM, New York-NY-USA, pp. 51-56.

29. Gadia SK (1988) A homogeneous relational model and query languages for temporal databases. ACM Transactions on Database Systems (TODS) 13: $418-448$

30. Snodgrass RT, Ahn I (1985) A taxonomy of time databases. ACM SIGMOD Record 14: 236-246.

31. Snodgrass RT, Ahn I (1986) Temporal Databases. Computer 19: 35-42.

32. Gadia SK, Yeung CS (1988) A generalized model for a relational temporal database. ACM SIGMOD Record 17: 251-259.

33. Langran G, Chrisman NR (1988)A framework for temporal geographic information. Cartographica: The International Journal for Geographic Information and Geovisualization 25: 1-14.

34. Worboys MF (1994) A unified model for spatial and temporal information The Computer Journal 37: 26-34

35. Rumbaugh JR, Blaha MR, Lorensen W, Eddy F, Premerlani W (1991) Object-Oriented Modeling and Design, Prentice Hall, Upper Saddle RiverNJ-USA.

36. Goodchild MF (1992) Geographical Information Science. International Journal of Geographical Information Systems 6: 31-45.

37. NCGIA NC (1989) The research plan of the National Center for Geographic Information and Analysis. International Journal of Geographical Information Systems 3: 117-136.

38. Arnaud AM, Craglia M, Masser I, Salgé F, Scholten H (1993) The research agenda of the European Science Foundation's GISDATA scientific programme. International Journal of Geographical Information Systems 7 : 463-470.

39. United States Geological Survey USGS (2007) A research agenda for Geographic Information Science, The National Academies Press, Washington D.C. - USA.

40. Yuan M (2008) Adding Time into Geographic Information Systems Databases', in The Handbook of Geographic Information Science, eds. Wilson J \& Fotheringham AS, Blackwell Publishing Ltd, Oxford-UK, pp. 169-184.

41. Hunter GJ, Williamson IP (1990) The development of a historical digital cadastral database', International Journal of Geographical Information Systems 4: 169-179.

42. Worboys MF (1992) Object-Oriented Models of Spatiotemporal Information' in GIS/LIS'92, American Congress on Surveying and Mapping, BethesdaMD-USA, pp. 825-834

43. Claramunt C, Thériault M (1995) Managing Time in GIS: An Event-Oriented Approach', in Recent Advances in Temporal Databases: Proceedings of the International Workshop on Temporal Databases, eds. J. Clifford \& A. Tuzhilin, Springer Verlag, London-UK, pp. 23-42.

44. Yuan M (1997b) Use of knowledge acquisition to build wildfire representation in Geographical Information Systems. International Journal of Geographical Information Science11: 723-746.

45. Hunter GJ, Williamson IP (1990) The development of a historical digital cadastral database', International Journal of Geographical Information Systems 4: 169-179.

46. Worboys MF (1992) Object-Oriented Models of Spatiotemporal Information', in GIS/LIS'92, American Congress on Surveying and Mapping, BethesdaMD-USA, pp. 825-834.

47. Claramunt C, Thériault M (1995) Managing Time in GIS: An Event-Oriented Approach', in Recent Advances in Temporal Databases: Proceedings of the International Workshop on Temporal Databases, eds. J. Clifford \& A. Tuzhilin, Springer Verlag, London-UK, pp. 23-42.

48. Yi J, Du Y, Liang F, Zhou C, Wu D, et al. (2014) A representation framework for studying spatiotemporal changes and interactions of dynamic geographic phenomena. International Journal of Geographical Information Science 28: 1010-1027.
49. van de Weghe N, de Roo B, Qiang Y, Versichele M, et al. (2014) The continuous spatio-temporal model (CSTM) as an exhaustive framework for multi-scale spatio-temporal analysis. International Journal of Geographical Information Science 28: 1047-1060.

50. Zhu R, Guilbert E, Wong MS (2017) Object-oriented tracking of the dynamic behavior of urban heat islands', International Journal of Geographical Information Science 31: 405-424.

51. Shook E, Wang S, Tang W (2013) A communication-aware framework for parallel spatially explicit agent-based models', International Journal of Geographical Information Science 27: 2160-2181.

52. Bothwell J, Yuan M (2010) Apply concepts of fluid kinematics to represent continuous space-time fields in temporal GIS. Annals of GIS 16: 27-41.

53. Long JA, Nelson TA (2013) A review of quantitative methods for movement data. International Journal of Geographical Information Science 27: 292318.

54. Egenhofer MJ, Glasgow J, Günther O, Herring JR, Peuquet DJ (1999) Progress in computational methods for representing geographical concepts. International Journal of Geographical Information Science 13: 775-796.

55. Goodchild MF, Egenhofer MJ, Kemp KK, Mark DM, Sheppard E (1999) Introduction to the Varenius project. International Journal of Geographical Information Science 13: 731-745.

56. OGC OG (2012/10/18), OpenGIS $®$ Standards and Specifications, [Online] Open GIS Consortium Inc.

57. Edsall RM, Peuquet DJ (1997) A Graphical User Interface for the Integration of Time into GIS', in 1997 American Congress of Surveying and Mapping Annual Convention and Exhibition, pp. 182-189.

58. Jensen CS, Snodgrass RT (2011/09/02), TimeCenter, [Online], Aalborg Universitet,

59. Esri. (2017/03/16), ArcGIS, [Online], ESRI.

60. Quantum GIS. (2017/02/26), Welcome to the QGIS Project, [Online], OSGeo,

61. Shaw SL, Yu H (2008/12/25), Towards a GIS-based Analytical Timegeographic Framework for Physical and Virtual Activities (Bibliography), [Online], The University of Tennessee.

62. Yu H, Shaw SL (2008) Exploring potential human activities in physical and virtual spaces: a spatio-temporal GIS approach. International Journal of Geographical Information Science 22: 409-430.

63. Jernigan K (2009) Oracle Total Recall with Oracle Database 11g Release 2, Oracle Corporation, Redwood Shores-CA-USA.

64. Davis J (2012/01/24), PERIOD Data Type Reference, [Online], GitHub Inc.

65. Güting RH, Almeida V, Ansorge D, Behr T, Ding Z, et al. (2005) SECONDO: An Extensible DBMS Platform for Research Prototyping and Teaching', in 21st International Conference on Data Engineering -ICDE 2005-, IEEE Computer Society, Los Alamitos-CA-USA, pp. 1115-1116.

66. Güting RH, Behr T, Düntgen C (2010) SECONDO: A Platform for Moving Objects Database Research and for Publishing and Integrating Research Implementations. IEEE Data Engineering Bulletin 33: 56-63.

67. Pelekis N, Theodoridis Y, Vosinakis S, Panayiotopoulos T (2006) Hermes-A Framework for Location-Based Data Management, in Advances in Database Technology - EDBT 2006, eds. Y. Ioannidis, M. H. Scholl, J. W. Schmidt, F. Matthes, M. Hatzopoulos, K. Boehm, A. Kemper, T. Grust \& C. Boehm, Springer Verlag, Berlin - Germany, pp. 1130-1134.

68. Pelekis N, Frentzos E, Giatrakos N, Theodoridis Y (2008) HERMES: Aggregative LBS via a Trajectory DB Engine', in 2008 ACM SIGMOD International Conference on Management of Data, eds. L. V. Lakshmanan, R. T. Ng \& D. Shasha, ACM, New York-NY-USA, pp. 1255-1258.

69. Kapler T, Wright W (2005) GeoTime Information Visualization', Information Visualization 4: 136-146.

70. Oculus Inc. (2013/04/28), GeoTime, [Online], Oculus.

71. Johnson I (1997) Mapping the fourth dimension: the TimeMap project', in Computer Applications in Archaeology Conference -CAA'97-, BAR International Series, Oxford-UK, pp. 1-21.

72. Wilson A, Johnson I (2003) The TimeMap Project: Developing Time-Based GIS Display for Cultural Data. Journal of GIS Archaeology 1: 123-135.

73. Discovery Software (2011/04/21), STEMgis Mapping in Time, [Online], Discovery Software Ltd.

74. Yuan M (1994) Wildfire conceptual modeling for building GIS space-time models', in GIS/LIS '94, American Society for Photogrammetry and Remote Sensing, Bethesda-MD-USA, pp. 860-889. 
75. Yuan M (1997a) Modeling semantical, temporal and spatial information in geographic information systems', in Geographic Information Research: Bridging the Atlantic, eds. M. Craglia \& H. Couclelis, Taylor \& Francis, London-UK, pp. 334-347.

76. Yuan M (1999) Use of a Three-Domain Representation to Enhance GIS Support for Complex Spatiotemporal Queries. Transactions in GIS 3: 137159.

77. Yuan M (1996) Temporal GIS and spatio-temporal modeling', in 3rd International Conference on Integrating GIS and Environmental Modeling University of California, Santa Barbara-CA-USA, pp. 21-26.

78. Wachowicz M (1999) Object-Oriented Design for Temporal GIS, Taylor \& Francis, London-UK

79. Bian L (2000) Object-oriented representation for modelling mobile objects in an aquatic environment. International Journal of Geographical Information Science 14: 603-623

80. Laube P (2014) Computational Movement Analysis, Springer Verlag, Berlin - Germany.

81. Dodge S, Weibel R, Ahearn SC, Buchin M, Miller JA (2016) Analysis of movement data. International Journal of Geographical Information Science 30: 825-834

82. Worboys MF, Hearnshaw HM, Maguire DJ (1990a) Object-oriented data and query modelling for geographical information systems', in 4th International Symposium on Spatial Data Handling -SDH'90-, eds. K Brassel \& H. Kishimoto, IGU Commission on Geographical Data Sensing and Processing, Ohio - USA, pp. 679-689.

83. Worboys MF, Hearnshaw HM, Maguire DJ (1990b) Object-oriented data modelling for spatial databases. International Journal of Geographical Information Systems, vol. 4, no. 4, pp. 369-383.

84. Galton AP, Worboys MF (2005) Processes and events in dynamic geonetworks', in GeoSpatial Semantics, eds. A. Rodríguez, I. F. Cruz, M. J. Egenhofer \& S. Levashkin, Springer Verlag, Berlin - Germany, pp. 45-59.

85. Yuan M (2001) Representing Complex Geographic Phenomena in GIS. Cartography and Geographic Information Science 28: 83-96.

86. Berry BJ (1964) Approaches to regional analysis: a synthesis. Annals of the Association of American Geographers 54: 2-11.

87. Sinton DF (1978) The inherent structure of information as a constraint to analysis: Mapped thematic data as a case study', in First International Advanced Study Symposium on topological data structures for Geographic Information Systems, ed. G. Dutton, Harvard University Laboratory for Computer Graphics and Spatial Analysis, Cambridge-MA-USA, pp. 1-17.

88. Hornsby K, Egenhofer MJ (2000) Identity-based change: a foundation for spatio-temporal knowledge representation. International Journal of Geographical Information Science 14: 207-224

89. Xu J, Güting RH (2013) A generic data model for moving objects Geolnformatica 17: 125-172.

90. Kuijpers B, Grimson R, Othman W (2011) An analytic solution to the alib query in the space-time prisms model for moving object data', International Journal of Geographical Information Science 25: 293-322.

91. Elmongui HG, Mokbel MF, Aref WG (2013) Continuous aggregate nearest neighbor queries. Geolnformatica 17: 63-95

92. Orellana D, Wachowicz M (2011) Exploring Patterns of Movement Suspension in Pedestrian Mobility. Geographical Analysis 43: 241-260.

93. Wachowicz M, Ong R, Renso C, Nanni M (2011) Finding moving flock patterns among pedestrians through collective coherence. International Journal of Geographical Information Science 25: 1809-1864

94. Orellana D, Bregt AK, Ligtenberg A, Wachowicz M (2012) Exploring visitor movement patterns in natural recreational areas. Tourism Management 33 $672-682$.

95. Zheng $Y$, Zhou X (eds.) (2011) Computing with Spatial Trajectories, Springer, New York-NY-USA.

96. Fang Z, Li Q, Zhang X, Shaw SL (2012) A GIS data model for landmarkbased pedestrian navigation', International Journal of Geographical Information Science 26: 817-838.

97. Wentz EA, Peuquet DJ, Anderson S (2010) An ensemble approach to space-time interpolation. International Journal of Geographical Information Science 24: 1309-1325

98. Pragera SD, Barber JJ (2012) Modeling unobserved true position using multiple sources and information semantics. International Journal of Geographical Information Science 26: 15-37.
99. Noyon V, Devogele T, Claramunt C (2005) A Formal Model for Representing Point Trajectories in Two-Dimensional Spaces', in Perspectives in Conceptual Modeling, eds. J. Akoka, S. W. Liddle, I.-Y. Song, M. Bertolotto, I. Comyn-Wattiau, W.-J. van den Heuvel, M. Kolp, J. Trujillo, C. Kop \& H. C. Mayr, Springer Verlag, Berlin - Germany, pp. 208-217.

100. Noyon V, Claramunt C, Devogele T (2007) A Relative Representation of Trajectories in Geogaphical Spaces. Geolnformatica11: 479-496.

101. Stewart Hornsby K, Cole S (2007) Modeling Moving Geospatial Objects from an Event-based Perspective. Transactions in GIS 11: 555-573.

102. Sistla AP, Wolfson O, Chamberlain S, Dao S (1997) Modeling and querying moving objects', in 13th International Conference on Data Engineering IEEE Computer Society, Los Alamitos-CA-USA, pp. 422-432.

103. Wolfson O, Xu B, Chamberlain S, Jiang L (1998) Moving Objects Databases: Issues and Solutions', in 10th International Conference on Scientific and Statistical Database Management, IEEE Computer Society, Los Alamitos-CA-USA, pp. 111-122.

104. Wolfson O, Sistla AP, Chamberlain S, Yesha Y (1999) Updating and Querying Databases that Track Mobile Units', Distributed and Parallel Databases 7: 257-387.

105. Güting $\mathrm{RH}$, Böhlen $\mathrm{MH}$, Erwig $M$, Jensen $C S$, Lorentzos $N A$, et al. (2000) A foundation for representing and querying moving objects. ACM Transactions on Database Systems (TODS) 25: 1-42.

106. Yang Y, Claramunt C (2003) A Process-oriented Multi-representation of Gradual Changes. Journal of Geographic Information and Decision Analysis 7: 1-13.

107. Huere Peña JL, Santos MY (2011) Representing, Storing and Mining Moving Objects Data', in World Congress on Engineering 2011, eds. S. I. Ao, L. Gelman, D. W. Hukings, A. Hunter \& A. M. Korsunsky, Newswood Limited, Kwun Tong - Hong Kong, pp. 1823-1828.

108. Renolen A (1996) History graphs: conceptual modeling of Spatio-Temporal Data', in GIS Frontiers in Business and Science Conference, ed. M. Konecny, International Cartographic Association -ICA-, Bern - Switzerland.

109. Del Mondo G, Rodríguez MA, Claramunt C, Bravo L, Thibaud R (2013) Modeling consistency of spatio-temporal graphs. Data \& Knowledge Engineering 84: 59-80.

110. Del Mondo G, Stell JG, Claramunt C, Thibaud R (2010) A Graph Model for Spatio-temporal Evolution. Journal of Universal Computer Science 16: 1452-1477.

111. Clifford J, Croker A (1988) Objects in Time. IEEE Data Engineering Bulletin 11: 11-18.

112. Brown DG, Xie $Y$ (2006) Spatial agent-based modeling. International Journal of Geographical Information Science 20: 941-943.

113. Yu C, Peuquet DJ (2009) A GeoAgent-based framework for knowledgeoriented representation: Embracing social rules in GIS', International Journal of Geographical Information Science 23: 923-960.

114. Shoham $Y$ (1993) Agent-oriented programming. Artificial Intelligence 60: 51-92.

115. Chen PP (1976) The entity-relationship model - Toward a unified view of data', ACM Transactions on Database Systems (TODS) 1: 9-36.

116. Booch G, Rumbaugh J, Jacobson I (1999) The Unified Modeling Language User Guide, Addison-Wesley, Redwood City-CA-USA.

117. Galton AP (2003) Desiderata for a Spatio-temporal Geo-ontology', in Spatial Information Theory. Foundations of Geographic Information Science, International Conference -COSIT 2003-, eds. W. Kuhn, M. F. Worboys \& S. Timpf, Springer Verlag, Berlin - Germany, pp. 1-12.

118. Galton AP (2005) Dynamic collectives and their collective dynamics', in Spatial Information Theory. International Conference -COSIT 2005-, eds. A. G. Cohn \& D. M. Mark, Springer Verlag, Berlin - Germany, pp. 300-315.

119. Galton AP (2001) A formal theory of objects and fields', in Spatial Information Theory. Foundations of Geographic Information Science, International Conference COSIT 2001, ed. D. R. Montello, Springer Verlag, Berlin - Germany, pp. 458-473.

120. Snodgrass RT (1992) Temporal databases', in Theories and Methods of Spatio-Temporal Reasoning in Geographic Space, eds. A. U. Frank, I. Campari \& U. Formentini, Springer Verlag, Berlin - Germany, pp. 22-64.

121. Frank AU (1998) Different Types of "Times" in GIS', in Spatial and Temporal Reasoning in Geographic Information Systems, eds. M. J. Egenhofer \& R. G. Golledge, Oxford University Press, New York-NY-USA, pp. 40-62.

122. Bull WE (1960) Time, Tense, and the Verb: A Study in Theoretical and Applied Linguistics, with Particular Attention to Spanish, University of California Press, Berkeley-CA-USA. 
Citation: Siabato W (2017) An Annotated Bibliography on Spatio-temporal Modelling Trends. Int J Earth Environ Sci 2: 135. doi: https://doi.org/10.15344/2456$351 X / 2017 / 135$

Page 26 of 26

123. Langefors B (1966) Theoretical analysis of information systems Studentlitteratur, Lund - Sweden.

124. Prior AN (1967) Past, Present and Future, The Clarendon Press, OxfordUK.

125. McArthur RP (1976) Tense Logic, D. Reidel Publishing, Dordrecht - The Netherlands.

126. Allen JF (1983) Maintaining knowledge about temporal intervals Communications of the ACM 26: 832-843.

127. Allen JF (1984) Towards a General Theory of Action and Time. Artificial Intelligence 23: 123-154.

128. Miller HJ (2005a)A Measurement Theory for Time Geography. Geographical Analysis $37:$ 17-45.

129. Miller HJ (2005b) Necessary space - time conditions for human interaction', Environment and Planning B: Planning and Design 32: 381-401.

130. Miller HJ (2005c) What about people in geographic information science?', in Re-Presenting GIS, eds. P. Fisher \& D. J. Unwin, Wiley, Chichester-UK pp. 215-242.

131. Delafontaine M, Neutens T, van de Weghe N (2012) A GIS toolkit for measuring and mapping space-time accessibility from a place-based perspective. International Journal of Geographical Information Science 26: 1131-1154.

132. Abraham T, Roddick JF (1999) Survey of spatio-temporal databases', Geolnformatica 3: 61-99.

133. Al-Taha KK, Snodgrass RT, Soo MD (1993) Bibliography on spatiotemporal databases. ACM SIGMOD Record 22: 59-67.

134. Al-Taha KK, Snodgrass RT, Soo MD (1994) Bibliography on spatiotempora databases', International Journal of Geographical Information Systems 8: 95-103.

135. Barrera R, Al-Taha KK (1990) Models in Temporal Knowledge Representation and Temporal DBMS, National Center for Geographic Information and Analysis, Santa Barbara-CA-USA.

136. Bettini C, Dyreson CE, Evans WS, Snodgrass RT, Wang XS (1998) A glossary of time granularity concepts', in Temporal Databases: Research and Practice, eds. O. Etzion, S. Jajodia \& S. Sripada, Springer Verlag, Berlin - Germany, pp. 406-413.

137. Böhlen MH (1995) Temporal database system implementations. ACM SIGMOD Record 24: 53-60.

138. Bolour A, Anderson TL, Dekeyser LJ, Wong HK (1982a) The role of time in information processing: a survey. ACM SIGART Bulletin 80: 28-46.

139. Bolour A, Anderson TL, Dekeyser LJ, Wong HK (1982b) The role of time in information processing: a survey. ACM SIGMOD Record 12: 27-50.

140. Chomicki J (1994) Temporal query languages: A survey', in Temporal Logic eds. D. M. Gabbay \& H. J. Ohlbach, Springer Verlag, Berlin - Germany, pp. 506-534

141. Clarke K, Irmischer IJ (2017) On Scale in Space, Time and Space-Time', in Integrating Scale in Remote Sensing and GIS, eds. D. A. Quattrochi, E. Wentz \& N. S. Lam, Emerson, Charles W., CRC Press, Boca Raton-FLUSA, pp. 1-10.

142. Demšar U, Buchin K, Cagnacci F, Safi K, Speckmann B, et al. (2015) Analysis and visualisation of movement: an interdisciplinary review. Movement Ecology 3: 5.

143. Dyreson CE, Grandi F, Käfer W, Kline N, Lorentzos NA, et al. (1994) A consensus glossary of temporal database concepts. ACM SIGMOD Record 23: 52-64.

144. Güting RH (1994) An introduction to spatial database systems. The VLDB Journal The International Journal on Very Large Data Bases 3: 357-399.

145. Jensen CS, Clifford J, Gadia SK, Segev A, Snodgrass RT (1992) A glossary of temporal database concepts. ACM SIGMOD Record 21: 35-43.

146. Jensen CS, Dyreson CE, Böhlen MH, Clifford J, Elmasri R, et al. (1998) The consensus glossary of temporal database concepts-February 1998 version', in Temporal Databases: Research and Practice, eds. O. Etzion, S. Jajodia \& S. Sripada, Springer Verlag, Berlin - Germany, pp. 367-405.

147. Kline N (1993) An update of the temporal database bibliography. ACM SIGMOD Record 22: 66-80.

148. Langran $G$ (1989) A review of temporal database research and its use in GIS applications. International Journal of Geographical Information Systems 3: 215-232.

149. McKenzie E (1986) Bibliography: Temporal databases. ACM SIGMOD Record 15: 40-52.
150. Ozsoyoglu G, Snodgrass RT (1995) Temporal and Real-Time Databases: A Survey. IEEE Transactions on Knowledge and Data Engineering 7: 513532.

151. Pavlopoulos A (1998) Evaluation and comparison of spatio-temporal data models, Master's Thesis, University of Manchester.

152. Rahm E, Bernstein PA (2006) An online bibliography on schema evolution', ACM SIGMOD Record 35: 30-31.

153. Ratcliffe JH, McCullagh MJ (1998) Aoristic crime analysis. International Journal of Geographical Information Science 12: 751-764.

154. Renolen A (1997) Temporal Maps and Temporal Geographical Information Systems', Dimension: Contemporary German Arts and Letters, pp. 1-12.

155. Ríos Viqueira JR, Lorentzos NA, Brisaboa NR (2005) Survey on Spatial Data Modelling Approaches', in Spatial Databases: Technologies, Techniques and Trends, eds. Y. Manolopoulos, A. Papadopoulos \& M. G. Vassilakopoulos, IGI Global, Hershey-PA-USA, pp. 1-22.

156. Roddick JF (1992) Schema evolution in database systems: an annotated bibliography. ACM SIGMOD Record 21: 35-40.

157. Roddick JF (1995) A survey of schema versioning issues for database systems', Information and Software Technology 37: 383-393.

158. Roddick JF, Patrick JD (1992) Temporal Semantics in Information Systems -A survey', Information Systems 17: 249-267.

159. Roddick JF, Spiliopoulou M (1999) A bibliography of temporal, spatial and spatio-temporal data mining research. ACM SIGKDD Explorations Newsletter 1: 34-38.

160. Roddick JF, Hornsby K, Spiliopoulou M (2001) An Updated Bibliography of Temporal, Spatial, and Spatio-temporal Data Mining Research, in Temporal, Spatial, and Spatio-Temporal Data Mining, eds. J. F. Roddick \& K. Hornsby, Springer Verlag, Berlin - Germany, pp. 147-163.

161. Sellis T (1999) Research Issues in Spatio-temporal Database Systems', in Advances in Spatial Databases, eds. R. H. Güting, D. Papadias \& F. H. Lochovsky, Springer Verlag, Berlin - Germany, pp. 5-11.

162. Siabato W, Claramunt C, Camossi E (2017) An Annotated Bibliography on Spatio-temporal Modelling Trends. International Journal of Earth and Environmental Science 2: 1-45.

163. Snodgrass RT (1990) Temporal databases status and research directions', ACM SIGMOD Record 19: 83-89.

164. Snodgrass RT (1995) Temporal object-oriented databases: a critical comparison', in Modern Database Systems, ed. W. Kim, Addison-Wesley/ ACM Press, New York-NY-USA, pp. 386-408.

165. Snodgrass RT (1996) Temporal Databases: A Meta-Bibliography, The University of Arizona, Tucson-AZ-USA.

166. Soo MD (1991) Bibliography on temporal databases. ACM SIGMOD Record 20: 14-23.

167. Stam RB, Snodgrass, RT (1988) A bibliography on temporal databases. Data Engineering Bulletin 11: 53-61.

168. Tansel AU, Clifford J, Gadia S, Jajodia S, Segev A, et al. (eds.) 1993, Temporal databases: theory, design, and implementation, Benjamin Cummings, Redwood City-CA-USA.

169. Theodoulidis $\mathrm{Cl}$, Loucopoulos $P(1991)$ The time dimension in conceptual modeling. Information Systems 16: 273-300.

170. Tsotras VJ, Kumar A (1996) Temporal Database Bibliography Update. ACM SIGMOD Record 25: 41-51.

171. Ulusoy Ö (1995) An annotated bibliography on real-time database systems', ACM SIGMOD Record 24: 40-45.

172. Wu Y, Jajodia S, Wang XS (1998) Temporal database bibliography update', in Temporal Databases: Research and Practice, eds. O. Etzion, S. Jajodia \& S. Sripada, Springer Verlag, Berlin - Germany, pp. 338-366.

173. Zhang W, Hunter GJ (2000) Temporal Interpolation of Spatially Dynamic Object. Geolnformatica 4: 403-418. 